\title{
Physiological mechanisms determining eccrine sweat composition
}

\author{
Lindsay B. Baker ${ }^{1}$ (D) Anthony S. Wolfe ${ }^{2}$ \\ Received: 10 December 2019 / Accepted: 11 February 2020 / Published online: 2 March 2020 \\ (c) The Author(s) 2020
}

\begin{abstract}
Purpose The purpose of this paper is to review the physiological mechanisms determining eccrine sweat composition to assess the utility of sweat as a proxy for blood or as a potential biomarker of human health or nutritional/physiological status. Methods This narrative review includes the major sweat electrolytes (sodium, chloride, and potassium), other micronutrients (e.g., calcium, magnesium, iron, copper, zinc, vitamins), metabolites (e.g., glucose, lactate, ammonia, urea, bicarbonate, amino acids, ethanol), and other compounds (e.g., cytokines and cortisol).

Results Ion membrane transport mechanisms for sodium and chloride are well established, but the mechanisms of secretion and/or reabsorption for most other sweat solutes are still equivocal. Correlations between sweat and blood have not been established for most constituents, with perhaps the exception of ethanol. With respect to sweat diagnostics, it is well accepted that elevated sweat sodium and chloride is a useful screening tool for cystic fibrosis. However, sweat electrolyte concentrations are not predictive of hydration status or sweating rate. Sweat metabolite concentrations are not a reliable biomarker for exercise intensity or other physiological stressors. To date, glucose, cytokine, and cortisol research is too limited to suggest that sweat is a useful surrogate for blood.

Conclusion Final sweat composition is not only influenced by extracellular solute concentrations, but also mechanisms of secretion and/or reabsorption, sweat flow rate, byproducts of sweat gland metabolism, skin surface contamination, and sebum secretions, among other factors related to methodology. Future research that accounts for these confounding factors is needed to address the existing gaps in the literature.
\end{abstract}

Keywords Glucose $\cdot$ Lactate $\cdot$ Ammonia $\cdot$ Urea $\cdot$ Bicarbonate $\cdot$ Amino acids $\cdot$ Ethanol $\cdot$ Cytokines $\cdot$ Electrolytes $\cdot$ Biomarker

\begin{tabular}{|c|c|c|c|}
\hline \multicolumn{2}{|c|}{ Abbreviations } & $\mathrm{Ca}^{2+}$ & Calcium \\
\hline \multirow{2}{*}{$\begin{array}{l}\text { ACh } \\
\text { ATP }\end{array}$} & Acetylcholine & CFTR & Cystic fibrosis transmembrane conductance \\
\hline & Adenosine triphosphate & & regulator \\
\hline AQP & Aquaporin & $\mathrm{Cl}^{-}$ & Chloride \\
\hline Best & Bestrophin & $\mathrm{Cu}^{2+}$ & Copper \\
\hline \multirow[t]{4}{*}{ BK } & Large conductance $\mathrm{Ca}^{2+}$-activated $\mathrm{K}^{+}$ & $\mathrm{CV}$ & Coefficient of variation \\
\hline & channel & $\mathrm{ENaC}$ & Epithelial sodium channel \\
\hline & & $\mathrm{Fe}^{2+}$ & Iron \\
\hline & & GLUT & Glucose transporter \\
\hline \multicolumn{2}{|c|}{ Communicated by Michael Lindinger. } & $\mathrm{H}^{+}$ & Hydrogen \\
\hline \multirow{2}{*}{\multicolumn{2}{|c|}{$\begin{array}{l}\text { Electronic supplementary material The online version of this } \\
\text { article (https://doi.org/10.1007/s00421-020-04323-7) contains } \\
\text { supplementary material, which is available to authorized users. }\end{array}$}} & IK & $\begin{array}{l}\text { Intermediate conductance } \mathrm{Ca}^{2+} \text {-activated } \\
\mathrm{K}^{+} \text {channel }\end{array}$ \\
\hline & & IL & Interleukin \\
\hline \multirow{3}{*}{$\triangle \mathrm{L}$} & Baker & $\mathrm{K}^{+}$ & Potassium \\
\hline & r@pensico.com & $\mathrm{Mg}^{2+}$ & Magnesium \\
\hline & r@pepsico.com & MCT & Monocarboxylate transport \\
\hline \multirow{2}{*}{$\begin{array}{l}\mathrm{G} \\
\mathrm{S}\end{array}$} & orts Science Institute, PepsiCo R\&D Life & mRNA & Messenger ribonucleic acid \\
\hline & 17 W. Main St., Barrington, IL 60010, USA & $\mathrm{Na}^{+}$ & Sodium \\
\hline G & orts Science Institute, PepsiCo R\&D Life & NHE & $\mathrm{Na}^{+} / \mathrm{H}^{+}$exchanger \\
\hline
\end{tabular}




\begin{tabular}{|c|c|}
\hline $\mathrm{NH}_{3}$ & Ammonia \\
\hline $\mathrm{NMF}$ & Natural moisturizing factors \\
\hline $\mathrm{pKa}$ & $\begin{array}{l}\text { Negative log of the acid dissociation } \\
\text { constant }\end{array}$ \\
\hline SGLT & Sodium-dependent glucose transporter \\
\hline SLC & Solute carrier \\
\hline TGF & Transforming growth factor \\
\hline TNF & Tumor necrosis factor \\
\hline TMEM16A & Transmembrane member $16 \mathrm{~A}$ \\
\hline TRPC & Transient receptor potential channel \\
\hline TRPV1 & $\begin{array}{l}\text { Transient receptor potential cation channel } \\
\text { subfamily V member } 1\end{array}$ \\
\hline & Zinc \\
\hline 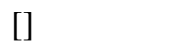 & Concentration \\
\hline
\end{tabular}

\section{Introduction}

There has been considerable interest recently in sweat diagnostics, that is, the use of sweat as a non-invasive alternative to blood analysis to provide insights into human physiology, health, and performance. Since extracellular fluid is the precursor to primary sweat in the secretory coil of eccrine sweat glands (Cage and Dobson 1965; Sato 1977), it is then anticipated that sweat solute concentrations excreted onto the sweat surface provide a surrogate for blood or are at least directly correlated with that of blood. However, eccrine sweat is a very complex mixture of solutes (Sato 1977, 1993; Sato et al. 1989), of which the composition can change significantly along its passage in the sweat duct and during collection on the skin surface. Furthermore, there are still many unanswered questions about the mechanisms of sweat secretion and sweat composition. For instance, while ion membrane transport mechanisms for sodium $\left(\mathrm{Na}^{+}\right)$and chloride $\left(\mathrm{Cl}^{-}\right)$have been described (Quinton 1981; Sato 1993; Sato et al. 1991), the mechanisms underlying the concentrations of many other solutes in final sweat are poorly understood. Moreover, relatively few well-designed, adequately powered studies have investigated the correlation between sweat and blood solute concentrations. Thus, while the notion of sweat diagnostics as a non-invasive tool for real-time hydration, nutrition, and health monitoring is attractive, its application has been limited to date (Brothers et al. 2019; Gao et al. 2018; Heikenfeld et al. 2018).

Most publications on sweat diagnostics have primarily focused on the development of skin-interfaced platforms capable of capturing and performing quantitative measurements of sweat chemistry. These papers, mostly published in journals with a focus on engineering and sensor technology, have demonstrated significant advances in materials, mechanics, and microsystem designs (Bandodkar et al. 2019; Brothers et al. 2019; Salim and Lim 2019). Notwithstanding these technological advances, very few sensor studies discuss the composition of sweat from a physiological perspective or provide direct evidence from a mechanistic basis that the sweat solute concentrations measured at the surface of the skin provide insight into the participants' hydration or nutritional status or other physiological changes.

To understand the potential utility of sweat as a reflection of blood, one must first have a thorough understanding of the physiological mechanisms determining the composition of sweat-from the composition of primary sweat in the secretory coil, to the mechanisms of reabsorption and secretion in the duct, which influence final sweat excreted onto the skin surface. While several excellent classic reviews on sweat composition and mechanisms of sweat gland function have been published (Costill 1977; Robinson and Robinson 1954; Sato 1977; Sato et al. 1989), very few recent reviews have provided an update on mechanisms underlying sweat composition in the context of sweat as a potential biomarker of human health (Baker 2019). It is critical to identify what is known and what is not yet known regarding the physiology of sweat composition to generate mechanism-based hypotheses and guide the direction of future research in the area of sweat diagnostics.

The objective of this paper is to review the physiological mechanisms determining eccrine sweat composition during passive and active heat stress. The review will include the major sweat electrolytes $\left(\mathrm{Na}^{+}, \mathrm{Cl}^{-}\right.$, and potassium $\left(\mathrm{K}^{+}\right)$), as well as other micronutrients (e.g., calcium $\left(\mathrm{Ca}^{2+}\right)$, magnesium $\left(\mathrm{Mg}^{2+}\right)$, iron $\left(\mathrm{Fe}^{2+}\right)$, copper $\left(\mathrm{Cu}^{2+}\right)$, zinc $\left(\mathrm{Zn}^{2+}\right)$, and vitamins), metabolites (e.g., glucose, lactate, ammonia, urea, bicarbonate, amino acids, and ethanol), and other compounds (e.g., cytokines and cortisol) present in sweat. The findings could help elucidate which sweat constituents, if any, could serve as a potential surrogate for blood, identify gaps in the literature, and inform the direction of future research.

\section{Eccrine sweat glands and thermoregulatory sweating}

Sweat glands are classified into three main types: eccrine, apocrine, and apoeccrine (Sato 1993; Sato et al. 1989). Eccrine sweat glands will be the focus of this review because they are the most numerous (2-4 million), distributed across most of the body surface area (Sato 1983, 1993) and are responsible for the highest volume of sweat production. Evaporation of sweat is the primary avenue of heat loss during exercise and/or passive heat stress. When water on the skin surface is converted to water vapor, $2426 \mathrm{~J}$ of heat per $1 \mathrm{~g}$ of evaporated sweat is removed from the body (Sawka et al. 2011; Wenger 1972). Whole body sweating rates vary considerably, depending upon the evaporative requirement for heat balance (Bain et al. 2011; Gagnon et al. 2013), but 
have been reported to be $\sim 0.2$ to $3 \mathrm{~L} / \mathrm{h}$ across a wide range of individuals, activities, and environmental conditions (Barnes et al. 2019). Whole body sweating rate can be $>3.0 \mathrm{~L} / \mathrm{h}$ (Armstrong et al. 1986; Barnes et al. 2019; Bergeron 2003; Godek et al. 2005, 2010; Palmer and Spriet 2008). For example, Alberto Salazar's sweating rate was reported to be 3.7 L/h during the 1985 Olympic Marathon $\left(23.9-27.8^{\circ} \mathrm{C}\right)$. Sweating rates this high are not commonly observed $(<1 \%$ of athletes based on normative data from Barnes et al. 2019); but when they are, extreme circumstances related to environment conditions, workload (running pace), fitness/acclimatization, and/or large body mass are usually involved. The rate of sweat production over the whole body is a product of active sweat gland density and the secretion rate per gland. The initial response at the onset of sweating is a rapid increase in the recruitment of sweat glands, followed by a more gradual increase in sweat secretion per gland (Kondo et al. 1998, 2001; Kuno 1956; Randall 1946).

The anatomical structure of the eccrine sweat gland consists of two main functional components: a secretory coil and a duct, both made up of a simple tubular epithelium (Sato 1983). The secretory coil has three types of cells: clear, dark, and myoepithelial. Upon stimulation, clear cells of the secretory coil secrete primary sweat, which is nearly isotonic with blood plasma (Costill 1977; Sato 1977; Sato and Sato 1990). Briefly, secretion of sweat by the clear cells occurs primarily in response to increases in body temperature (Nadel 1979; Nadel et al. 1971; Sato 1993; Wingo et al. 2010), which is sensed by central and skin thermoreceptors. In turn, this information is processed by the preoptic area of the hypothalamus to initiate the sudomotor response-mediated predominately by sympathetic cholinergic stimulation (Sato 1993$)$ and to a lesser extent $(\sim 10 \%)$ by adrenergic stimulation (Sato 1973). Eccrine glands also secrete sweat in response to non-thermal stimuli (separate from changes in skin or body temperature) associated with exercise, such as central command, muscle metabo-/mechanoreceptors, osmoreceptors, and possibly baroreceptors (Shibasaki and Crandall 2010). The dark cells of the secretory coil are distinguishable by the abundance of dark cell granules in the cytoplasm, but their function is poorly understood (Sato 1993; Sato et al. 1991). The myoepithelial cells provide structural support against the hydrostatic pressure generated in the gland during sweat production (Sato 1983). The eccrine duct has two cell layers: basal and luminal cells. The primary function of the duct is reabsorption of $\mathrm{Na}^{+}$and $\mathrm{Cl}^{-}$ions, most of which occurs in the proximal duct (Sato 1983), resulting in a hypotonic final sweat excreted onto the skin surface (Sato 1977, 1993).

Apocrine and apoeccrine glands differ from eccrine glands in that they are limited to certain body regions and, therefore, play a lesser role in the overall volume of sweat secretion (Montagna and Parakkal 1974a; Robertshaw 1983;
Sato et al. 1987). However, their secretions are still of interest and have potential utility for use as biomarkers. Apocrine and apoeccrine gland secretions are also important to understand because they can impact the composition of eccrine sweat, depending upon the region of sample collection. Briefly, apocrine sweat glands become active after puberty. They are larger than eccrine glands and are found in the axilla, breasts, face, scalp, and perineum. Apocrine glands open into hair follicles and produce a viscous sweat containing lipids, proteins, sugars, and ammonia (Montagna and Parakkal 1974a; Robertshaw 1983). Apoeccrine sweat glands develop from eccrine glands located in the axillary region between $\sim 8$ and 14 years of age. They produce copious salt-water secretions which empty directly onto the skin surface (Sato et al. 1987; Sato and Sato 1987b). For more information on apocrine and apoeccrine glands, the reader is referred to other detailed reviews (Hu et al. 2018; Sato et al. 1989; Weiner and Hellmann 1960).

Figure 1 provides a general view of eccrine and apocrine sweat glands. For more details on thermoregulatory sweating and sweat gland structure/function, the reader is referred to more comprehensive reviews (Baker 2019; Gagnon and Crandall 2018; Sato 1983). Hereafter, the focus of the review will be sweat composition. Sweating rate will be discussed only in the context of its impact on sweat solute concentrations.

\section{Overview of sweat composition}

Table 1 shows the range of concentrations of several constituents present in sweat. This is not intended to be an exhaustive list, but does include some of the more commonly researched substances in the sweat diagnostics literature. In the sections that follow, we will discuss the physiological mechanisms and other factors that determine the constituent concentrations measured in final sweat. Since eccrine sweat is mostly salt water, we will first discuss the electrolyte composition of sweat, focusing largely on the mechanisms of $\mathrm{Na}$ and $\mathrm{Cl}$ secretion and ductal reabsorption. As shown in Table 1, sweat contains a mixture of many other chemicals in varying concentrations, including additional micronutrients (e.g., $\mathrm{K}^{+}, \mathrm{Ca}^{2+}$, $\mathrm{Mg}^{2+}, \mathrm{Fe}^{2+}$, and vitamins) as well as metabolites (e.g., glucose, lactate, ammonia, urea, bicarbonate, amino acids, ethanol), cytokines, and cortisol. The concentrations listed in Table 1 are approximate ranges based on the available literature (see Supplemental Table 1 for references). Where possible, values were obtained from studies that took measures to prevent epidermal contamination (e.g., pre-rinsed skin, removed initial sweat, and/or analyzed cell-free sweat) in regional or whole body sweat. While normative data are available for $\mathrm{Na}^{+}$and $\mathrm{Cl}^{-}$(Barnes et al. 


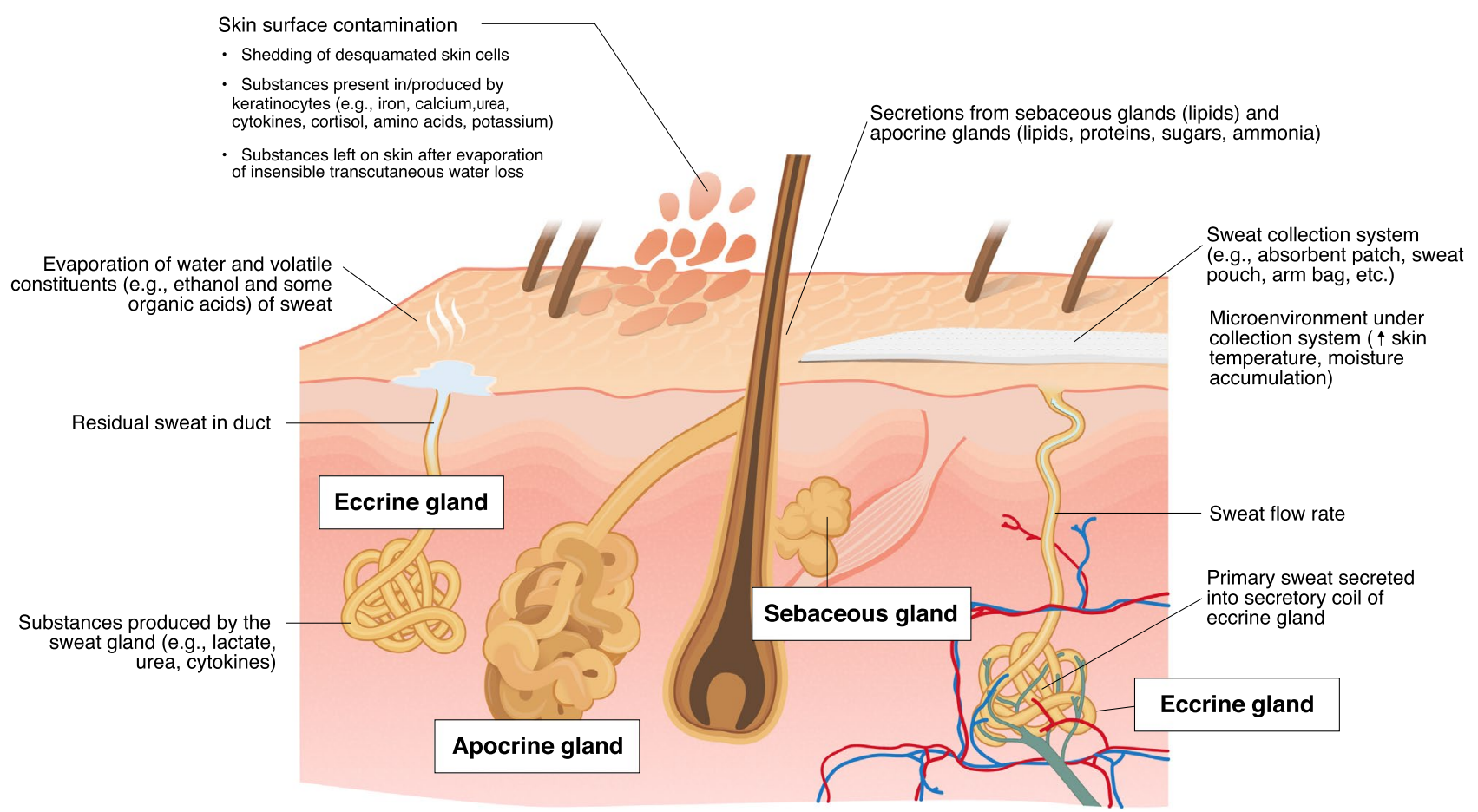

Fig. 1 Physiological and methodological factors impacting the composition of final sweat collected from the skin surface

2019; Hammond et al. 1994; Wescor 2005), there are insufficient studies to identify reference ranges for other sweat constituents. However, one can see from Table 1 that $\mathrm{Na}^{+}$and $\mathrm{Cl}^{-}$are by far the most concentrated, ranging from $\sim 10$ up to $\sim 90 \mathrm{mmol} / \mathrm{L}$. Substances present at lower millimolar concentrations include lactate, ethanol, urea, ammonia, bicarbonate, and $\mathrm{K}^{+}$. Most other constituents shown in Table 1 are measured on a micromolar $\left(\mathrm{Ca}^{2+}\right.$, $\mathrm{Mg}^{2+}, \mathrm{Fe}^{2+}, \mathrm{Zn}^{2+}, \mathrm{Cu}^{2+}$, ascorbic acid, glucose, and individual amino acids) or even smaller scale (nanomolar: thiamine, cortisol; picomolar: cytokines).

For each constituent, reference ranges for corresponding blood plasma concentrations are also shown in Table 1 . Because extracellular fluid is the precursor fluid for primary sweat, it follows that many components of the blood plasma are also found in final sweat. However, as shown in Fig. 1, there are many other factors impacting solute concentrations of final sweat collected from the skin surface. For example, some substances do not originate from precursor sweat (extracellular fluid), but instead enter the sweat gland as a result of production by the eccrine gland (e.g., lactate, urea, and cytokines) or appear in final sweat on the skin surface via contact with keratinocytes (e.g., iron, calcium, urea, cytokines, cortisol, amino acids, and potassium). There are also methodological factors that influence and often confound sweat composition, as will be discussed in detail in the next section.

\section{Overview of sweat collection and analytical techniques}

\section{Collection methods}

Scientists and practitioners have employed various methods to collect sweat samples for composition analysis. Whole body washdown is considered the most accurate method because sweat runoff from the entire body surface area is collected and accounted for and it does not interfere with normal evaporative sweating. Recovery of water and $\mathrm{Na}^{+}$using this method has been reported to be $~ 99$ to $102 \%$ and has a within-method coefficient of variation (CV) of 4\% (Baker et al. 2018b; Shirreffs and Maughan 1997). For these reasons, the WBW method is recommended, especially when conducting nutrient balance studies or if interested in determining total loss of micronutrients or other constituents via sweating. However, WBW is a meticulous method that requires a wellcontrolled laboratory setting. Therefore, in most studies, sweat is collected from one or more small regions of the body using a myriad of techniques, which have been described in detail elsewhere (Baker 2017, 2019; Taylor and Machado-Moreira 2013). Briefly, regional sweat collection techniques for sweat composition analysis include scraping or dripping methods, filter paper, absorbent 


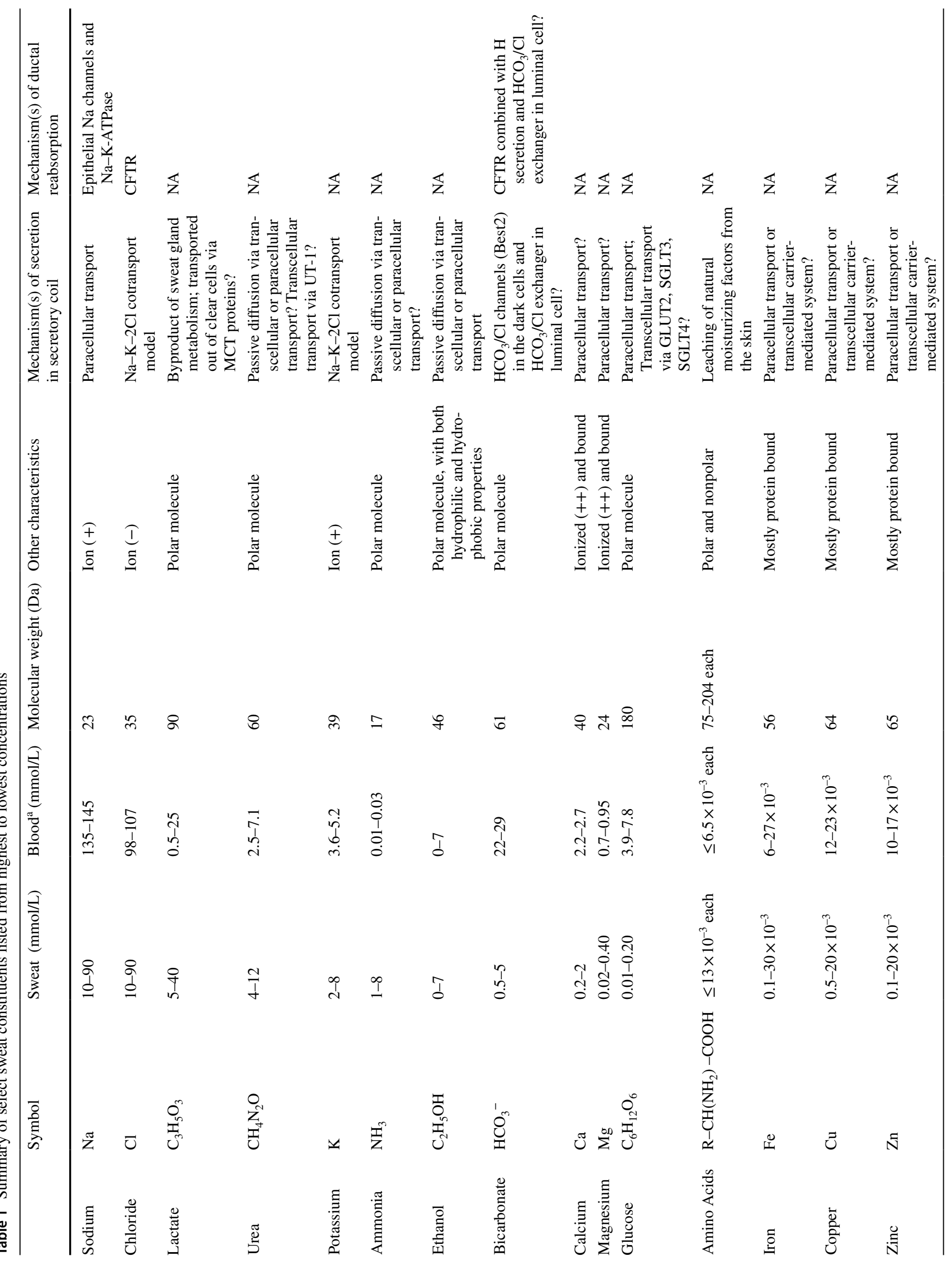




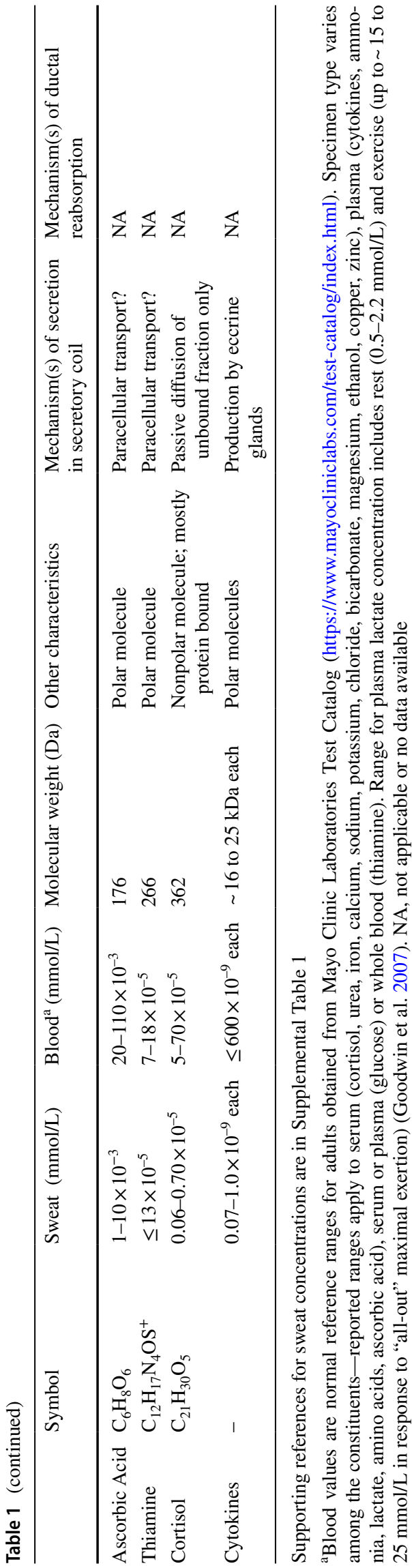

patches, sweat pouches, sweat capsules, arm gloves/bags, and sweat collectors (e.g., Macroduct ${ }^{\circledR} /$ Megaduct). While regional sweat collection is practical, each method has its limitations, and some more than others. For example, covering the skin surface with the collection system can alter the local environment, impacting skin temperature and/or skin wettedness (Fig. 1). In turn, these changes can have confounding effects on the sweating process and/or introduce skin surface contaminants into the sweat sample. On the other hand, open-air collection techniques (scraping or dripping methods) allow evaporation of water and volatile constituents of sweat (Buono 1999; Talbert 1922) (Fig. 1). Depending on the collection device (material), the exact methods used (timing, skin preparation, etc.), and the constituent of interest, the confounding effect (background noise) could range from negligible to very large. These factors will be discussed in more detail in "Contamination considerations".

Another important consideration is inter-regional variability in the sweat constituent concentrations. It is well documented that many sweat micronutrient (e.g., $\mathrm{Na}^{+}, \mathrm{Cl}^{-}$, $\left.\mathrm{Ca}^{2+}, \mathrm{Fe}^{2+}, \mathrm{Mg}^{2+}, \mathrm{Zn}^{2+}, \mathrm{Cu}^{2+}\right)$ concentrations can vary by up to two- to fourfold among anatomical sites (Aruoma et al. 1988; Baker et al. 2019, 2009; Patterson et al. 2000; Vellar and Askevold 1968). Inter-regional variability data are sparse for most other sweat constituents, but the few studies available seem to follow the same general trend, with sweat amino acid concentrations reported to vary by up to twofold (Liappis and Hungerland 1972), sweat lactate by up to two- to fourfold (Collins 1962; Patterson et al. 2000) and sweat bicarbonate by up to sixfold (Patterson et al. 2000) among body regions. One study measured the metabolomic profiles of sweat samples collected from the forearm, lower back, and neck (Hooton and Li 2017) over a 24-h period. The authors noted that the concentrations of many of the metabolites were very different among sites (shown via heat maps), but the inter-regional differences were not quantified.

Regional sweat concentrations can also differ significantly from WBW measurements. For example, sweat $\left[\mathrm{Na}^{+}\right]$ and $\left[\mathrm{Cl}^{-}\right]$measured from the forehead, torso, and upper arms are often greater than whole body measurements. However, sweat $\left[\mathrm{Na}^{+}\right]$and $\left[\mathrm{Cl}^{-}\right]$from other sites such as the foot, calf, and thigh are similar to that of the whole body (Baker et al. 2019, 2009, 2018b; Patterson et al. 2000). For most other constituents $\left(\mathrm{Ca}^{2+}, \mathrm{Mg}^{2+}, \mathrm{Fe}^{2+}, \mathrm{Zn}^{2+}, \mathrm{Cu}^{2+}\right.$, lactate, urea, ammonia, and lead), regional sweat measurements have led to overestimations of whole body sweat concentrations (Baker et al. 2011; Cohn and Emmett 1978; Colombani et al. 1997; Lemon et al. 1986; Patterson et al. 2000) albeit regional body mapping has not been as thorough (i.e., included as many regions) as that of $\mathrm{Na}^{+}$and $\mathrm{Cl}^{-}$studies. The physiological explanation underlying the inter-regional variability is unclear, but may be related to inter-regional 
differences in sweating rate and/or skin characteristics (e.g., presence of sebaceous glands, apocrine glands, hair/nails, etc.) as discussed in the next section.

\section{Contamination considerations}

As summarized in Fig. 1, there are several confounding factors that play a role in determining sweat composition. For instance, if sweat is collected in an area dense with apocrine glands and/or sebaceous glands (e.g., axilla, face, forehead, scalp) their secretions could artificially elevate lipid, protein, sugar, and ammonia concentrations of sweat samples collected from the skin surface (Montagna and Parakkal 1974a, b; Porter 2001). Other substances present in sweat may be there as a result of production in the sweat gland rather than (or in addition to) having originated from primary sweat secretion into the secretory coil. Some substances potentially produced by the eccrine gland include lactate, urea, cytokines, proteolytic enzymes, and antibodies (Gordon et al. 1971; Murota et al. 2015; Sato 1977; Sato et al. 1991; Sato and Sato 1994; Yokozeki et al. 1991), but mechanisms are not fully understood.

Residual sweat in the eccrine duct left over from a previous thermal event could also confound sweat composition initially excreted on the skin surface (i.e., at the beginning of exercise or heat stress). Similarly, skin surface contamination could originate from minerals, amino acids, and other constituents deposited on the skin after evaporation of everyday insensible transcutaneous water loss (Mitchell and Hamilton 1949; Rothman et al. 1949). As shown in Supplemental Table 2, several studies have found significantly higher constituent concentrations in initial sweat samples versus subsequent collections (Boysen et al. 1984; Brune et al. 1986; Ely et al. 2011; Paulev et al. 1983). For example, Paulev et al. (1983) collected sweat from the back of endurance athletes at 10-min intervals during cycling and found that sweat $\left[\mathrm{Fe}^{2+}\right]$ gradually decreased (by 2.2 -fold) over the first 20-30 min and did not change thereafter. Similar results have been reported by other investigators for $\mathrm{Fe}^{2+}, \mathrm{Ca}^{2+}$, $\mathrm{Mg}^{2+}, \mathrm{Cu}^{2+}, \mathrm{Zn}^{2+}$, protein, and urea (Boysen et al. 1984; Brune et al. 1986; Ely et al. 2011). For these reasons, it is recommended that the skin is cleaned (e.g., alcohol wipe) and rinsed with deionized water and that initial sweat is removed from the skin surface prior to sweat collection. Allowing participants to sweat for at least 20-30 min prior to applying the sweat collection device will facilitate flushing of duct and surface contaminants and will allow time for steady-state sweating rates to be reached.

Scientists have also assessed the impact of skin surface contamination by comparing sweat collected with and without an oil barrier (Supplemental Table 2). The advantage of this method, also known as the anaerobic sweat pouch technique, is that the oil interface prevents contact between the skin and the sweat. Using this approach, one study found that urocanic acid concentration was sevenfold higher in arm sweat collected with the filter paper technique versus the anaerobic method (Brusilow and Ikai 1968). Boysen et al. (1984) found 2.5-fold higher $\left[\mathrm{Ca}^{2+}\right], 1.6$-fold higher [protein], and 1.4-fold higher [urea] in sweat collected from the upper back using the pouch technique without oil compared with the pouch with oil. Using the scraping method resulted in even more epidermal contamination, as Boysen et al. (1984) reported 6-fold, 2.7-fold, and 2.4-fold increases in sweat $\left[\mathrm{Ca}^{2+}\right]$, [protein], and [urea], respectively, in scraped sweat versus the anaerobic method. Yet another approach to assessing the impact of epidermal contamination on sweat composition is to separate a sample into cell-rich and cellpoor aliquots. Cell-rich sweat is defined as the sweat analyzed 'as is' after collection from the skin surface, while cell-poor sweat is the supernatant obtained after centrifugation of that sample. Several studies (listed in Supplemental Table 2) employed this method when assessing sweat $\mathrm{Fe}$ and found 2- to 24-fold higher concentrations in cell-rich versus cell-poor sweat (Adams et al. 1950; Brune et al. 1986; Foy and Kondi 1957; Hussain and Patwardhan 1959; Prasad et al. 1963).

The potential for skin surface contamination to impact sweat sample concentrations varies depending upon the constituent of interest. Several substances that are of interest for sweat diagnostics are present in or produced by keratinocytes. As shown in Fig. 1, the skin-derived substances likely to confound sweat concentrations include (but are not limited to) $\mathrm{Fe}^{2+}$ (Weintraub et al. 1965), $\mathrm{Ca}^{2+}$ (Verissimo et al. 2007), $\mathrm{K}^{+}$(Verissimo et al. 2007), cytokines (Dai et al. 2013; Hanel et al. 2013), cortisol (Slominski 2005; Terao and Katayama 2016), and amino acids (Dunstan et al. 2016; Sato et al. 1989). Using nuclear microscopy, Verissimo et al. (2007) obtained quantitative profiles of various elements in skin cross sections. It was found that some minerals, such as $\mathrm{Ca}^{2+}$, were abundant in the dead cells of the stratum corneum and less so in the living cells of the deeper layers of the epidermis. This is important because the content of the stratum corneum is likely to have the greatest impact on sweat sample contamination (through mixing of desquamated skin cells with sweat on the skin surface). According to Verissimo et al. (2007), there is $\sim 500$ to $2500 \mathrm{ng}$ of $\mathrm{Ca}^{2+}$ present in $\mathrm{a} \mathrm{cm}^{2}$ of the stratum corneum. If this amount of $\mathrm{Ca}^{2+}$ were incorporated into a $1 \mathrm{~mL}$ sample of sweat collected over a $10 \mathrm{~cm}^{2}$ surface area (typical absorbent patch size), it would equate to $0.12-0.62 \mathrm{mmol} / \mathrm{L}$ of $\mathrm{Ca}^{2+}$ contaminating the sweat $\left[\mathrm{Ca}^{2+}\right]$ value. To put this in perspective, the range in sweat $\left[\mathrm{Ca}^{2+}\right]$ typically reported is 0.2 to $2.0 \mathrm{mmol} / \mathrm{L}$ (Baker 2019). Based on these estimations, skin surface contamination could artificially elevate sweat $\left[\mathrm{Ca}^{2+}\right]$ by two- to fourfold, which is in line with findings from studies comparing cell-rich vs. cell-poor sweat in Supplemental 
Table 2 (Boysen et al. 1984; Ely et al. 2011). By contrast, sweat $\left[\mathrm{Na}^{+}\right]$and $\left[\mathrm{Cl}^{-}\right]$seem to be minimally impacted by surface contamination (Arn and Reimer 1950; Boysen et al. 1984; Ely et al. 2011; Freyberg and Grant 1937; Robinson and Robinson 1954).

Taken together, it is apparent that the composition of sweat collected from the skin surface is influenced by not only internal sweat secretion mechanisms but also epidermal composition itself. To complicate matters further, the degree of contamination varies depending upon the method/ duration of sweat collection and sweating rate. For example, prolonged encapsulation of the skin with occlusive coverings leads to moisture accumulation, which in turn accelerates desquamation. This may explain the very high concentrations of minerals often reported in studies using the arm bag technique (Cohn and Emmett 1978; Collins et al. 1971; Ely et al. 2011; Van Heyningen and Weiner 1952). In addition, for a given amount of mineral or metabolite from epidermal sources, the impact on measured sweat mineral concentration will be influenced by sweating rate such that higher sweat volumes will dilute the effect of epidermal contamination (Costill 1977; Dunstan et al. 2016). Finally, it is also important to consider potential environmental contamination, such as condensation of water vapor onto the skin surface in a sauna (Zech et al. 2015).

\section{Sample storage and analytical techniques}

Sample storage methodology is another potential source of variability in sweat constituent concentrations and, not surprisingly, one of the most important factors is proper sealing of the sample vials. When well-sealed and stored at room temperature $\left(23-25{ }^{\circ} \mathrm{C}\right)$, refrigeration $\left(4-8{ }^{\circ} \mathrm{C}\right)$, or frozen $\left(-20^{\circ} \mathrm{C}\right.$ ) for up to 7 days, minimal sweat evaporation and minimal change in sweat $\left[\mathrm{Na}^{2+}\right],\left[\mathrm{Cl}^{-}\right]$, and $\left[\mathrm{K}^{+}\right]$has been reported (Baker et al. 2018a; Bergeron et al. 2011; Jones et al. 2008). However, when vials were capped but not sealed with Parafilm-M ${ }^{\circledR}$ for 3 or 5 days, $19 \%$ and $32 \%$ sample evaporation has occurred; storing the vials in a plastic bag was associated with 16 and $27 \%$ sample evaporation, respectively. This translates to a significant increase in sweat electrolyte concentrations. For example, Bergeron et al. (2011) reported a $12-66 \%$ increase in sweat $\left[\mathrm{Cl}^{-}\right]$after 5 days of storage without Parafilm- $\mathrm{M}^{\circledR}$ sealing.

Differences in sample storage temperature seem to have minimal impact on sweat electrolyte concentrations, as (Baker et al. 2018a) found negligible changes in sweat $\left[\mathrm{Na}^{+}\right],\left[\mathrm{Cl}^{-}\right]$, and $\left[\mathrm{K}^{+}\right]$between same-day analysis and post7-day storage (in Parafilm- $\mathrm{M}^{\circledR}$-sealed vials) at $-20^{\circ} \mathrm{C}, 8^{\circ} \mathrm{C}$, and $23{ }^{\circ} \mathrm{C}$. There is a paucity of research measuring the effect of storage conditions on other sweat constituents. One study compared amino acid concentrations in aliquots of sweat stored at room temperature $\left(25^{\circ} \mathrm{C}\right)$ versus $37^{\circ} \mathrm{C}$ for up to $90 \mathrm{~min}$, prior to longer term storage at $-80{ }^{\circ} \mathrm{C}$ (Harshman et al. 2019). The authors reported that, in general, amino acid concentrations were stable at both conditions, with $90 \%$ of measurements being within $10 \%$ of the control condition (flash freezing). However, within certain individuals there were large differences in sweat alanine, arginine, and threonine concentrations between storage conditions (Harshman et al. 2019).

Because of differences in ease of use and equipment cost, a wide range of analytical techniques have been used by scientists and practitioners to measure sweat composition (Baker 2017). However, caution should be used when comparing results across the literature because sweat $\left[\mathrm{Na}^{+}\right]$ varies significantly among common analytical techniques; in general, ion conductivity $>$ flame photometry $\geq$ indirect ion-selective electrode $>$ direct ion-selective electrode $\geq$ ion chromatography (Baker et al. 2014; Boisvert and Candas 1994; Dziedzic et al. 2014; Goulet et al. 2017, 2012). One study directly compared sweat $\left[\mathrm{Na}^{+}\right]$analyzed with all five different techniques (Goulet et al. 2017). While all techniques had low within-method variability $(\mathrm{CVs} \leq 2.6 \%)$, there was significant variability between techniques, with ion conductivity producing sweat $\left[\mathrm{Na}^{+}\right]$values most different $(\mathrm{CV}=12.3 \%)$ from the reference ion chromatography method (Goulet et al. 2017). Sweat $\left[\mathrm{Cl}^{-}\right]$and $\left[\mathrm{K}^{+}\right]$have been assessed in only a few studies, but follow a similar pattern as $\left[\mathrm{Na}^{+}\right]$with respect to differences among analytical techniques (Baker et al. 2014; Boisvert and Candas 1994). Future research is needed to determine the effect of variations in storage temperature/duration and analytical technique on other sweat constituents.

\section{Mechanisms determining sweat composition}

The precursor fluid to primary sweat is the water and dissolved solutes in the interstitial fluid space, which together with the plasma makes up the extracellular fluid (in approximate equilibrium). There are two basic mechanisms by which water and solutes can cross the lipid bilayer membrane of clear cells and into the lumen of the secretory coil: transcellularly (through cells) or paracellularly (between cells) (Kutchai 1998). Passive diffusion via the transcellular and paracellular route is governed primarily by polarity and size of the constituent of interest (Yang and Hinner 2015). Nonpolar lipid-soluble molecules and small gasses like $\mathrm{O}_{2}$ diffuse rapidly with permeability coefficients reported as high as $2.3 \times 10^{1} \mathrm{~cm} / \mathrm{s}$ (Yang and Hinner 2015). Small polar molecules such as ammonia exhibit a relatively high permeability coefficient on the order of $10^{-1} \mathrm{~cm} / \mathrm{s}$, whereas urea, a slightly larger polar molecule, is closer to $10^{-6} \mathrm{~cm} / \mathrm{s}$ (Walter and Gutknecht 1986; Yang and Hinner 2015). Transcellular permeability is nearly 
non-existent for large uncharged polar molecules like glucose. Passive movement of water and solutes occurs according to electrochemical gradients. Paracellular movement of solutes against concentration gradients can also occur with the help of ion transporters (e.g., $\mathrm{Na}^{+}-\mathrm{K}^{+}-$ ATPase) via active or energy-requiring processes (Yang and Hinner 2015). Larger polar molecules and charged ions or molecules move paracellularly during the process of sweat secretion (Heikenfeld et al. 2019). Paracellular permeability is dictated by tight junctions, which allow free passage of water and small polar molecules but limit the passage of larger molecules (Kutchai 1998). However, tight junctions are dynamic and their bond strength varies depending on the cell type and when exposed to stressors (Schneeberger and Lynch 1992).

Mechanisms of water and electrolyte $\left(\mathrm{Na}^{+}, \mathrm{Cl}^{-}\right.$, and $\mathrm{K}^{+}$) secretion and reabsorption in the eccrine sweat gland have been fairly well studied (Buono et al. 2007; Cage and Dobson 1965; Gerrett et al. 2019; Reddy and Quinton 2003; Sato 1983, 1993). Thus, current knowledge (as well as some remaining gaps in knowledge) of the transporters/ channels, their regulatory control, and other mechanisms involved in $\mathrm{Na}^{+}, \mathrm{Cl}^{-}$, and $\mathrm{K}^{+}$movement across cell membranes in the eccrine gland are discussed in detail below. On the other hand, the exact mechanisms determining the secretion of other ions or compounds in the secretory coil are largely unknown. Based on the available literature and basic concepts in membrane physiology, some potential mechanisms will be discussed for these solutes. Figure 2 shows the mechanisms of water and solute passage into the secretory coil.

\section{Electrolytes (sodium, chloride, and potassium)}

$\mathrm{Na}^{+}$and its conjugate anion $\mathrm{Cl}^{-}$comprise the most osmotically active components of the extracellular fluid. $\mathrm{K}^{+}$is the major cation in the intracellular fluid compartment. Electrolyte balance plays an important role in governing passive water movement according to osmotic gradients between the intracellular and extracellular water spaces (Mack and Nadel 1996). Because $\mathrm{Na}^{+}$is the primary extracellular osmolyte, ingestion of $\mathrm{Na}^{+}$helps maintain extracellular fluid volume, including plasma volume. Furthermore, an increase serum $\left[\mathrm{Na}^{+}\right]$and osmolality with $\mathrm{Na}^{+}$ingestion stimulates renal water reabsorption for more complete rehydration (Evans et al. 2017). Individuals with salty sweat (e.g., $\left[\mathrm{Cl}^{-}\right]$and $\left[\mathrm{Na}^{+}\right] \geq 70$ to $80 \mathrm{mmol} / \mathrm{L}$ ) have an increased risk of $\mathrm{NaCl}$ imbalances during prolonged periods of heavy sweating (Baker 2019; Montain et al. 2006). Because of the large inter-individual variability in sweating rate and sweat $\left[\mathrm{Na}^{+}\right]$ personalized fluid/ $\mathrm{Na}^{+}$replacement strategies are recommended to maintain fluid and $\mathrm{Na}^{+}$balance during exercise
(Belval et al. 2019; McDermott et al. 2017; Sawka et al. 2007).

\section{Secretory mechanisms}

Secretion of primary sweat occurs in clear cells of the secretory coil according to the $\mathrm{Na}^{+}-\mathrm{K}^{+}-2 \mathrm{Cl}^{-}$cotransport model (Hu et al. 2018; Sato 1993; Sato et al. 1991; Wilson and Metzler-Wilson 2015) illustrated in Fig. 2. Briefly, binding of acetylcholine to muscarinic receptors on the clear cell stimulates the release of intracellular $\mathrm{Ca}^{2+}$ from the sarcoplasmic reticulum (via $\mathrm{IP}_{3}$-activated $\mathrm{Ca}^{2+}$ and $\mathrm{Ca}^{2+}$-induced $\mathrm{Ca}^{2+}$ release channels, not depicted in Fig. 2) and an influx of extracellular $\mathrm{Ca}^{2+}$ into the cytoplasm (via TRPV1, Orai, TRPC, and L-type voltage-gated $\mathrm{Ca}^{2+}$ channels, not depicted in Fig. 2). An efflux of $\mathrm{K}^{+}$(via $\mathrm{Ca}^{+}$activated IK and BK channels) and $\mathrm{Cl}^{-}$(via TMEM16A and Best2) then leads to cell shrinkage, triggering an influx of $\mathrm{Na}^{+}, \mathrm{K}^{+}$, and $\mathrm{Cl}^{-}$from the extracellular fluid through $\mathrm{Na}^{+}-\mathrm{K}^{+}-2 \mathrm{Cl}^{-}$cotransporters on the basolateral membrane. Subsequently, $\mathrm{Na}^{+}$and $\mathrm{K}^{+}$ efflux occurs through $\mathrm{Na}^{+}-\mathrm{K}^{+}$-ATPase and $\mathrm{K}^{+}$channels (IK and $\mathrm{BK}$ ) on the basolateral membrane as well as $\mathrm{Cl}^{-}$efflux into the lumen via $\mathrm{Cl}^{-}$channels (TMEM16A and Best2) on the apical membrane. CFTR are also expressed on the apical membrane of clear cells and play a role in chloride secretion in response to beta-adrenergic stimulation (SaintCriq and Gray 2017). An electrochemical gradient is created by increased $\mathrm{Cl}^{-}$concentration in the lumen. In turn, $\mathrm{Na}^{+}$ secretion occurs through passive movement across the cell junction (paracellular transport) (Sato 1993; Sato et al. 1989, 1991). The net $\mathrm{K}^{+}$and $\mathrm{Cl}^{-}$efflux also creates an osmotic gradient for water movement into the lumen via aquaporin-5 channels (Inoue et al. 2013; Nejsum et al. 2002; Xie et al. 2017). Thus water, $\mathrm{Na}^{+}, \mathrm{Cl}^{-}$, and $\mathrm{K}^{+}$are secreted via this $\mathrm{Na}^{+}-\mathrm{K}^{+}-2 \mathrm{Cl}^{-}$cotransport model (Fig. 2) and primary sweat in the lumen of the secretory coil is nearly isotonic with blood plasma with respect to $\mathrm{Na}^{+}$and $\mathrm{K}^{+}$and slightly hypertonic for $\mathrm{Cl}^{-}$(Dobson 1965; Sato 1977; Sato and Sato 1987a, 1990).

\section{Reabsorption mechanisms}

It is important to note, however, that the electrolyte concentrations of final sweat usually differ (i.e., hypotonic with respect to $\mathrm{Na}^{+}$and $\mathrm{Cl}^{-}$) from that of primary sweat. This is a result of $\mathrm{Na}^{+}$and $\mathrm{Cl}^{-}$reabsorption in the eccrine duct prior to sweat excretion onto the skin surface. Reabsorption of $\mathrm{Na}^{+}$and $\mathrm{Cl}^{-}$is thought to occur via the modified Ussing leak-pump model (Sato 1977; Ussing and Zerahn 1951). As shown in Fig. 2, the mechanism involves passive influx of $\mathrm{Na}^{+}$through amiloride-sensitive epithelial $\mathrm{Na}^{+}$channels in the apical membrane of the luminal cells. This is followed by active transport of $\mathrm{Na}^{+}$(via $\mathrm{Na}^{+}-\mathrm{K}^{+}$-ATPase) across the 


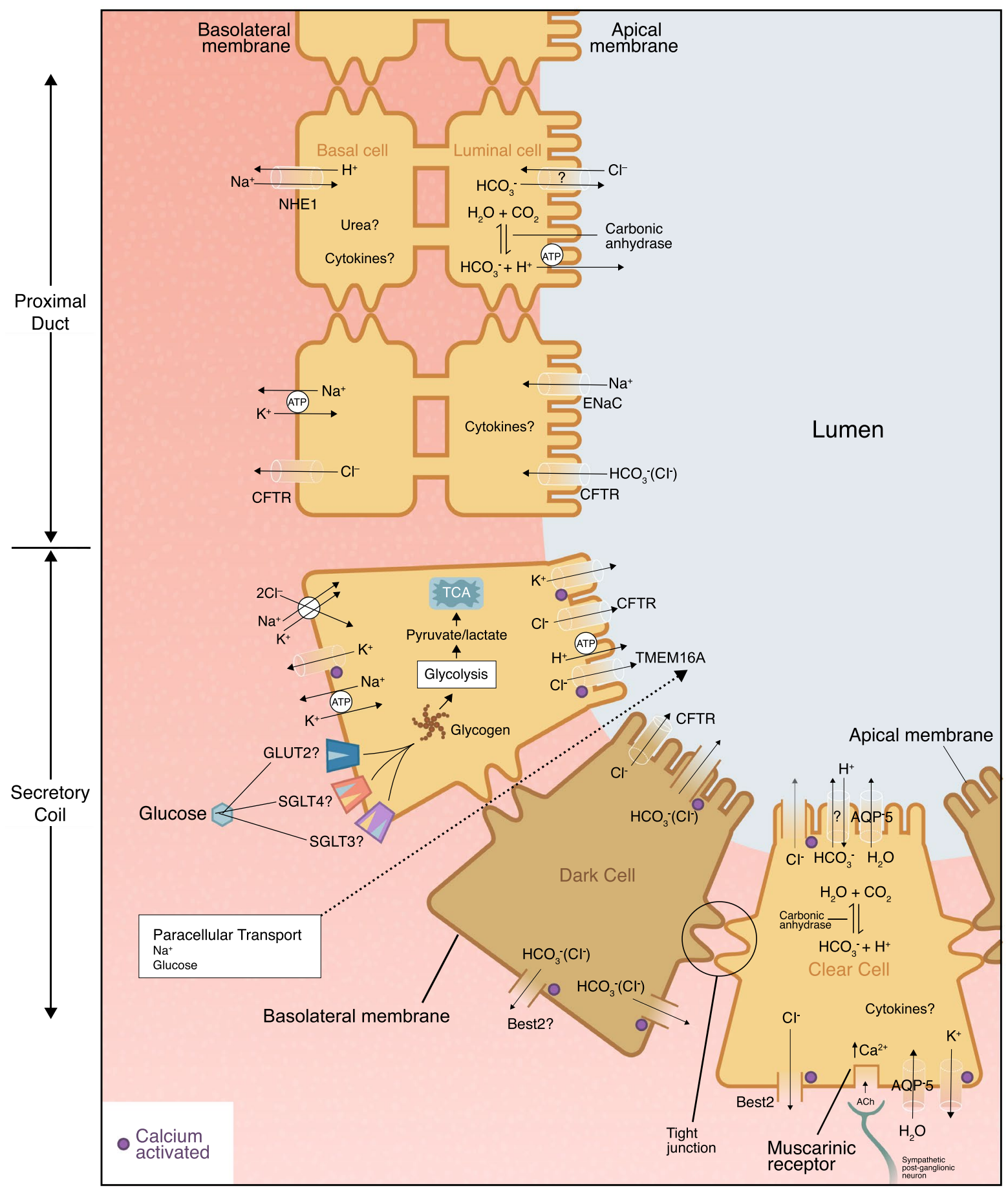

Fig. 2 Mechanisms of water, ion, and metabolite passage into the secretory coil. ACh acetylcholine, AQP-5 aquaporin-5, Best 2 bestrophin 2, CFTR cystic fibrosis transmembrane conductance regulator (note that chloride secretion via CFTR in the clear cells is activated by beta-adrenergic stimulation, which is not depicted), $E N a C$

basolateral membrane of the basal cells and passive efflux of $\mathrm{K}^{+}$through the basolateral membrane. $\mathrm{Cl}^{-}$reabsorption is epithelial Na channel, GLUT2 glucose transporter 2, NHE1 Na ${ }^{+} / \mathrm{H}^{+}$ exchanger isoform 1, SGLT3 sodium-dependent glucose transporter 3, SGLT4 sodium-dependent glucose transporter 4, TMEM16A transmembrane member $16 \mathrm{~A}$

largely passive via movement through cystic fibrosis transmembrane conductance regulator (CFTR) channels on both 
the apical and basolateral membranes (Quinton 1981; Reddy and Quinton 1994b; Sato 1993). Most $\mathrm{Na}^{+}$and $\mathrm{Cl}^{-}$reabsorption occurs in the proximal segment of the eccrine duct, as these cells contain more mitochondria and $\mathrm{Na}^{+}-\mathrm{K}^{+}$-ATPase activity than that of the distal duct (Sato 1983). Sweat secretion and $\mathrm{Na}^{+}$reabsorption are active processes and the main avenue of energy production for sweat gland function is oxidative phosphorylation of plasma glucose (Dobson and Sato 1972; Elizondo 1973; Elizondo et al. 1972; Sato 1977; Sato and Dobson 1973; Weiner and Van Heyningen 1952). Sweat gland metabolism and its byproducts can have an impact on final sweat composition, as discussed further in "Metabolites". In addition, impeding oxygen supply to the sweat gland inhibits sweat secretion and ion reabsorption, resulting in reduced sweating rates and increased lactate and $\mathrm{NaCl}$ concentrations (Elizondo 1973; Elizondo et al. 1972; Sato 1977; Weiner and Van Heyningen 1952).

Taken together, the $\left[\mathrm{Na}^{+}\right]$and $\left[\mathrm{Cl}^{-}\right]$of final sweat are determined primarily by the rate of ion reabsorption in the duct relative to the rate of ion secretion in the clear cells of the secretory coil. Therefore, $\mathrm{Na}^{+}-\mathrm{K}^{+}$-ATPase activity and CFTR channel function play important roles in determining final sweat $\left[\mathrm{Na}^{+}\right]$and $\left[\mathrm{Cl}^{-}\right]$. The activity of $\mathrm{Na}^{+}-\mathrm{K}^{+}$-ATPase is influenced by plasma aldosterone concentration and sweat gland sensitivity to aldosterone (Kirby and Convertino 1986; Ladell and Shephard 1961; Sato and Dobson 1970). Resting (genomic) plasma aldosterone concentration is influenced by an individual's chronic physiological condition (e.g., heat acclimation, fitness, and diet). Non-genomic factors (e.g., exercise and dehydration) stimulate acute changes in circulating aldosterone (Yoshida et al. 2006). The relative importance of these genomic and non-genomic factors on final sweat $\left[\mathrm{Na}^{+}\right]$will be covered in more detail below.

The abundance of CFTR $\mathrm{Cl}^{-}$channels also impacts the rate of ductal $\left[\mathrm{Na}^{+}\right]$and $\left[\mathrm{Cl}^{-}\right]$reabsorption. With lower CFTR abundance, there is less ion reabsorption in the duct and, therefore, higher final sweat $\left[\mathrm{Na}^{+}\right]$and $\left[\mathrm{Cl}^{-}\right]$excreted onto the skin surface. The reduced reabsorption of $\mathrm{Na}^{+}$as well as $\mathrm{Cl}^{-}$is a result of the functional interaction between CFTR and $\mathrm{ENaC}$, as $\mathrm{ENaC}$ activation depends on functioning CFTR (Reddy and Quinton 2003). CFTR availability is reduced with defects in CFTR genes (i.e., cystic fibrosis) (Goodman and Percy 2005; Quinton 1999, 2007; Reddy and Quinton 2003; Rowe et al. 2005). Thus, with cystic fibrosis, defects in CFTR also impose a loss of ENaC activity (Reddy and Quinton 2003). There is also some evidence to suggest that healthy individuals with salty sweat may exhibit lower abundance of eccrine duct $\mathrm{Cl}^{-}$channel CFTR (Brown et al. 2011).

Sweat flow rate Sweat flow rate is another important factor determining final sweat $\left[\mathrm{Na}^{+}\right]$and $\left[\mathrm{Cl}^{-}\right]$. Several studies have reported a direct relation between sweating rate and final sweat $\left[\mathrm{Na}^{+}\right]$and $\left[\mathrm{Cl}^{-}\right]$(Buono et al. 2007; 2008; Cage and Dobson 1965; Dill et al. 1938; Lichton 1957; Sato 1977,1983; Sato et al. 1989). This finding is consistent whether measured at the whole-body level (Baker et al. 2019), within given skin regions (Buono et al. 2008; Cage and Dobson 1965), or isolated sweat glands (Sato 1977). For example, Buono et al. (2008) found that as forearm sweating rate increased from $\sim 0.25$ to $0.82 \mathrm{mg} / \mathrm{cm}^{2} / \mathrm{min}$ (stimulated via a progressive increase in exercise intensity from 50 to $90 \% \mathrm{HR}_{\text {max }}$ ), sweat $\left[\mathrm{Na}^{+}\right]$increased from $19 \pm 5$ to $59 \pm 10 \mathrm{mmol} / \mathrm{L}$. This is because the rate of $\mathrm{Na}^{+}$secretion in primary sweat increased proportionally more than the rate of $\mathrm{Na}^{+}$reabsorption in the duct (Buono et al. 2008). That is, the percentage of secreted $\mathrm{Na}^{+}$that was reabsorbed in the duct decreased with a rise in sweating rate. Specifically, $86 \pm 3 \%$ of the secreted $\mathrm{Na}^{+}$was reabsorbed at the lowest sweating rate, while only $65 \pm 6 \%$ of $\mathrm{Na}^{+}$was reabsorbed at the highest sweating rate (Buono et al. 2008). Further research is needed to elucidate underlying mechanisms to explain why faster flow rates are associated with a decreased percentage of $\mathrm{Na}^{+}$reabsorption.

It is important to note that while the relation between sweat flow rate and sweat $\left[\mathrm{Na}^{+}\right]$has been well established in studies where participants served as their own control, this relation does not necessarily hold true for between-participant comparisons (Baker et al. 2018b). It may be that other factors affecting sweat $\left[\mathrm{Na}^{+}\right]$and $\left[\mathrm{Cl}^{-}\right]$, such as CFTR abundance in the eccrine duct or genomic effects of aldosterone on $\mathrm{Na}^{+}-\mathrm{K}^{+}$-ATPase, play a larger role (than acute changes in sweating rate) in determining inter-individual differences in sweat $\left[\mathrm{Na}^{+}\right]$and $[\mathrm{Cl}]$. This complexity makes it all the more difficult to use sweat $\left[\mathrm{Na}^{+}\right]$to estimate sweating rate or other biomarkers.

Skin temperature While it is well established that increases in skin temperature enhance sweat production (Nadel et al. 1971), the effect of skin temperature on sweat composition is less clear. Some (Johnson et al. 1944; Robinson et al. 1950; Weiner and Van Heyningen 1952), but not all (Bulmer and Forwell 1956), early studies found that higher skin temperatures were associated with higher sweat $\left[\mathrm{Na}^{+}\right]$and $\left[\mathrm{Cl}^{-}\right]$. More recently, Shamsuddin et al. (2005) investigated the effect of changes in mean skin temperature on ion reabsorption rates as measured via assessments of the relation between sweating rate and sweat conductivity. Moderately warm ambient conditions $\left(25^{\circ} \mathrm{C}\right)$ resulted in a lower threshold and greater slope of the relation between local (back) sweating rate and sweat conductivity compared with cool conditions $\left(15^{\circ} \mathrm{C}\right)$ (Shamsuddin et al. 2005). Based on these results, Shamsuddin et al. (2005) suggested that ion reabsorptive capacity of eccrine glands was increased by higher (by $\sim{ }^{\circ} \mathrm{C}$ ) mean skin temperatures. Indeed, some in vitro experiments suggest that ion channel $(\mathrm{ENaC})$ activity is tem- 
perature dependent, such that higher temperature increases excitability and open probability (Chraibi and Horisberger 2002, 2003; Ruff 1999).

It is important to note, however, that sweating rate and sweat ion conductivity (index of sweat ion concentration) in the study by Shamsuddin et al. (2005) were actually higher in the $25^{\circ} \mathrm{C}$ than the $15^{\circ} \mathrm{C}$ trial. This agrees with the notion (discussed in "Sweat flow rate") that final sweat $\left[\mathrm{Na}^{+}\right]$and $\left[\mathrm{Cl}^{-}\right]$increase with increasing sweating rate. However, there may be an interaction effect, such that changes in skin temperature impact the relation between sweating rate and ion concentration. That is, at a given sweating rate, sweat ion concentration may be lower with warmer skin temperatures because of enhanced reabsorptive capacity in the sweat duct (Shamsuddin et al. 2005). Nevertheless, research to date indicate that relatively large increases in mean $\left(>3{ }^{\circ} \mathrm{C}\right)$ or local $\left(>6^{\circ} \mathrm{C}\right)$ skin temperature (Gerrett et al. 2019) are required before ion reabsorption rates are significantly affected.

\section{Final sweat sodium, chloride, and potassium concentrations}

The mechanisms of $\mathrm{Na}^{+}$and $\mathrm{Cl}^{-}$secretion and reabsorption along with the various modifying factors described above illustrate why sweat $\left[\mathrm{Na}^{+}\right]$and $\left[\mathrm{Cl}^{-}\right]$vary considerably within and among individuals. Sweat $\left[\mathrm{Na}^{+}\right]$and $\left[\mathrm{Cl}^{-}\right]$values reported in the literature are typically $\sim 10$ to $90 \mathrm{mmol} / \mathrm{L}$ across a wide range of participants tested in various exercise and environmental conditions (Baker et al. 2009, 2018b; Barnes et al. 2019; Maughan and Shirreffs 1998; Patterson et al. 2000; Robinson and Robinson 1954; Shirreffs and Maughan 1997; Verde et al. 1982) (Table 1).

Potassium secretion occurs according to the $\mathrm{Na}^{+}-\mathrm{K}^{+}-2 \mathrm{Cl}^{-}$cotransport model described above. Final sweat typically has a $\left[\mathrm{K}^{+}\right]$similar to that of primary sweat and blood plasma (3.6-5.2 $\mathrm{mmol} / \mathrm{L})$, which may suggest that minimal changes in sweat $\left[\mathrm{K}^{+}\right]$occur during sweat passage along the duct (Gibinski et al. 1973). Some studies report sweat $\left[\mathrm{K}^{+}\right]$values with a slightly broader range (e.g., $\sim 2$ to $8 \mathrm{mmol} / \mathrm{L}$ ) than blood plasma (Baker et al. 2009; Patterson et al. 2000; Taylor and Machado-Moreira 2013), but the underlying reasons for this discrepancy (between sweat and plasma) are unclear to date. Moreover, there have been mixed results with respect to the relation between flow rate and sweat $\left[\mathrm{K}^{+}\right]$(Baker 2019; Gordon and Cage 1966; Patterson et al. 2000; Sato 1977). Other papers speculate that $\mathrm{K}^{+}$is secreted in the eccrine duct (Buono et al. 2016; Sato 1980), but more research is needed.

Even when testing conditions and sweat collection/analysis methodologies are standardized and well controlled, $\sim 5$ to $16 \%$ intra-individual day-to-day variability (CVs) in sweat $\left[\mathrm{Na}^{+}\right]$and $\left[\mathrm{Cl}^{-}\right]$is observed (Baker et al. 2009, 2018b;
Hayden et al. 2004). The day-to-day $\mathrm{CV}$ for sweat $\left[\mathrm{K}^{+}\right]$is 6-19\% (Baker et al. 2009). Assuming that 1 to $5 \%$ of this $\mathrm{CV}$ is due to intra-instrument variability (Baker et al. 2014; Boulyga et al. 2007; Doorn et al. 2015; Goulet et al. 2017, 2012; Pullan et al. 2013), this suggests that the remaining up to $\sim 5$ to $14 \% \mathrm{CV}$ is probably due to physiological variability.

\section{Other micronutrients (calcium, magnesium, iron, copper, zinc, vitamins)}

Very few studies have investigated mechanisms of sweat secretion for any micronutrients other than $\mathrm{Na}^{+}, \mathrm{Cl}^{-}$, and $\mathrm{K}^{+}$. As discussed above, research concerning trace elements and vitamins in sweat is confounded by skin cell contamination. Studies that have taken measures to collect cell-poor sweat suggest that final sweat micronutrient concentrations are similar to or less than blood plasma concentrations. Sweat trace element concentrations have been reported to be much more varied than that of the blood plasma (Table 1). Because of the paucity of data, it is unknown whether this is due to varying mechanisms of secretion/reabsorption in the sweat gland or the difficulty in measuring true sweat trace element concentrations untainted by the contents of skin cells.

While $\mathrm{Ca}^{2+}$ ions play an important role as a second messenger in the process of sweat secretion, the mechanism of $\mathrm{Ca}^{2+}$ movement into the lumen of the secretory coil is not well understood. In a series of studies by Gibinski et al. $(1973,1974)$, radioisotopes of $\mathrm{Ca}^{2+}, \mathrm{K}^{+}$, and $\mathrm{Na}^{+}$ were administered (orally or intravenously) $4-5 \mathrm{~h}$ before heat exposure and their concentrations were subsequently measured in sweat. Radio-labeled $\mathrm{K}^{+}$and $\mathrm{Na}^{+}$appeared in sweat within minutes of administration (Gibinski et al. 1973). Radio-labeled $\mathrm{K}^{+}$in sweat was similar to that of blood after $\sim 1 \mathrm{~h}$ of sweating. By contrast, radio-labeled $\mathrm{Ca}^{2+}$ appearance in sweat was slow and did not exceed 5\% of blood plasma concentrations (Gibinski et al. 1974). The authors suggested that the binding of $\mathrm{Ca}^{2+}$ may explain the difference in the dynamics of $\mathrm{Ca}^{2+}$ compared with $\mathrm{K}^{+}$and $\mathrm{Na}^{+}$appearance in sweat. Approximately $50 \%$ of plasma $\mathrm{Ca}^{2+}$ is bound to protein or complexed with citrate, bicarbonate, or phosphate, while the other $50 \%$ is free, ionized $\mathrm{Ca}^{2+}$ (Jahnen-Dechent and Ketteler 2012). Similarly, 30-45\% of plasma $\mathrm{Mg}^{2+}$ is bound or complexed, while $55-70 \%$ is free, ionized $\mathrm{Mg}^{2+}$ (Jahnen-Dechent and Ketteler 2012). Charged ions such as free $\mathrm{Ca}^{2+}$ and $\mathrm{Mg}^{2+}$ are hydrophilic but small so they may be secreted readily via the paracellular route. By contrast, protein-bound fractions of $\mathrm{Ca}^{2+}$ and $\mathrm{Mg}^{2+}$ may not be as readily available for secretion and/or may occur at a slower rate. This may explain why $\left[\mathrm{Ca}^{2+}\right]$ and $\left[\mathrm{Mg}^{2+}\right]$ of cell-poor sweat are more similar to ionized than to total plasma $\left[\mathrm{Ca}^{2+}\right]$ and $\left[\mathrm{Mg}^{2+}\right]$ concentrations (Gibinski et al. 1974). 
Most ( 70\%) of plasma $\mathrm{Zn}^{2+}$ (albumin) and nearly all $(\geq \sim 95 \%)$ of plasma $\mathrm{Cu}^{2+}$ (ceruloplasmin) and plasma $\mathrm{Fe}^{2+}$ (transferrin) are bound to carrier proteins. It is unclear how these trace elements are secreted by clear cells of the eccrine gland. In other cells throughout the body divalent metal transporter 1, divalent cation transporter 1 , or other carriermediated systems play an important role in moving $\mathrm{Fe}^{2+}$, $\mathrm{Zn}^{2+}$, and $\mathrm{Cu}^{2+}$ across the membrane (Anderson and Frazer 2017; Jahnen-Dechent and Ketteler 2012; McArdle 1992; Roohani et al. 2013). With regard to vitamin secretion in sweat, ascorbic acid and thiamine are large polar molecules (Table 1) and, therefore, may be secreted through a paracellular route albeit exact mechanisms are unknown. Few studies have measured water-soluble vitamin concentrations in sweat (Mickelsen and Keys 1943; Thapar et al. 1976) and in some cases interpretation is difficult due to limited methodologies (scraping) used (Tang et al. 2016). The authors are unaware of any studies reporting sweat concentrations of fat-soluble vitamins. More research is needed to understand mechanisms of trace element and vitamin movement across cell membranes of the eccrine gland secretory coil and duct.

\section{Metabolites}

\section{Glucose}

There is significant interest in sweat glucose as a possible noninvasive alternative to blood glucose monitoring in diabetic patients. While glucose is present in sweat, as first demonstrated by Silvers et al. (1928), its concentration is $\sim 100 \times$ lower than that of blood glucose (Boysen et al. 1984; Jajack et al. 2018; Katchman et al. 2018; Lobitz and Mason 1948; Moyer et al. 2012; Ono et al. 2018). There is still speculation regarding the exact mechanism of glucose secretion into sweat. Most studies suggest that blood glucose is the primary source of sweat glucose (Boysen et al. 1984; Jajack et al. 2018; Moyer et al. 2012; Ono et al. 2018) albeit its large size and polarity likely limit the passage of glucose into the lumen of the eccrine gland.

Early studies on the mechanisms determining sweat glucose concentrations were often limited by analytical techniques using reducing agents that may have included sugars other than glucose. More recent studies have directly measured sweat glucose concentration. Boysen et al. (1984) collected thermally induced sweat and were the first to show a connection between blood glucose and sweat glucose concentrations. The investigators observed a concomitant rise in sweat and plasma glucose concentrations following oral and intravenous glucose administration in two participants (Boysen et al. 1984). In addition, Moyer et al. (2012) demonstrated a correlation between sweat and blood glucose in diabetic patients after pilocarpine administration. However, neither study investigated potential mechanisms of glucose secretion. Some recent papers have suggested a potential route of glucose transport that is paracellular in nature (Heikenfeld et al. 2019; Jajack et al. 2018; Katchman et al. 2018). Paracellular transport is highly regulated via tight junctions that function to limit large molecule transport (Kutchai 1998). Glucose flux in sweat has been shown to change with the modulation of tight junctions in the sweat gland epithelium (Jajack et al. 2018). Using citrate, a calcium chelator, Jajack et al. (2018) were able to modify paracellular pathways and found a $>10$-fold increase in sweat glucose flux. However, it is unclear whether paracellular transport of glucose may occur in the secretory coil (Jajack et al. 2018) or duct (La Count et al. 2018) of the eccrine gland.

A recent study has suggested there may be a transcellular route by which glucose is secreted into sweat. Ono et al. (2018) measured sweat glucose concentration in patients with and without atopic dermatitis and found an increase in sweat glucose concentration in those with atopic dermatitis. The investigators also found an increased expression of glucose transporter GLUT2 mRNA, along with a potential luminal translocation in atopic dermatitis patients. However, it is unclear if the increased expression of GLUT2 or the increased sweat glucose concentration is what caused the luminal localization (Murota et al. 2018; Ono et al. 2018). Expression of sodium-dependent glucose transporters SGLT3 and SGLT4 were also observed, but it was unclear if these transporters were upregulated in atopic dermatitis patients (Ono et al. 2018). Further studies are needed to elucidate the mechanisms of glucose secretion into sweat.

\section{Lactate}

Plasma lactate concentration is often monitored in competitive runners/cyclists and used as a tool to design exercise training regimens and set race pace. Thus, there is some interest in sweat lactate as a more practical means to monitor exercise intensity and physiological stress in athletes. However, as discussed in more detail below, sweat lactate concentrations generally do not correlate well with that of the blood (Alvear-Ordenes et al. 2005; Fellmann et al. 1983; Green et al. 2000; Weiner and Van Heyningen 1952). This is likely due, at least in part, to lactate production by the eccrine gland itself (Astrand 1963; Gordon et al. 1971; Wolfe et al. 1970).

The presence of glycogen in eccrine glands has been shown histochemically since the early 1900s (Brunner 1906). Studies have also shown that glycogen becomes depleted with sweating and is repleted with rest (Yuyama 1935). Glycogen content and phosphatase activity in the secretory coil (Bunting et al. 1948; Shelley and Mescon 1952), combined with in vivo and in vitro studies, have led many investigators to the conclusion that lactate is produced via eccrine gland 
metabolism as an end-type process of glycolysis (Ament et al. 1997; Kuno 1956; Robinson and Robinson 1954; Sato 1977; Sato and Dobson 1973; Sato et al. 1989; Weiner and Van Heyningen 1952; Wolfe et al. 1970). Furthermore, a tracer study that injected ${ }^{14} \mathrm{C}$-labeled glucose and lactate indicated that the excreted lactate was derived from blood glucose rather than blood lactate (Gordon et al. 1971). Collective observations throughout the literature indicate that sweat lactate concentration typically exceeds that of blood lactate (Ament et al. 1997; Derbyshire et al. 2012; Fellmann et al. 1983; Green et al. 2000; Weiner and Van Heyningen 1952; Whitehouse 1935), especially at the onset of initial sweating when flow rates are low. There seems to be an inverse relation between flow rate and lactate concentration such that sweat lactate concentration decreases as sweating rate increases, possibly as a result of dilution (Ament et al. 1997; Astrand 1963; Buono et al. 2010; Derbyshire et al. 2012; Falk et al. 1991). Studies have found a direct relation between sweating rate and lactate excretion rate in terms of $\mathrm{mmol} / \mathrm{cm}^{2} / \mathrm{min}$ (Astrand 1963; Buono et al. 2010) albeit this is not surprising given that lactate excretion rate is a function of sweating rate as well as sweat lactate concentration.

To the authors' knowledge, no study has been performed to determine the mechanism by which lactate is transported across cell membranes of the eccrine gland and into the lumen. Gordon et al. (1971) first implied that the high rate of glycolysis in eccrine gland tissue and the production of lactate is linked to the secretory process, which seems to be corroborated by the finding that oxidative phosphorylation of plasma glucose is the main energy production route (Sato 1977; Sato and Dobson 1973). Considering that the cellular location of glycogen is likely limited to the clear cells of the secretory coil, it seems sweat lactate may be derived from the same location (Sato 1977). It has been speculated that due to a low $p \mathrm{Ka}$ and a small molecular size, lactate is capable of passive diffusion (Sato 1977; Sonner et al. 2015). However, recent transcriptomic and proteomic analysis of human eccrine cells identified similarities in gene expression between the human kidney and sweat glands, indicating that many genes expressed within the cortex of the kidney are also expressed within eccrine glands ( $\mathrm{Na}$ et al. 2019). Of particular interest is the finding of solute carrier family (SLC) proteins previously only found in the kidneys. Lactate is actively transported by monocarboxylate transport proteins (MCT), also within the SLC gene family (Price et al. 1998), which has been linked to kidney cells located within the proximal tubule and cortex (Wang et al. 2006). It may be possible that MCT proteins are also expressed in clear cells of sweat glands and aid in the transport of lactate out of the cell. However, these mechanisms of lactate partitioning are complex and speculative and future studies are needed to better characterize lactate transport in eccrine sweat glands.

\section{Ammonia}

Ammonia is a waste formed mostly through bacteria in the intestines during protein digestion and used as substrate in the urea cycle. Various amino acids produced as metabolites of proteins are then converted into glutamic acid (glutamate) and subsequently deaminated by glutamate dehydrogenase in the mitochondria to produce ammonia. Ammonia is a small uncharged polar molecule typically found in higher concentrations in sweat than in blood (Table 1). The mechanisms underlying sweat ammonia concentration have been speculated for decades, beginning with Mosher (1933) and the proposal that ammonia is a byproduct of urea catabolism in eccrine glands. More recently, Czarnowski et al. (1992) have proposed instead that plasma ammonia is the main source of ammonia in sweat. In their study, ammonia and urea concentrations were measured in blood and sweat samples collected from four groups: controls, cirrhotic hyperammonemic patients, uremic patients, and a group that ingested ammonium chloride (Czarnowski et al. 1992). Increased plasma ammonia (in cirrhotic patients and from ammonium ingestion) resulted in increased sweat ammonia concentrations, but no increase in sweat urea concentrations. Furthermore, this (Czarnowski et al. 1992) and other studies (Brusilow and Gordes 1965) have found that uremic patients had increased sweat urea concentrations, but their sweat ammonia concentrations were similar to controls. Taken together, these results suggest that ammonia in sweat did not come from urea breakdown, but instead originated primarily from the plasma (Czarnowski et al. 1992).

This does not, however, explain the significantly higher ammonia concentrations typically found in sweat versus blood. Brusilow and Gordes (1968) have proposed that diffusion and ionic ammonium trapping is only the final step of ammonia secretion, as glandular production may also be a source of sweat ammonia. These authors investigated the partial pressure of ammonia $\left(\mathrm{pNH}_{3}\right)$ in sweat samples of differing $\mathrm{pH}$ and suggested that alkaline sweat containing a higher $\mathrm{pNH}_{3}$ than blood was evidence for glandular ammonia production (Brusilow and Gordes 1968). However, isolated gland studies and direct evidence for this idea is lacking. Another hypothesis proposed by Itoh and Nakayama (1952) suggests that sweat ammonia may be derived from glutamine catabolism in the skin. The investigators isolated glutaminase I activity in human skin tissue and measured ammonia production following incubation in several amino acid solutions. In this study, only glutamine caused large increases in ammonia concentration. The large amount of amino acids found within sweat and the relatively small concentration of glutamine (Coltman et al. 1966; Dunstan et al. 2016; Gitlitz et al. 1974; Liappis et al. 1979) would seem to support this conclusion. Furthermore, several investigators have found that the skin itself has the capability to emit 
ammonia (Nose et al. 2005; Schmidt et al. 2013; Turner et al. 2008). In summary, while plasma ammonia plays an important role in determining sweat ammonia concentrations (Czarnowski et al. 1992; Sato 1977), the source of excess ammonia in sweat compared with blood is equivocal. Sweat ammonia concentration could be impacted by ammonia formation in skin tissue, production in the sweat gland, and/or possibly from some form of skin emissionsweat incorporation.

Given that the permeability for ammonia is similar to water (due to molecular size and polarity), Czarnowski et al. (1992) and others (Sato 1977; Sato et al. 1989) have suggested that the $\mathrm{pH}$ gradient between blood, sweat, and water compartments allows ammonia to passively diffuse across membranes. Due to the low $\mathrm{pH}$ of final sweat ( 5 to 7$)$, ammonia $\left(\mathrm{NH}_{3}\right)$ molecules that diffuse into the glandular lumen protonate to ammonium $\left(\mathrm{NH}_{4}{ }^{+}\right)$effectively trapping the molecules from the ionization and acquired charge (Sato et al. 1989; Sonner et al. 2015). This notion is in accordance with work from Brusilow and Gordes (1968) who found a negative correlation between the sweat-to-blood ammonia concentration ratio and sweat $\mathrm{pH}$. Similarly, Ament et al. (1997) found that ammonia and lactate were present in the same order of magnitude throughout exercise. Thus, lactate may be acidifying sweat, thereby establishing the $\mathrm{pH}$ gradient needed for ammonia flux and subsequent shift into the glandular lumen. These results suggest ammonia may pass either through or between the cells of the secretory coil by way of a passive diffusion mechanism although direct evidence from permeability studies is lacking.

\section{Urea}

Urea is a nitrogenous compound formed in the liver from ammonia and is the final end product of protein metabolism. Excretion of urea is accomplished primarily by the kidneys; but it is also excreted by sweat glands, most notably demonstrated by the urea frost found on the skin of uremic patients (al-Tamer et al. 1997; Sato et al. 1989). Urea is a small polar molecule and easily crosses the glandular wall and cell membrane (Komives et al. 1966; Sato et al. 1989). Thus, sweat urea is thought to be derived from the plasma (Komives et al. 1966; Sato 1977; Sato et al. 1989). However, reported sweat urea concentrations are often higher than that of the plasma in both healthy and uremic patients (Table 1 and Supplemental Table 4). Several hypotheses for the increased urea in sweat have been proposed. These include urea production (Araki and Ando 1953; Brusilow and Gordes 1968; Sato et al. 1989) or 'insensible' metabolism (Brusilow 1967; Rothman et al. 1949) stemming from the split of arginine to ornithine and urea via arginase activity in the eccrine gland or skin (Rothman and Sullivan 1949; Talbert et al. 1927), water resorption in the eccrine duct
(Schwartz et al. 1953), and/or a finite pool of urea located in the epidermis and/or gland (Brusilow 1967; Brusilow and Gordes 1968; Gordon et al. 1976).

Urea tracer studies provide perhaps the best evidence regarding the source of urea in sweat (Brusilow 1967; Gordon et al. 1976). Brusilow (1967) found that the sweat-toplasma ratio of ${ }^{14} \mathrm{C}$-labeled urea after oral administration was 1.08 , while the ratio for total urea was 1.43 . These results support the notion that urea passes readily into sweat from plasma and also suggests a non-plasma source of urea since unlabeled urea was present in final sweat. Gordon et al. (1976) reported similar results and postulated that the source of non-plasma urea was a finite pool of urea in the epidermis, presumed to be concentrated through insensible evaporation of water (Fig. 1). Further support for this hypothesis is provided by studies showing a progressive decline in the sweat urea-to-blood urea ratios to near unity during periods of profuse sweating (Komives et al. 1966). By contrast, the idea that sweat constituents become concentrated via water reabsorption in the duct lacks support (Amatruda and Welt 1953; Gordon et al. 1976; Hew-Butler et al. 2014).

While urea is a small molecule able to diffuse through and/or between cell walls, recent literature suggests that eccrine glands may express localized urea transporter subtypes (Keller et al. 2016; Na et al. 2019; Xie et al. 2017). The expression of urea transporter 1 isoform 1 (UT-1) at the transcriptome and proteome level suggests the facilitation of transmembrane urea movement (Keller et al. 2016; Xie et al. 2017). UT-A1 and UT-B1 protein expression and localization have been found in cells of both the secretory coil (clear cells) and duct (Keller et al. 2016), with significantly higher mRNA expression in uremic patients compared with normal controls (Xie et al. 2017). These findings suggest that with excess urea production, there may be an active mechanism of urea excretion through sweat. Additionally, the overlap in gene expression found between eccrine glands and kidneys may indicate that sweat is another way to excrete metabolic wastes (Na et al. 2019), albeit the effectiveness of this function remains uncertain (Baker 2019).

\section{Bicarbonate}

Bicarbonate is present in most body fluids and organs and plays an important role in acid-base balance. It has been proposed that bicarbonate is secreted and reabsorbed in the eccrine gland, dictating the $\mathrm{pH}$ of sweat in the process; although exact mechanisms have not been established (Sato 1983; Sato and Sato 1990). One proposed mechanism involves a bicarbonate/ $\mathrm{Cl}^{-}$exchanger (Quinton and Reddy 1989; Reddy and Quinton 1994a) in combination with a hydrogen-ATPase pump, which could create a favorable gradient for bicarbonate luminal secretion following $\mathrm{Cl}^{-}$reabsorption (Patterson et al. 2000). Furthermore, a recent study 
has proposed a new mechanism stemming from a possible Best 2 bicarbonate/ $\mathrm{Cl}^{-}$channel located in the dark cells of the secretory coil (Cui and Schlessinger 2015). This suggested working model may be involved in acid-base balance and sweat secretion via elevated $\mathrm{Ca}^{2+}$ action leading to bicarbonate secretion specifically from dark cells (Cui and Schlessinger 2015). Similarly, Cui et al. (2016) detected mRNA expression of a bicarbonate/ $\mathrm{Cl}^{-}$exchanger termed pendrin (SLC26a4) in isolated secretory cells of murine footpad sweat glands. This anion exchange protein may also play a role in bicarbonate secretion (Cui et al. 2016; SaintCriq and Gray 2017).

Carbonic anhydrase, the enzyme responsible for catalyzing the reaction of carbon dioxide plus water and bicarbonate plus hydrogen, has been immunohistochemically located in both clear cells and apical lumen cells of the eccrine gland (Briggman et al. 1983; Clunes et al. 2004). It has been suggested that the appearance of both isoforms of carbonic anhydrase in clear cells indicates that the enzyme may play a role in bicarbonate secretion into the lumen (Clunes et al. 2004). Similarly, the presence of carbonic anhydrase in the apical lumen cells in combination with a luminal bicarbonate/ $\mathrm{Cl}^{-}$exchanger (Bonar and Casey 2008; Bovell and Quinton 2002; Quinton and Reddy 1989; Reddy and Quinton 1994a) suggests a possible route for bicarbonate reabsorption. Briefly, it has been hypothesized that the hydrogen-ATPase transports hydrogen into the lumen, creating a gradient for bicarbonate entry, which is then neutralized to carbonic acid. The carbon dioxide in combination with the carbonic anhydrase in the luminal cell cytoplasm would create a continuous cycle of bicarbonate production for $\mathrm{Cl}^{-}$exchange (Quinton and Reddy 1989; Reddy and Quinton 1994a).

Bicarbonate is also thought to be reabsorbed in the sweat duct via CFTR, combined with hydrogen secretion, leading to the acidification of final sweat (Choi et al. 2001). Much like $\mathrm{Na}^{+}$and $\mathrm{Cl}^{-}$, bicarbonate reabsorption is inversely related to sweating rate. Thus, lower sweat flow rates are associated with a lower bicarbonate concentration and lower pH of final sweat (Collins et al. 1966; Kaiser et al. 1974). While these theories are still speculative, it seems most likely that sweat $\mathrm{pH}$ is an artifact of a reabsorptive duct function and hydrogen ion secretion via an apical membrane hydrogen-ATPase pump activity (Bovell et al. 2000), basolateral $\mathrm{Na}^{+} / \mathrm{H}^{+}$exchange (Granger et al. 2003; Kaiser et al. 1974), or bicarbonate reabsorption (Patterson et al. 2000, 2002).

\section{Amino acids}

Amino acids are organic compounds that combine to form proteins. The human body uses amino acids to break down food, repair body tissues, and, in some cases as fuel. In the skin, amino acids or their derivatives function as natural moisturizing factors that can act as humectants (Watabe et al. 2013). Amino acids were first identified in sweat in 1910 (Embden and Tachau 1910) and since then several more studies have isolated up to 20 different amino acids in sweat collected on the skin surface (Coltman et al. 1966; Dunstan et al. 2016; Gitlitz et al. 1974; Hier et al. 1946; Rothman and Sullivan 1949). Possible mechanisms underlying amino acid appearance in sweat may include selective secretion by the gland, selective reabsorption (Araki and Ando 1953), or a combination of both (Gitlitz et al. 1974). It may be that the transfer of amino acids from the interstitial fluid into eccrine sweat is influenced by molar volume, polarity, or ligand binding, among other factors (Gitlitz et al. 1974). More work is needed to elucidate mechanisms of sweat amino acid composition. Nonetheless, it is apparent that amino acid appearance in sweat is not merely a result of filtration from the plasma, as Hier et al. (1946) found that amino acid ingestion did not affect sweat amino acid concentrations.

The non-plasma source of amino acids in sweat is likely the skin itself, as recent research has found a strong similarity between sweat amino acid composition and natural moisturizing factors (NMF) and epidermal proteins (Mark and Harding 2013). Moreover, several NMF produced in the stratum corneum (serine, histidine, ornithine, glycine, alanine, lysine, aspartic acid) appear in higher concentrations in the sweat than blood (Dunstan et al. 2016). It may be that the stratum corneum influences the amino acid content of sweat via the hydrolysis of the epidermal protein filaggrin, present in keratohyalin granules of the acrosyringium (Langbein et al. 2005; Mark and Harding 2013). This hydrolysis would allow filaggrin-derived amino acids to diffuse into the sweat directly from the ductal lining as it passes onto the surface of the skin (Mark and Harding 2013). Another line of evidence for the hypothesis that amino acids are leached from the skin is that the amount of NMF in sweat declines as exercise duration increases (Dunstan et al. 2016). Several studies have also found an inverse relation between sweating rate and sweat amino acid concentration (Araki and Ando 1953; Dunstan et al. 2016; Gitlitz et al. 1974; Itoh and Nakayama 1952), suggesting possible dilution of amino acid concentration occurring with greater sweat (water) volume. In summary, the exact mechanism underlying the presence of amino acids in eccrine sweat is uncertain; however, it seems that skin NMF plays a large role in sweat amino acid composition. The variation in sweat amino acid profiles among studies and individuals may stem from the capacity to replenish skin NMF (Dunstan et al. 2016). 


\section{Ethanol}

A commonly perceived function of eccrine glands is the elimination of ethanol from the body via enhanced sweating rates and increased sweat ethanol concentration. There is no experimental evidence that alcohol ingestion leads to an increase in sweating rate (Baker 2019). It does appear that sweat ethanol concentration increases linearly with ethanol ingestion, as several investigators have demonstrated a significant positive correlation between sweat and blood ethanol concentrations (Brown 1985; Buono 1999; Gamella et al. 2014; Hauke et al. 2018; Phillips and McAloon 1980). Because of its small size and hydrophilic-lipophilic nature, ethanol is easily distributed throughout body water via passive diffusion (Cederbaum 2012; Jacobsen 1952; Nyman and Palmlov 1936; Paton 2005; Pawan and Grice 1968), and is likely secreted into sweat by the same mechanism.

It is important to note, however, that while a strong relation between sweat and blood ethanol concentrations exists (Brown 1985; Gamella et al. 2014; Hauke et al. 2018), the primary mechanism of ethanol elimination is oxidation within the liver. Briefly, a combination of four alcohol dehydrogenases catalyze multiple reactions breaking ethanol into acetaldehyde, acetate, and eventually acetyl CoA (Cederbaum 2012; Paton 2005). It is through this process that $90 \%$ of ethanol is eliminated with a remaining $2-10 \%$ thought to be excreted through breath, sweat, and urine (Cederbaum 2012; Jacobsen 1952; Paton 2005).

\section{Others}

\section{Cytokines}

Cytokines are small secreted proteins with pleiotropic effects important in autocrine, paracrine, and endocrine cell signaling (Zhang and An 2007). Interest in sweat cytokines likely stems from their relation to inflammation, infection, and immune response. Their large molecular weight would seem to preclude secretion into eccrine sweat; however, suggestive mechanisms have been proposed (Heikenfeld et al. 2019; Sonner et al. 2015). The presence of cytokines in human sweat was first reported by Didierjean et al. (1990). This study involved active, passive, and thermal stimulation and all samples expressed at least one form of interleukin (IL)- $1 \alpha$ or IL-1 $\beta$. Other investigators have found similar results regarding IL-1 and have also detected IL-6, IL-8, IL-10, IL-31, tumor necrosis factor (TNF)- $\alpha$, and transforming growth factor (TGF)- $\beta$ in sweat (Cizza et al. 2008; Dai et al. 2013; Hladek et al. 2018; Jones et al. 1995; Marques-Deak et al. 2006; Sato and Sato 1994) although IL-6 and TNF- $\alpha$ are not consistently detected (Dai et al. 2013; Faulkner et al. 2014).
The secretory coil, as well as straight and coiled portion of the duct, expresses immunohistochemical activity of IL- $1 \alpha$ and IL-1 $\beta$. Expression of these cytokines is found in both luminal and basal cells of the duct, but more intense staining is exhibited in luminal cells. Only the clear cells of the secretory coil express IL- $1 \alpha$ and IL- $1 \beta$ (Ahmed et al. 1996; Grellner 2002; Reitamo et al. 1990; Sato and Sato 1994). Likewise, immunolabeling of the eccrine gland has shown expression of IL-6, IL-8, IL-31, TGF- $\beta$, and TNF- $\alpha$ (Ahmed et al. 1996; Anttila et al. 1992; Dai et al. 2013; Grellner 2002; Jones et al. 1995; Tian and Stacey 2003). It seems these cytokines follow a similar trend as IL-1, with strong staining exhibited in the clear cells of the secretory coil and in the luminal cells of the duct (Ahmed et al. 1996; Dai et al. 2013; Jones et al. 1995; Tian and Stacey 2003). Furthermore, in situ hybridization studies have found that mRNA encoding for IL- $1 \alpha$, IL- $1 \beta$, IL- 8 , and TNF- $\alpha$ are present in the secretory coil and duct (Boehm et al. 1994; Jones et al. 1995), suggesting that these cytokines are innately expressed in eccrine glands.

While generally linked to inflammation, cytokines in sweat appear with and without associated local inflammation. Furthermore, the finding that insensible sweat cytokine concentration is correlated with plasma concentrations suggests at least a portion is derived from the circulating stores (Cizza et al. 2008; Marques-Deak et al. 2006). However, the hypothesis that cytokines are cleared from the blood via sweat is not fully supported by the current available literature. It seems more likely that these cytokines are derived from the eccrine gland itself. The intense staining pattern of clear secretory coil cells and lumen duct cells would seem to indicate a cell-associated relationship (Ahmed et al. 1996). Likewise, the elevated sweat cytokine concentrations during exercise and thermal stress (Didierjean et al. 1990; Sato and Sato 1994) combined with the regional differences in sweat cytokine concentration (Didierjean et al. 1990) would indicate stress-induced cell secretion rather than an origination from the blood. The gradual taper of IL-1 secretion in sweating lasting over $1 \mathrm{~h}$ might suggest the diminishing of these stores, with the presence of mRNA indicating to the ability to resynthesize following secretion (Dai et al. 2013; Murphy 1995; Sato and Sato 1994). However, given study limitations, it is not possible to rule out that cytokine sweat concentration could be the consequence of a storage function or due to the rate of synthesis by the gland.

Some have suggested that sweat cytokines play a role in pathophysiological function: hypotheses include surveillance and readiness for rapid response and cell recruitment to stress, immune, and environmental insults (Boehm et al. 1994; Didierjean et al. 1990; Tian and Stacey 2003), ductal regulatory function (Boehm et al. 1994), and further cytokine regulation in cascade-based fashion (Sato and Sato 
1994). However, direct mechanisms of cytokine secretion in eccrine sweat remain speculative.

\section{Cortisol}

Cortisol acts as the main glucocorticoid hormone produced by the adrenal cortex and is often used to assess adrenocortical function. Release of cortisol is both spontaneous and in response to biochemical agents or psychological/physiological stimuli (Kirschbaum and Hellhammer 1989, 2000). Approximately $90 \%$ of the endogenous hormone is bound to carriers, and it is believed that the remaining $5-10 \%$ of unbound or free cortisol is biologically active on target tissues (Ekins 1990). Unbound cortisol is thought to diffuse readily into cells due to their lipid-rich cell membrane (Kirschbaum and Hellhammer 1989). This passive transport through lipid bilayer membranes is what likely allows for the detection of cortisol in many bodily fluids in addition to blood, such as saliva (Kirschbaum and Hellhammer 1989; Perogamvros et al. 2010; Umeda et al. 1981), sweat (Jenkins et al. 1969; Jia et al. 2016; Lewis and Thorn 1955; Nichols and Miller 1948; Russell et al. 2014), and human hair (Raul et al. 2004).

The most compelling study on sweat cortisol mechanisms was published by Jenkins et al. (1969), who used an intravenous tracer method to track the movement of cortisol from blood to sweat. In this study, participants received an intravenous infusion of ${ }^{14} \mathrm{C}$ labeled-cortisol prior to thermally induced sweating. Only $0.024-0.073 \%$ of the labeled cortisol appeared in sweat as the unchanged compound or unconjugated metabolites. Based on radioactivity of the samples, a larger quantity of unbound cortisol was secreted in sweat compared with cortisol tightly bound to plasma proteins. Unconjugated cortisone concentrations in sweat were similar to that of plasma but less than plasma cortisol (Jenkins et al. 1969). These results are in agreement with the findings of Lewis and Thorn (1955), who reported that low concentrations $(<8 \mu \mathrm{g}$ per $100 \mathrm{ml})$ of cortisol and cortisone were present in sweat. Interestingly, a low concentration of cortisol in sweat remained even following a $25 \mathrm{mg}$ injection of exogenous cortisol prior to exercise, while urine cortisol excretion increased approximately threefold (Lewis and Thorn 1955).

Jenkins et al. (1969) speculated that, because of the comparable histology of eccrine glands and parotid glands, a similar enzymatic conversion of cortisol to cortisone may take place during the thermal sweat secretion process. These results suggest that protein-bound fractions may not be readily available for secretion and or conversion, whereas the smaller unbound or unconjugated fractions are able to diffuse into secretory fluid. While this concept has been investigated in saliva, it is largely speculative in eccrine glands. However, some evidence, stemming from in vitro metabolic studies of human skin, seems to suggest a transformation of cortisol may take place (Hsia et al. 1964). Furthermore, an enzyme recognized to convert cortisol to cortisone (11 $\beta$-hydroxysteroid-dehydrogenase Type 2) has been immunolocalized to luminal duct cells of eccrine glands (Hirasawa et al. 1997; Kenouch et al. 1994; Smith et al. 1996), but found to be lacking in hair follicles, epidermis and sebaceous glands (Hirasawa et al. 1997; Smith et al. 1996). The localization of $11 \beta$-hydroxysteroid-dehydrogenase Type 2 to eccrine glands and the finding of cortisone and cortisol in hair suggest an incorporation following active or passive diffusion from eccrine sweat (Raul et al. 2004). Incorporation of molecules into human hair depends on basicity, melanin affinity, and lipophilicity (Raul et al. 2004) resulting in three potential mechanisms for incorporation: active or passive diffusion from blood into the growing follicle, diffusion from secretions during hair shaft formation, and external sources following shaft formation (Kintz et al. 2000; Wennig 2000). If diffusion is responsible for cortisol incorporation into hair, it seems possible that a similar process may explain cortisol diffusion into eccrine sweat. Nonetheless, this rationale is still speculative and more research is needed to understand the mechanisms of cortisol movement.

\section{Differences in sweat composition with passive versus active sweating}

There are two main ways by which sweat secretion is stimulated: sweating induced by passive and active methods. Passive sweating occurs while the participant is at rest and can be induced by pharmacological manipulation or by increasing the temperature of the surrounding air (e.g., dry heat or sauna bathing). Active sweating refers to exercise-induced sweat secretion. Pharmacologically induced sweating involves the use of a small electrical current (iontophoresis) to propel charged cholinergic agonists (e.g., pilocarpine or methacholine) transdermally to stimulate the muscarinic receptors on the sweat glands (Gibson and Cooke 1959; Webster 1983). Pilocarpine iontophoresis is commonly used in research and is the gold-standard sweat-testing method for cystic fibrosis (Mishra et al. 2005). It is often the method of choice from a practical perspective since it is relatively quick and circumvents the discomfort of heat stress and/or physical exercise. However, it is important to note that pharmacological methods induce sweat gland secretion only via local cholinergic stimulation. With exercise and/or passive heat stress, other local (e.g., skin temperature, skin blood flow, adrenergic stimulation, and other neuromodulators) and central mediators (e.g., body core temperature, central command, and exercise pressor reflex) are involved in stimulation of sweating (Shibasaki and Crandall 2010). 
Several studies have compared the local sudomotor response to pharmacological stimulation, passive heat stress, and/or exercise. Forearm sweating rate has been reported to be higher with exercise and/or thermal stress compared with pilocarpine iontophoresis (Hjortskov et al. 1995; VimieiroGomes et al. 2005). The reason for the discrepancy between methods could be related to the different mechanisms involved in sweat stimulation (Vimieiro-Gomes et al. 2005). In general, higher sweating rates have been reported with exercise than passive heating (Taylor and Machado-Moreira 2013) albeit the differences may be attenuated when heat production, body core temperature, and skin temperatures are consistent between methods (Nielsen and Nielsen 1965).

\section{Sodium chloride and other micronutrients}

Supplemental Table 3 summarizes the literature comparing the effect of different sweat stimulation methodologies on sweat composition. The results have been mixed and difficult to interpret, due in part to a lack of statistical analysis in some of the early papers. Separate studies have found higher (Ikai et al. 1969), lower (Fukumoto et al. 1988; Kozlowski and Saltin 1964), or similar (Verde et al. 1982) sweat $\left[\mathrm{Na}^{+}\right]$ and $\left[\mathrm{Cl}^{-}\right]$with exercise versus passive heat stress. Likewise, sweat $\left[\mathrm{Na}^{+}\right]$and $\left[\mathrm{Cl}^{-}\right]$have been reported to be higher (Collins 1962; Sato et al. 1970; Shwachman and Antonowicz 1962) or similar (di Sant'Agnese and Powell 1962; Shwachman and Antonowicz 1962) with pharmacological stimulation versus passive heating. As shown in Supplemental Table 3, results were also equivocal for sweat $\left[\mathrm{K}^{+}\right]$, $\left[\mathrm{Ca}^{2+}\right]$, and $\left[\mathrm{Mg}^{2+}\right]$ and no data to the authors' knowledge are available for $\mathrm{Zn}^{2+}, \mathrm{Cu}^{2+}$, or vitamins. In most of these studies, sweating rate was not standardized or not reported. Even when sweating rate was matched between exercise and passive heating the impact on sweat $\left[\mathrm{Na}^{+}\right]$and $\left[\mathrm{Cl}^{-}\right]$ was inconsistent (Kozlowski and Saltin 1964; Verde et al. 1982). Some studies collected sweat from different body regions (di Sant'Agnese and Powell 1962) or via different techniques (Shwachman and Antonowicz 1962) between stimulation methods, which further confound the interpretation of results.

Passive and active mechanisms of sweat stimulation have also been compared in studies measuring maximum ion reabsorption rates. Recently, Gerrett et al. (2018) compared the effects of exercise and passive heating on sweat gland ion reabsorption rates on the forearm, chest, and lower back by determining the sweating rate threshold for increasing galvanic skin conductance (Amano et al. 2016). While sweat ion concentrations were not measured, this study found that maximum ion reabsorption rates were higher during moderate-intensity exercise $\left(60 \% \mathrm{VO}_{2 \max }\right.$ for $\left.30 \mathrm{~min}\right)$ than passive heating (immersion of lower legs in $43{ }^{\circ} \mathrm{C}$ water bath for $30 \mathrm{~min}$ ). These results suggest that factors associated with physical activity may influence the rate of $\mathrm{Na}^{+}$and $\mathrm{Cl}^{-}$reabsorption in the eccrine duct (Gerrett et al. 2018). More work is needed to clarify whether exercise mediates enhanced ion reabsorption rates via thermal (body core temperature or mean skin temperature) and/or nonthermal (sympathetic or hormonal) mechanisms.

Discrepancies between methods of sweat stimulation can confound interpretation of studies investigating the impact of various host or external factors on sweat electrolyte concentrations. For example, one study found lower local sweating rates and a higher sweat $\left[\mathrm{Na}^{+}\right]$on tattooed skin than contralateral non-tattooed skin when stimulated by pilocarpine iontophoresis (Luetkemeier et al. 2017). However, in another study, skin tattoos did not alter local sweating rate or sweat $\left[\mathrm{Na}^{+}\right]$of exercise-induced sweating (Rogers et al. 2019). As expected, sweating rates were much larger in the exercise study (mean of $1.19 \mathrm{mg} / \mathrm{cm}^{2} / \mathrm{min}$ ) than the pilocarpine iontophoresis study (means of 0.18 and $0.35 \mathrm{mg} / \mathrm{cm}^{2} / \mathrm{min}$ ), which reiterates the mechanistic and practical differences between active and passive pharmacological sweat stimulation.

Taken together, the ecological validity of sweat solute concentrations of pharmacological sweat is questionable. As such, stimulation methodology should be carefully considered when designing research and interpreting sweat composition results. The methods used to induce sweating should fit the purpose of sweat testing and intended application of the data. For example, if the intent is to use the results to inform athletes on their individual sweat electrolyte losses, then the sweat testing should be conducted during exercise and in conditions (i.e., thermal environment) specific/relevant to their sport (Baker 2017).

\section{Metabolites and cytokines}

As shown in Supplemental Table 3, most of the literature suggests that sweat metabolite concentrations are higher with active versus passive sweating. For instance, concentrations of lactate (Astrand 1963; Mitsubayashi et al. 1994), ammonia (Mitsubayashi et al. 1994), amino acids (Liappis and Hungerland 1972), creatinine and urea nitrogen (Fukumoto et al. 1988) have been higher in sweat when stimulated via exercise as compared with passive heating. Most amino acid (Souza et al. 2018), alcohol, carbohydrate, and fatty acid (Delgado-Povedano et al. 2018) concentrations have been higher with exercise than pharmacologically induced sweating. However, there are exceptions, as one study found higher concentrations of lipid mediators in pharmacological sweat than exercise-induced sweat (Agrawal et al. 2018) and another study reported no differences in lactate concentration between exercise and passive heating (Fellmann et al. 1983). Sweat $\mathrm{pH}$ does not seem to vary between active and passive sweating, as long as the local environment (ventilation and humidity) is standardized between stimulation 
methods (Talbert 1919, 1922). Few studies have compared the two types of passive sweating, but available data suggest that lactate (Collins 1962) and amino acid (Souza et al. 2018) concentrations may be higher with passive heating than pharmacological sweat.

With respect to underlying mechanisms, it is interesting to note that the higher sweat lactate concentrations were generally associated with lower sweating rates (Astrand 1963; Collins 1962). This is consistent with the notion that sweat lactate concentrations become diluted with higher volumes of sweat (Buono et al. 2010). However, many of the other studies did not standardize sweating rate and/or anatomical location of sweat collection between methods. It is, therefore, difficult to determine the reason for higher concentrations of other metabolites with active versus passive sweating.

Only one study has compared the effects of different stimulation techniques on sweat cytokine concentrations. Didierjean et al. (1990) measured IL- $1 \alpha$ and IL- $1 \beta$ in sweat collected from the hand after stimulation via passive heating, sauna bathing, or spontaneous sweating. Both IL-1 cytokines were significantly higher with passive heating (Supplemental Table 3), which was also associated with maximum sweat induction (Didierjean et al. 1990). Because epidermal contamination was avoided (via use of the anaerobic technique with a petroleum barrier), the authors concluded that at least some of the IL-1 may have originated from the sweat glands themselves (Didierjean et al. 1990). However, it is unclear whether the differences in sweat IL-1 concentrations were due to the method of stimulation or factors (e.g., increased gland stress) associated with profuse sweating.

\section{Effects of heat acclimation, diet, and physical training on sweat composition}

\section{Sodium chloride and other micronutrients}

It is well established that heat acclimation results in a significant enhancement in the rate of sweat secretion by eccrine glands, resulting in improved tolerance to passive and active heat stress (Allan and Wilson 1971; Kirby and Convertino 1986; Pandolf et al. 1988). Partial acclimation occurs with passive heat stress or exercise training, but exposure to both exercise and heat stress is required to achieve full heat acclimation (Saat et al. 2005; Tipton et al. 2008). In addition, heat acclimation is usually associated with a decrease in sweat $\left[\mathrm{Na}^{+}\right]$and $\left[\mathrm{Cl}^{-}\right]$. The decrease in sweat $\left[\mathrm{Na}^{+}\right]$and $\left[\mathrm{Cl}^{-}\right]$begins after 2-3 consecutive days of heat exposure and continues over time (Buono et al. 2018; Karlsen et al. 2015), resulting in an up to 30-60\% decrease after 7-10 days (Allan and Wilson 1971; Buono et al. 2007, 2018; Chinevere et al. 2008; Johnson et al. 1944; Karlsen et al. 2015; Kirby and
Convertino 1986; Nielsen et al. 1997; Robinson et al. 1950). Seasonal variation in sweat $\left[\mathrm{Na}^{+}\right]$has also been reported to be $~ 30$ to $60 \%$ decrease from winter to summer (Bates and Miller 2008; Inoue et al. 1995). The linear relation between sweat flow rate and sweat $\left[\mathrm{Na}^{+}\right]$(discussed above) is maintained with heat acclimation. However, there is a downward shift in the regression line such that at any given sweating rate on the forearm, heat acclimation results in significantly lower forearm sweat $\left[\mathrm{Na}^{+}\right]$(Buono et al. 2007). The decrease in sweat $\left[\mathrm{Na}^{+}\right]$and $\left[\mathrm{Cl}^{-}\right]$despite an increase in sweating rate can be explained by the contrasting effects of acute changes in sweat flow rate versus the longer term adaptations in the sweat gland that occur with heat acclimation. The physiological mechanism underlying the decreased sweat $\left[\mathrm{Na}^{+}\right]$and $\left[\mathrm{Cl}^{-}\right]$with heat acclimation is related to alterations in the hormonal control of $\mathrm{Na}^{+}$reabsorption by aldosterone, possibly increased sensitivity of the eccrine gland to circulating aldosterone concentrations (Kirby and Convertino 1986). As described above, aldosterone influences $\mathrm{Na}^{+}$reabsorption by increasing the activity of $\mathrm{Na}^{+}-\mathrm{K}^{+}$-ATPase on the basolateral membrane in the eccrine sweat duct (Ladell and Shephard 1961; Sato and Dobson 1973).

It is important to note that a salt deficit is required to stimulate enhancement in $\mathrm{NaCl}$ reabsorption. Studies have found no change or a marginal increase in sweat $\left[\mathrm{Na}^{+}\right]$and $\left[\mathrm{Cl}^{-}\right]$ when salt intake is sufficient to replace sweat electrolyte losses incurred during the heat acclimation protocol, (Armstrong et al. 1985a; Eichner 2008; McCance 1938; Weiner and Van Heyningen 1952). This finding is in line with the notion that $\mathrm{NaCl}$ conservation by the sweat glands is mediated by circulating aldosterone. Moreover, Yoshida et al. (2006) found that individual variations in sweat $\left[\mathrm{Na}^{+}\right]$during exercise were correlated with resting plasma aldosterone concentration, but not to plasma aldosterone during exercise. Therefore, the genomic action of aldosterone (influenced by chronic $\mathrm{NaCl}$ balance as a result of heat acclimation and diet) may have a stronger impact on inter-individual variations in sweat $\left[\mathrm{Na}^{+}\right]$than the rapid non-genomic action of aldosterone (influenced by acute exercise and dehydration) (Yoshida et al. 2006). This concept is supported by two recent studies that induced plasma aldosterone changes via dietary $\mathrm{Na}^{+}$restriction for 3-5 days (Braconnier et al. 2019; McCubbin et al. 2019). McCubbin et al. (2019) reported a significant negative correlation between resting pre-exercise plasma aldosterone and sweat $\left[\mathrm{Na}^{+}\right]$measured during a subsequent bout of 2-h exercise in endurance athletes. Braconnier et al. (2019) also found that $\left[\mathrm{Na}^{+}\right]$of passive sweat (stimulated via pilocarpine iontophoresis) was negatively correlated with plasma aldosterone concentration in healthy normotensive participants.

The changes in sweat $\left[\mathrm{Na}^{+}\right]$and $\left[\mathrm{Cl}^{-}\right]$with altered dietary salt intake have been extensively reviewed in recent publications (Baker 2019; McCubbin and Costa 2018) 
and, therefore, will not be discussed in detail here. In brief, most (Allsopp et al. 1998; Armstrong et al. 1985a; Braconnier et al. 2019; Costa et al. 1969; Hargreaves et al. 1989; Komives et al. 1966; McCance 1938; McCubbin et al. 2019; Sigal and Dobson 1968; Weiner and Van Heyningen 1952) but not all (Costill et al. 1975; Koenders et al. 2017; Konikoff et al. 1986; Robinson et al. 1956) studies have shown that dietary $\mathrm{Na}^{+}$restriction is associated with a decrease in sweat $\left[\mathrm{Na}^{+}\right]$and $\left[\mathrm{Cl}^{-}\right]$. The mixed results may be explained in part by methodological differences among studies, including the duration and degree of dietary manipulation. Changes in sweat $\left[\mathrm{Na}^{+}\right]$and $\left[\mathrm{Cl}^{-}\right]$seem to be less likely when salt consumption is altered by smaller (and perhaps more realistic) amounts (Costill et al. 1975; Koenders et al. 2017) or for a short period of time (less than 3 days, including just before/during exercise) (Hamouti et al. 2012; Koenders et al. 2017; Konikoff et al. 1986; Robinson et al. 1956, 1955). This result is perhaps not surprising based on the time course of sweat gland responsiveness to changes in aldosterone and the notion that genomic effects of aldosterone on sweat $\left[\mathrm{Na}^{+}\right]$are stronger than nongenomic actions.

Relatively few studies have tested the effect of physical training on sweat composition. This may be due in part to the difficulty in separating the effects of training from heat acclimation, since regular physical exercise elicits partial heat acclimation. The available studies suggest that aerobic training is associated with an increased sweat flow rate related to an increased cholinergic sensitivity and decreased threshold for sweat onset (Araki et al. 1981; Buono et al. 1991; Buono and Sjoholm 1988; Greenleaf et al. 1972; Inoue et al. 1999). However, the effect on sweat $\left[\mathrm{Na}^{+}\right]$and $\left[\mathrm{Cl}^{-}\right]$is less clear because no longitudinal studies are available. To the authors' knowledge, mostly cross-sectional studies comparing groups with different aerobic capacities have been conducted to date. For example, Araki et al. (1981) measured sweat $\left[\mathrm{Cl}^{-}\right]$ from the upper back of trained and untrained women during $2 \mathrm{~h}$ cycling at fixed absolute workloads (79 and 160 Watts) in a hot, humid, still-air environment. Sweat $\left[\mathrm{Cl}^{-}\right]$ was significantly lower in trained participants at both work rates in both winter and summer test sessions. However, the authors also reported hidromeiosis in the trained group, which could explain in part their lower sweat $\left[\mathrm{Cl}^{-}\right]$(Araki et al. 1981). In another study, Henkin et al. (2010) measured sweat $\left[\mathrm{Na}^{+}\right]$and $\left[\mathrm{Cl}^{-}\right]$from the scapula of swimmers $\left(V \mathrm{O}_{2 \max }=54.2 \pm 5.7 \mathrm{ml} / \mathrm{kg} / \mathrm{min}\right)$, runners $(60.5 \pm 5.8 \mathrm{ml} / \mathrm{kg} /$ $\mathrm{min})$, and non-athletes $(45.2 \pm 2.9 \mathrm{ml} / \mathrm{kg} / \mathrm{min})$ during $30 \mathrm{~min}$ cycling in the heat at a fixed relative intensity of $65-75 \%$ maximal heart rate. Despite the significantly higher aerobic capacity and 50\% higher sweating rate of the swimmers compared with the non-athletes there were no differences in sweat $\left[\mathrm{Na}^{+}\right]$or $\left[\mathrm{Cl}^{-}\right]$. By contrast, sweat $\left[\mathrm{Na}^{+}\right]$and $\left[\mathrm{Cl}^{-}\right]$ were significantly lower in the runners than swimmers and non-athletes (Henkin et al. 2010). This may suggest potential
$\mathrm{NaCl}$ conservation by the sweat glands with training, but the confounding effect of partial heat acclimation cannot be ruled out in this study since it was conducted in Brazil in the later winter where outdoor temperature reached $24{ }^{\circ} \mathrm{C}$ (Henkin et al. 2010).

Hamouti et al. (2011) measured sweat $\left[\mathrm{Na}^{+}\right]$from the lower back of trained $\left(V \mathrm{O}_{\text {2peak }}=4.0 \pm 0.8 \mathrm{~L} / \mathrm{min}\right)$ and untrained $\left(V \mathrm{O}_{2 \text { peak }}=3.4 \pm 0.7 \mathrm{~L} / \mathrm{min}\right)$ participants during three bouts $\left(40,60\right.$, and $\left.80 \% V \mathrm{O}_{2 \text { peak }}\right)$ of cycling in the heat. As expected, sweat $\left[\mathrm{Na}^{+}\right]$increased with an increase in workload for both trained and untrained participants. Sweat $\left[\mathrm{Na}^{+}\right]$tended to be higher in trained versus untrained participants at the two higher workloads. However, local sweating rate was also higher in the trained participants (since absolute workloads were higher in trained vs. untrained). When sweat $\left[\mathrm{Na}^{+}\right]$was normalized for local sweating rate (which accounts for lack of standardizing absolute workload), there were no differences between groups (Hamouti et al. 2011), thus suggesting that higher sweat $\left[\mathrm{Na}^{+}\right]$in trained individuals was a function of higher sweat flow rate rather than higher sweat $\left[\mathrm{Na}^{+}\right]$per se. Taken together these cross-sectional studies suggest that elevated aerobic fitness is not associated with enhanced $\mathrm{Na}^{+}$reabsorption in the sweat gland. Similar conclusions have been drawn from a sweat gland training study involving $2 \mathrm{~h}$ of sweating induced by twice daily intradermal injection of acetyl- $\beta$-methylcholine for 10-18 days (Johnson et al. 1969).

Recently, Amano et al. (2017) measured maximum sweat ion reabsorption rates (Amano et al. 2016) during exercise in distance runners $\left(V \mathrm{O}_{2 \max }=59.1 \pm 1.4 \mathrm{ml} / \mathrm{kg} / \mathrm{min}\right)$, sprinters $\left(V \mathrm{O}_{2 \max }=43.3 \pm 1.2 \mathrm{ml} / \mathrm{kg} / \mathrm{min}\right)$, and untrained $\left(V \mathrm{O}_{2 \max }=38.0 \pm 2.2 \mathrm{ml} / \mathrm{kg} / \mathrm{min}\right)$ participants. They found enhanced maximum sweat ion reabsorption rates on the back region of distance runners and sprinters compared with untrained individuals, but no differences between distance runners and sprinters (Amano et al. 2017). Furthermore, there were no differences in sweat ion reabsorption rates among groups on the forearm and actual sweat ion concentrations were not reported (Amano et al. 2017). Considering the mixed results among studies and paucity of longitudinal data, more research is needed to clarify the effects of physical training on sweat composition. Future research should assess sweat electrolyte concentrations with repeated physical training in a longitudinal study design, as parallel design studies comparing well-trained to moderately- or poorly trained participants cannot control for potential confounding factors that may impact sweat composition.

Another question of interest is how do sweat electrolyte concentrations change throughout the course of a single bout of physical activity? Prolonged heavy sweating and humid environments associated with elevated skin wettedness can lead to hidromeiosis, a condition that causes a gradual decline in sweating rate (Collins and Weiner 1962). The 
mechanism of suppressed sweat flow rate with hidromeiosis is thought to be due to mechanical occlusion of sweat ducts as a result of swelling of the keratinized layer around the duct (Brown and Sargent 1965). It is unclear whether sweat suppression impacts sweat $\left[\mathrm{Na}^{+}\right],\left[\mathrm{Cl}^{-}\right]$, or $\left[\mathrm{K}^{+}\right]$, as most hidromeiosis studies have not included sweat electrolyte measurements. Interestingly, with heat acclimation the sweat glands become resistant to hidromeiosis such that higher sweating rates can be maintained (Ogawa et al. 1982; Taylor 2014). It is also important to note that studies have reported no decline in sweating rate and no change in sweat $\left[\mathrm{Na}^{+}\right]$ or $\left[\mathrm{K}^{+}\right]$throughout 3-7 h of exercise of low intensity (e.g., walking) and light sweating (0.3-0.6 L/h) (Ely et al. 2011; Montain et al. 2007).

The effects of heat acclimation, physical training, and diet on sweat trace mineral concentrations have been studied to a lesser extent than $\mathrm{Na}^{+}$and $\mathrm{Cl}^{-}$. Some initial studies seemed to indicate a conservation of sweat trace mineral concentrations with heat acclimation (Chinevere et al. 2008; Hoshi et al. 2002; Klesges et al. 1996) and even throughout the course of a single bout of exercise (DeRuisseau et al. 2002; Montain et al. 2007; Waller and Haymes 1996). However, Ely et al. (2013) determined that the decline in sweat mineral concentrations in previous studies was likely an artifact of epidermal contamination when using the arm bag technique and/or not pre-washing/cleaning the skin at the site of collection (Ely et al. 2011). It may be that progressive flushing of mineral residue lying on the skin surface with repeated profuse sweating may have contributed to the decrease in sweat mineral concentrations in previous studies (Ely et al. 2013, 2011). There is little if any information available to suggest that physical training impacts sweat trace mineral or vitamin concentrations. Several studies have investigated the impact of acute supplementation or chronic dietary intake of trace minerals and vitamins on sweat composition. Most studies, particularly those in healthy individuals with no known mineral or vitamin deficiencies, have reported no association between dietary intake and sweat concentrations for $\mathrm{Zn}^{2+}$, $\mathrm{Fe}^{2+}, \mathrm{Ca}^{2+}, \mathrm{Cu}^{2+}$ or ascorbic acid (DeRuisseau et al. 2002; Jacob et al. 1981; Lugg and Ellis 1954; Mitchell and Hamilton 1949; Vellar 1968b; Wheeler et al. 1973).

\section{Metabolites}

The effects of heat acclimation or physical training on cytokine, immunoglobulin, or cortisol in human sweat have not been researched. A few studies have investigated sweat lactate, amino acid, and urea albeit with equivocal results regarding the impact of heat acclimation and physical training on these metabolites. Some (Fellmann et al. 1983; Lamont 1987; Pilardeau et al. 1988), but not all (Green et al. 2004) studies suggest that a higher fitness level is associated with lower sweat lactate concentrations. However, these results may be confounded by differences in sweating rate between groups. Lower sweat gland metabolism with lower sweat flow rates would result in less lactate production (Pilardeau et al. 1988). On the other hand, there could be a dilution effect of increased sweating rates (with physical training and/or increased absolute exercise intensity) on sweat lactate concentrations (Lamont 1987). Similarly, Liappis et al. (1979) found that total amino acid concentrations in sweat were significantly lower in trained (physically active for an average of $9 \mathrm{~h}$ per week) than untrained (average of $1 \mathrm{~h}$ of sports per week) men during $15 \mathrm{~min}$ of cycling at $150 \mathrm{~W}$ while covered with a plastic blanket $(12,797$ vs. $24,855 \mu \mathrm{mol} / \mathrm{L}$, respectively). The authors speculated that regular stimulation of sweating via physical training caused an adaptation in the sweat glands to limit excretion of essential amino acids (Liappis et al. 1979). However, sweating rate was not standardized between groups, as sample volume collected from the forearms ranged from 1 to $6 \mathrm{~mL}$ in $15 \mathrm{~min}$ (Liappis et al. 1979). Therefore, it is possible that the more fit individuals had a higher sweat volume that could have diluted the amino acid concentrations.

Limited data on heat acclimation and sweat metabolite concentrations are available. Weiner and Heyningen (1949) found that lactate concentrations in arm bag sweat decreased with 20 -day acclimation in one participant. However, in a follow-up study, the investigators found no changes in whole body lactate concentration with heat acclimation, despite an increase in sweating rate (Weiner and Van Heyningen 1952). The literature on heat acclimation and sweat urea has reported mixed results between studies (Robinson and Robinson 1954) and significant inter-individual variability (McCance 1938). To date, no study has investigated the effects of heat acclimation or physical fitness on sweat ammonia concentrations. Physical strain and muscular activity are known to increase blood ammonia due to metabolic degradation and purine nucleotide cycle activity (Mitsubayashi et al. 1994; Schulz and Heck 2003). Endurancetrained individuals produce less ammonia during submaximal exercise (Holloszy and Coyle 1984). In addition, since ammonia is thought to passively diffuse from the plasma into sweat (Sato et al. 1989), it may be logical to hypothesize that sweat ammonia concentrations should be lower in trained versus untrained participants. Still, this idea is speculative, and confounded by the impact of sweating rate and possible ammonia contamination from apocrine and sebaceous glands. More work is needed to understand how sweat ammonia, lactate, and other metabolites are impacted by changes in physical training and heat acclimation if they are to be used as a biomarker for fitness, training, or performance purposes. 


\section{Correlations between constituent concentrations in sweat versus blood}

\section{Sodium chloride and other micronutrients}

Supplemental Table 4 shows a summary of published studies comparing constituent concentrations in sweat versus blood. Although there is a long list of studies, few of them were well-controlled, adequately powered, and reported correlation and statistical results. Three of six studies suggested there was a significant positive correlation between sweat and blood $\left[\mathrm{Na}^{+}\right]$or $\left[\mathrm{Cl}^{-}\right]$, but only for a portion of the data set (Hew-Butler et al. 2010; Robinson et al. 1956; Talbert and Haugen 1927). The other three studies found no correlation between sweat and blood $\left[\mathrm{Na}^{+}\right]$or $\left[\mathrm{Cl}^{-}\right]$(Johnson et al. 1944; McCubbin et al. 2019; Mickelsen and Keys 1943). Thus, based on the available literature to date, there is no clear evidence of a correlation between sweat and blood for $\left[\mathrm{Na}^{+}\right]$and $\left[\mathrm{Cl}^{-}\right]$. This is perhaps not surprising because, even though primary sweat is isotonic with the blood, the rate of reabsorption of $\mathrm{Na}^{+}$and $\mathrm{Cl}^{-}$in the eccrine duct is independent of plasma electrolyte concentrations. For example, acute changes in sweating rate alone can result in up to threefold changes in final sweat $\left[\mathrm{Na}^{+}\right]$(Buono et al. 2008). Additionally, in a well-controlled study in 15 male endurance athletes, McCubbin et al. (2019) found a significant correlation between pre-exercise plasma aldosterone and sweat $\left[\mathrm{Na}^{+}\right]$ but no correlation between plasma $\left[\mathrm{Na}^{+}\right]$and sweat $\left[\mathrm{Na}^{+}\right]$ (McCubbin et al. 2019). This and other studies (discussed above) suggest that factors impacting resting plasma aldosterone play an important role in determining final sweat $\left[\mathrm{Na}^{+}\right]$(Braconnier et al. 2019; Yoshida et al. 2006).

Few studies have compared concentrations of other micronutrients in sweat and blood; nonetheless, most have reported no correlations for Fe (Paulev et al. 1983; Vellar 1968a) or ascorbic acid (Mickelsen and Keys 1943). This may be due in part to the methodological issues, such as inconsistency in accounting for skin contamination. Interestingly, the only significant correlation reported was between cell-free sweat $\left[\mathrm{Fe}^{2+}\right]$ and serum $\left[\mathrm{Fe}^{2+}\right]$ albeit the correlation coefficient was small ( $r=0.37)$ (Vellar 1968a). These results taken together with the lack of association between dietary micronutrient intake and corresponding sweat micronutrient concentrations suggest little support for using sweat as a surrogate for blood.

Some have suggested that sweat electrolyte concentrations can be used as a biomarker to detect dehydration or predict sweating rate (Alizadeh et al. 2018; Gao et al. 2016; Rose et al. 2015; Zhou et al. 2016); however, studies measuring sweat electrolyte concentrations alongside changes in hydration status have found mixed results. Sweat $\left[\mathrm{Na}^{+}\right]$, $\left[\mathrm{Cl}^{-}\right]$, and $\left[\mathrm{K}^{+}\right]$have been shown to increase (Lichton 1957;
Morgan et al. 2004), decrease (Armstrong et al. 1985b; Costill et al. 1976), or not change (Amatruda and Welt 1953; Morgan et al. 2004; Robinson et al. 1956; Walsh et al. 1994) in response to dehydration during exercise and/or heat stress. Furthermore, studies have demonstrated significant changes in sweat $\left[\mathrm{Na}^{+}\right],\left[\mathrm{Cl}^{-}\right]$, and/or $\left[\mathrm{K}^{+}\right]$in response to variations in exercise intensity (Baker et al. 2019), environment (Dziedzic et al. 2014), or diet (McCubbin et al. 2019) despite no significant differences in hydration status during exercise. Moreover, as discussed above, the correlation between sweating rate and sweat $\left[\mathrm{Na}^{+}\right]$for between-participant comparisons is poor (Baker et al. 2018b; Patterson et al. 2000).

\section{Metabolites and cytokines}

The correlation between blood and sweat metabolite concentrations are of recent interest due to novel biotechnological advances enabling local metabolite detection from micro-sampling devices (Hauke et al. 2018; Heikenfeld et al. 2018). Supplemental Table 4 summarizes studies that have tested the utility of sweat as a biomarker for changes in blood metabolite and cytokine concentrations. The results for urea, ammonia, bicarbonate, amino acids, and glucose have been mixed at best. Moyer et al. (2012) found a significant correlation between sweat and blood glucose concentration in diabetic patients in whom the range in blood glucose was quite broad ( 60 to $360 \mathrm{mg} / \mathrm{dl})$. Another study found a significant correlation in diabetic patients, but not healthy participants (Nyein et al. 2019). These results suggest that sweat glucose may be sensitive to large changes in blood glucose, but perhaps not to relatively small changes (e.g., in non-diabetics). In fact, there is currently little evidence of a correlation between sweat and blood for glucose or other metabolites such as lactate, amino acids, and urea in healthy individuals at rest or during exercise (Supplemental Table 4). This is due in part to significant methodological issues, such as sub-optimal analytical technique (Silvers et al. 1928), very low number of participants, or unclear/ incomplete analysis and reporting of results (see Supplemental Table 4). One study (Alvear-Ordenes et al. 2005) did find a significant correlation between sweat and blood in rugby players, but metabolite concentrations in sweat only accounted for 7\% (ammonia) or 45\% (urea) of the variation in blood concentrations. More well-controlled correlation studies are needed.

Several studies listed in Supplemental Table 4 did not report correlation results but observed the change in sweat metabolite concentration after manipulation of blood concentrations via substrate ingestion (glucose, amino acids, ammonium chloride, urea, or bicarbonate) or having participants perform exercise of various intensities (lactate, ammonia). In the ingestion studies, an increase in blood metabolite concentrations was sometimes (Boysen et al. 
1984; Czarnowski et al. 1992; Komives et al. 1966) but not always (Ament et al. 1997; Hier et al. 1946; Patterson et al. 2002) associated with a significant concomitant rise in sweat concentrations. In one study, significant increases in sweat glucose concentration were observed in two participants in response to infusion and ingestion of a glucose bolus, which caused an increase in blood glucose from 60 to $360 \mathrm{mg} / \mathrm{dl}$ (Boysen et al. 1984). Again, it is still unclear if smaller changes in blood glucose would elicit measurable concomitant changes in sweat glucose. An increase in blood lactate and ammonia concentrations during exercise has been associated with a decrease (Ament et al. 1997) or no change (Alvear-Ordenes et al. 2005; Green et al. 2000; Weiner and Van Heyningen 1952) in corresponding sweat lactate and ammonia concentrations. These and other studies (Buono et al. 2010) illustrate the lack of support for using sweat lactate or ammonia as biomarker for exercise intensity.

On the other hand, a few studies have consistently reported a strong correlation (Gamella et al. 2014; Hauke et al. 2018; Phillips and McAloon 1980) and close to 1:1 ratio (Buono 1999) for ethanol concentrations in sweat compared with blood. This may be explained by the straightforward mechanism of ethanol secretion (passive diffusion, as discussed above) and the low likelihood of surface contamination or eccrine gland production. Therefore, sweat ethanol could possibly be used as surrogate for blood ethanol concentration albeit breathalyzers are already available as a non-invasive practical alternative to blood. Finally, there is some interest in sweat cytokines and cortisol as biomarkers for health and wellness (inflammation, stress, etc.). Two studies by the same group (Cizza et al. 2008; Marques-Deak et al. 2006) have found significant correlations between 24-h insensible sweat and plasma cytokine concentrations. More work is needed, however, to corroborate these findings and determine the utility of sweat cytokines for monitoring healthy individuals or patient populations. No studies have compared cortisol concentrations in sweat and blood.

\section{Conclusions}

It is clear that final sweat composition is not only influenced by extracellular solute concentrations, but also mechanisms of secretion and/or reabsorption, sweat flow rate, byproducts of sweat gland metabolism, skin surface contamination from desquamated epidermal cells, and sebum secretions, among other factors. Thus, the concentrations of ions, metabolites, and other constituents in sweat are often much different from that of the blood. Some solutes are relatively dilute in sweat because of reabsorption in the duct $\left(\mathrm{Na}^{+}, \mathrm{Cl}^{-}\right.$, bicarbonate), others because of limitations in transport across/between cells of the eccrine gland (glucose, cytokines, cortisol). When solutes appear in final sweat at higher concentrations than that of blood, the contamination could be derived from sweat glands (lactate), skin cells (trace minerals, amino acids, cortisol), or both (urea, ammonia, cytokines). Furthermore, significant correlations between sweat and blood have not been established for most constituents, with the exception of ethanol. With respect to sweat diagnostics, it is well accepted that high sweat $\mathrm{Na}^{+}$and $\mathrm{Cl}^{-}$concentrations are useful as a screening tool for cystic fibrosis. However, sweat electrolyte concentrations are not predictive of hydration status or sweating rate. In addition, sweat metabolite concentrations are not a reliable biomarker for exercise intensity or other physiological stressors. To date, glucose, cytokine, and cortisol research is too limited to suggest that sweat is a useful proxy for blood.

More research is needed; therefore, the next section outlines suggestions for future investigations. Addressing these fundamental questions and methodological issues will help elucidate the potential utility of sweat as a surrogate for blood and/or as a biomarker for physiological/nutritional status.

\section{Suggestions for future research}

Future research concerning eccrine sweat composition should carefully consider the following methodological suggestions:

- Use sweat stimulation methods that are fit for the intended research question and application of the data (e.g., local vs. whole body, pharmacological vs. thermal, passive heat vs. exercise).

- Thoroughly clean the skin and allow $\geq 20$ min of sweating prior to sample collection.

- Avoid collection methods prone to skin surface contamination (arm bag technique, scraping or dripping methods).

- Avoid collecting sweat from regions high in sebaceous and apocrine glands.

- Use an oil barrier to avoid skin surface contamination and/or centrifuge the sweat sample and separate the supernatant to isolate cell-free sweat.

- Standardize, measure, and report corresponding sweating rate data. Consider reporting total sweat constituent flux (concentration $\times$ sweating rate).

- Use filter paper or the sweat pouch method for instantaneous collection of small volumes of sweat when the protocol calls for serial measurements or synchronization of blood and sweat samples.

The following research questions represent gaps in the literature: 
- Normative data and body mapping (local and whole body) for sweat mineral, metabolite, cytokine, and cortisol concentrations.

- Effect of heat acclimatization and physical training status on sweat composition.

- Correlation between sweat and blood constituent concentrations using well-controlled, adequately powered studies that report statistical analysis results and scatterplots of individual data.

- Mechanisms of secretion in the eccrine gland, especially for constituents where studies are limited or equivocal to date, such as glucose, ammonia, bicarbonate, cytokines, and cortisol, among others.

- Immunohistochemical, transcriptomic, and proteomic identification of active transport channels or transporters within isolated eccrine sweat glands.

- Potential links between the mechanisms of sweating and the physiology of other secretory/excretory processes (e.g., renal system, tear fluid, and saliva).

Acknowledgements The authors thank Ryan Nuccio and Michelle King for technical support and review of this manuscript. Financial support for this article was provided by the Gatorade Sports Science Institute, a division of PepsiCo, Inc. The views expressed in this article are those of the authors and do not necessarily reflect the position or policy of PepsiCo, Inc.

Author contributions LB conceived the review topic and wrote the proposal. LB and AW wrote the manuscript and approved the final version.

\section{Compliance with ethical standards}

Conflict of interest The authors are employed by the Gatorade Sports Science Institute, a division of PepsiCo, Inc. The views expressed in this article are those of the authors and do not necessarily reflect the position or policy of PepsiCo, Inc.

Open Access This article is licensed under a Creative Commons Attribution 4.0 International License, which permits use, sharing, adaptation, distribution and reproduction in any medium or format, as long as you give appropriate credit to the original author(s) and the source, provide a link to the Creative Commons licence, and indicate if changes were made. The images or other third party material in this article are included in the article's Creative Commons licence, unless indicated otherwise in a credit line to the material. If material is not included in the article's Creative Commons licence and your intended use is not permitted by statutory regulation or exceeds the permitted use, you will need to obtain permission directly from the copyright holder. To view a copy of this licence, visit http://creativecommons.org/licenses/by/4.0/.

\section{References}

Adams WS, Leslie A, Levin MH (1950) The dermal loss of iron. Proc Soc Exp Biol Med 74:46-48

Agrawal K, Waller JD, Pedersen TL, Newman JW (2018) Effects of stimulation technique, anatomical region, and time on human sweat lipid mediator profiles. Prostagland Other Lipid Mediat 134:84-92. https://doi.org/10.1016/j.prostaglandins.2017.09.007

Ahmed AA, Nordlind K, Schultzberg M, Liden S (1996) Proinflammatory cytokines and their corresponding receptor proteins in eccrine sweat glands in normal and cutaneous leishmaniasis human skin. An immunohistochemical study. Exp Dermatol $5: 230-235$

Alizadeh A et al (2018) A wearable patch for continuous monitoring of sweat electrolytes during exertion. Lab Chip 18:2632-2641. https://doi.org/10.1039/c8lc00510a

Allan JR, Wilson CG (1971) Influence of acclimatization on sweat sodium concentration. J Appl Physiol 30:708-712

Allsopp AJ, Sutherland R, Wood P, Wootton SA (1998) The effect of sodium balance on sweat sodium secretion and plasma aldosterone concentration. Eur J Appl Physiol Occup Physiol 78:516-521

al-Tamer YY, Hadi EA, Alsss B II (1997) Sweat urea, uric acid and creatinine concentrations in uraemic patients. Urol Res 25:337-340

Alvear-Ordenes I, Garcia-Lopez D, De Paz JA, Gonzalez-Gallego J (2005) Sweat lactate, ammonia, and urea in rugby players. Int J Sports Med 26:632-637. https://doi.org/10.1055/s-2004-830380

Amano T, Gerrett N, Inoue Y, Nishiyasu T, Havenith G, Kondo N (2016) Determination of the maximum rate of eccrine sweat glands' ion reabsorption using the galvanic skin conductance to local sweat rate relationship. Eur J Appl Physiol 116:281-290. https://doi.org/10.1007/s00421-015-3275-9

Amano T, Hirose M, Konishi K, Gerrett N, Ueda H, Kondo N, Inoue $Y$ (2017) Maximum rate of sweat ions reabsorption during exercise with regional differences, sex, and exercise training. Eur J Appl Physiol 117:1317-1327. https://doi.org/10.1007/s0042 1-017-3619-8

Amatruda TT, Welt LG (1953) Secretion of electrolytes in thermal sweat. J Appl Physiol 5:759-772

Ament W, Huizenga JR, Mook GA, Gips CH, Verkerke GJ (1997) Lactate and ammonia concentration in blood and sweat during incremental cycle ergometer exercise. Int J Sports Med 18:35-39. https://doi.org/10.1055/s-2007-972592

Anderson GJ, Frazer DM (1566S) Current understanding of iron homeostasis. Am J Clin Nutr 106:1559S-1566S. https://doi. org/10.3945/ajcn.117.155804

Anttila HS, Reitamo S, Erkko P, Ceska M, Moser B, Baggiolini M (1992) Interleukin-8 immunoreactivity in the skin of healthy subjects and patients with palmoplantar pustulosis and psoriasis. J Investig Dermatol 98:96-101. https://doi.org/10.1111/15231747.ep12495817

Araki Y, Ando S (1953) Urea, amino acid and ammonia in human sweat. Jpn J Physiol 3:211-218. https://doi.org/10.2170/jjphy siol.3.211

Araki T, Matsushita K, Umeno K, Tsujino A, Toda Y (1981) Effect of physical training on exercise-induced sweating in women. J Appl Physiol Respir Environ Exerc Physiol 51:1526-1532. https://doi. org/10.1152/jappl.1981.51.6.1526

Armstrong LE, Costill DL, Fink WJ, Bassett D, Hargreaves M, Nishibata I, King DS (1985a) Effects of dietary sodium on body and muscle potassium content during heat acclimation. Eur J Appl Physiol Occup Physiol 54:391-397

Armstrong LE, Hubbard RW, Szlyk PC, Matthew WT, Sils IV (1985b) Voluntary dehydration and electrolyte losses during prolonged exercise in the heat. Aviat Sp Environ Med 56:765-770

Armstrong LE, Hubbard RW, Jones BH, Daniels JJ (1986) Preparing Alberto Salazar for the heat of the Olympic marathon. Physician Sports Med 14:73-81

Arn KD, Reimer A (1950) Minimal sodium losses through the skin. J Clin Investig 29:1342-1346. https://doi.org/10.1172/JCI102371

Aruoma OI, Reilly T, MacLaren D, Halliwell B (1988) Iron, copper and zinc concentrations in human sweat and plasma; the effect of exercise. Clin Chim Acta Int J Clin Chem 177:81-87 
Astrand I (1963) Lactate content in sweat. Acta Physiol Scand 58:359367. https://doi.org/10.1111/j.1748-1716.1963.tb02658.x

Bain AR, Deren TM, Jay O (2011) Describing individual variation in local sweating during exercise in a temperate environment. Eur J Appl Physiol 111:1599-1607. https://doi.org/10.1007/s0042 1-010-1788-9

Baker LB (2017) Sweating rate and sweat sodium concentration in athletes: a review of methodology and intra/interindividual variability. Sports Med 47:111-128. https://doi.org/10.1007/s4027 9-017-0691-5

Baker LB (2019) Physiology of sweat gland function: the roles of sweating and sweat composition in human health. Temperature (Austin) 6:211-259. https://doi.org/10.1080/23328 940.2019.1632145

Baker LB, Stofan JR, Hamilton AA, Horswill CA (2009) Comparison of regional patch collection vs whole body washdown for measuring sweat sodium and potassium loss during exercise. J Appl Physiol 107:887-895. https://doi.org/10.1152/japplphysi ol.00197.2009

Baker LB, Stofan JR, Lukaski HC, Horswill CA (2011) Exerciseinduced trace mineral element concentration in regional versus whole-body wash-down sweat. Int J Sport Nutr Exerc Metab 21:233-239

Baker LB, Ungaro CT, Barnes KA, Nuccio RP, Reimel AJ, Stofan JR (2014) Validity and reliability of a field technique for sweat $\mathrm{Na}^{+}$ and $\mathrm{K}^{+}$analysis during exercise in a hot-humid environment. Physiol Rep 2:e12007. https://doi.org/10.14814/phy2.12007

Baker LB, Barnes KA, Sopena BC, Nuccio RP, Reimel AJ, Ungaro CT (2018a) Sweat sodium, potassium, and chloride concentrations analyzed same day as collection versus after 7 days storage in a range of temperatures. Int J Sport Nutr Exerc Metab 28:238-245. https://doi.org/10.1123/ijsnem.2017-0199

Baker LB et al (2018b) Body map of regional versus whole body sweating rate and sweat electrolyte concentrations in men and women during moderate exercise-heat stress. J Appl Physiol (1985). https ://doi.org/10.1152/japplphysiol.00867.2017

Baker LB, De Chavez PJD, Ungaro CT, Sopena BC, Nuccio RP, Reimel AJ, Barnes KA (2019) Exercise intensity effects on total sweat electrolyte losses and regional vs whole-body sweat $\left[\mathrm{Na}^{+}\right]$, $\left[\mathrm{Cl}^{-}\right]$, and $\left[\mathrm{K}^{+}\right]$. Eur J Appl Physiol 119:361-375. https://doi. org/10.1007/s00421-018-4048-z

Bandodkar AJ, Jeang WJ, Ghaffari R, Rogers JA (2019) Wearable sensors for biochemical sweat analysis. Annu Rev Anal Chem (Palo Alto Calif) 12:1-22. https://doi.org/10.1146/annurev-anche $\mathrm{m}-061318-114910$

Barnes KA et al (2019) Normative data for sweating rate, sweat sodium concentration, and sweat sodium loss in athletes: An update and analysis by sport. J Sports Sci 37:2356-2366. https://doi. org/10.1080/02640414.2019.1633159

Bates GP, Miller VS (2008) Sweat rate and sodium loss during work in the heat. J Occup Med Toxicol 3:4. https://doi. org/10.1186/1745-6673-3-4

Belval LN et al (2019) Practical hydration solutions for sports. Nutrients. https://doi.org/10.3390/nu11071550

Bergeron MF (2003) Heat cramps: fluid and electrolyte challenges during tennis in the heat. J Sci Med Sport Sports Med Aust 6:19-27

Bergeron J, Bachmann LM, Miller WG (2011) Influence of sample storage conditions on sweat chloride results. Clin Chem 57:641643. https://doi.org/10.1373/clinchem.2010.160267

Boehm KD, Yun JK, Garner C, Strohl KP, Elmets CA (1994) In situ detection of cytokine messenger RNAs in the eccrine sweat gland of normal human skin. Lymph Cytok Res 13:9-13

Boisvert P, Candas V (1994) Validity of the Wescor's sweat conductivity analyzer for the assessment of sweat electrolyte concentrations. Eur J Appl Physiol Occup Physiol 69:176-178
Bonar PT, Casey JR (2008) Plasma membrane Cl(-)/HCO(3)(-) exchangers: structure, mechanism and physiology. Channels (Austin) 2:337-345. https://doi.org/10.4161/chan.2.5.6899

Boulyga SF, Heilmann J, Prohaska T, Heumann KG (2007) Development of an accurate, sensitive, and robust isotope dilution laser ablation ICP-MS method for simultaneous multi-element analysis (chlorine, sulfur, and heavy metals) in coal samples. Anal Bioanal Chem 389:697-706. https://doi.org/10.1007/s0021 6-007-1485-7

Bovell DL, Quinton P (2002) The immunocytochemical localisation of anion exchangers (AE) in the reabsorptive duct of the human eccrine sweat gland. J Physiol 544:107P

Bovell DL, Clunes MT, Roussa E, Burry J, Elder HY (2000) Vacuolartype $\mathrm{H}+$-ATPase distribution in unstimulated and acetylcholine-activated isolated human eccrine sweat glands. Histochem J 32:409-413. https://doi.org/10.1023/a:1004087120735

Boysen TC, Yanagawa S, Sato F, Sato K (1984) A modified anaerobic method of sweat collection. J Appl Physiol 56:1302-1307

Braconnier P et al (2019) Short-term changes in dietary sodium intake influence sweat sodium concentration and muscle sodium content in healthy individuals. J Hypertens. https://doi.org/10.1097/ HJH.0000000000002234

Briggman JV, Tashian RE, Spicer SS (1983) Immunohistochemical localization of carbonic anhydrase I and II in eccrine sweat glands from control subjects and patients with cystic fibrosis. Am J Pathol 112:250-257

Brothers MC, DeBrosse M, Grigsby CC, Naik RR, Hussain SM, Heikenfeld J, Kim SS (2019) Achievements and challenges for real-time sensing of analytes in sweat within wearable platforms. Acc Chem Res 52:297-306. https://doi.org/10.1021/acs.accou nts. 8 b00555

Brown DJ (1985) The pharmacokinetics of alcohol excretion in human perspiration. Methods Find Exp Clin Pharmacol 7:539-544

Brown WK, Sargent F 2nd (1965) Hidromeiosis. Arch Environ Health $11: 442-453$

Brown MB, Haack KK, Pollack BP, Millard-Stafford M, McCarty NA (2011) Low abundance of sweat duct Cl- channel CFTR in both healthy and cystic fibrosis athletes with exceptionally salty sweat during exercise. Am J Physiol Regul Integr Comp Physiol 300:R605-615. https://doi.org/10.1152/ajpregu.00660.2010

Brune M, Magnusson B, Persson H, Hallberg L (1986) Iron losses in sweat. Am J Clin Nutr 43:438-443

Brunner H (1906) Über Glykogen in der gesunden und kranken. Haut Verh Dtsch derm Gesellschaft 9:521-535

Brusilow SW (1967) Evidence for a non-plasma source of urea in sweat. Nature 214:506. https://doi.org/10.1038/214506a0

Brusilow SW, Gordes EH (1965) Secretion of urea and thiourea in sweat. Am J Physiol 209:1213-1218. https://doi.org/10.1152/ ajplegacy.1965.209.6.1213

Brusilow SW, Gordes EH (1968) Ammonia secretion in sweat. Am J Physiol 214:513-517. https://doi.org/10.1152/ajple gacy.1968.214.3.513

Brusilow SW, Ikai K (1968) Urocanic acid in sweat: an artifact of elution from the epidermis. Science 160:1257-1258

Bulmer MG, Forwell GD (1956) The concentration of sodium in thermal sweat. J Physiol 132:115-122. https://doi.org/10.1113/jphys iol.1956.sp005506

Bunting H, Wislocki GB, Dempsey EW (1948) The chemical histology of human eccrine and apocrine sweat glands. Anatom Rec 100:61-77. https://doi.org/10.1002/ar.1091000106

Buono MJ, Sjoholm NT (1988) Effect of physical training on peripheral sweat production. J Appl Physiol (1985) 65:811-814

Buono MJ (1999) Sweat ethanol concentrations are highly correlated with co-existing blood values in humans. Exp Physiol 84:401-404 
Buono MJ, Claros R, Deboer T, Wong J (2008) Wong J (2008) $\mathrm{Na}^{+}$ secretion rate increases proportionally more than the $\mathrm{Na}^{+}$reabsorption rate with increases in sweat rate. J Appl Physiol (1985) 105:1044-1048. https://doi.org/10.1152/japplphysiol.90503 .2008

Buono MJ, McKenzie BK, Kasch FW (1991) Effects of ageing and physical training on the peripheral sweat production of the human eccrine sweat gland. Age Age 20:439-441

Buono MJ, Ball KD, Kolkhorst FW (2007) Sodium ion concentration vs. sweat rate relationship in humans. J Appl Physiol 103:990994. https://doi.org/10.1152/japplphysiol.00015.2007

Buono MJ, Lee NV, Miller PW (2010) The relationship between exercise intensity and the sweat lactate excretion rate. J Physiol Sci 60:103-107. https://doi.org/10.1007/s12576-009-0073-3

Buono MJ, Stone M, Cannon DT (2016) Leaching from the stratum corneum does not explain the previously reported elevated potassium ion concentration in sweat. J Basic Clin Physiol Pharmacol 27:171-173. https://doi.org/10.1515/jbcpp $-2015-0097$

Buono MJ, Kolding M, Leslie E, Moreno D, Norwood S, Ordille A, Weller R (2018) Heat acclimation causes a linear decrease in sweat sodium ion concentration. J Therm Biol 71:237-240. https://doi.org/10.1016/j.jtherbio.2017.12.001

Cage GW, Dobson RL (1965) Sodium secretion and reabsorption in the human eccrine sweat gland. J Clin Investig 44:1270-1276. https://doi.org/10.1172/JCI105233

Cederbaum AI (2012) Alcohol metabolism. Clin Liver Dis 16:667685. https://doi.org/10.1016/j.cld.2012.08.002

Chinevere TD, Kenefick RW, Cheuvront SN, Lukaski HC, Sawka MN (2008) Effect of heat acclimation on sweat minerals. Med Sci Sports Exerc 40:886-891. https://doi.org/10.1249/ MSS.0b013e3181641c04

Choi JY, Muallem D, Kiselyov K, Lee MG, Thomas PJ, Muallem S (2001) Aberrant CFTR-dependent $\mathrm{HCO}_{3}{ }^{-}$transport in mutations associated with cystic fibrosis. Nature 410:94-97. https ://doi.org/10.1038/35065099

Chraibi A, Horisberger JD (2002) Na self inhibition of human epithelial $\mathrm{Na}^{+}$channel: temperature dependence and effect of extracellular proteases. J Gen Physiol 120:133-145. https:// doi.org/10.1085/jgp.20028612

Chraibi A, Horisberger JD (2003) Dual effect of temperature on the human epithelial $\mathrm{Na}^{+}$channel Pflugers. Archiv Eur J Physiol 447:316-320. https://doi.org/10.1007/s00424-003-1178-9

Cizza G et al (2008) Elevated neuroimmune biomarkers in sweat patches and plasma of premenopausal women with major depressive disorder in remission: the POWER study. Biol Psychiatry 64:907-911. https://doi.org/10.1016/j.biops ych.2008.05.035

Clunes MT, Lindsay SL, Roussa E, Quinton PM, Bovell DL (2004) Localisation of the vacuolar proton pump $\left(\mathrm{V}-\mathrm{H}^{+}\right.$-ATPase $)$and carbonic anhydrase II in the human eccrine sweat gland. J Mol Histol 35:339-345

Cohn JR, Emmett EA (1978) The excretion of trace metals in human sweat. Ann Clin Lab Sci 8:270-275

Collins KJ (1962) Composition of palmar and forearm sweat. J Appl Physiol 17:99-102. https://doi.org/10.1152/jappl.1962.17.1.99

Collins KJ, Weiner JS (1962) Observations on arm-bag suppression of sweating and its relationship to thermal sweat-gland 'fatigue'. J Physiol 161:538-556

Collins KJ, Crockford GW, Weiner JS (1966) The local training effect of secretory activity on the response of eccrine sweat glands. J Physiol 184:203-214. https://doi.org/10.1113/jphysiol.1966. sp007911

Collins KJ, Eddy TP, Hibbs A, Stock AL, Wheeler EF (1971) Nutritional and environmental studies on an ocean-going oil tanker.
2. Heat acclimatization and nutrient balances. Br J Ind Med 28:246-258. https://doi.org/10.1136/oem.28.3.246

Colombani P, Spati S, Spleiss C, Frey-Rindova P, Wenk C (1997) Exercise-induced sweat nitrogen excretion: evaluation of a regional collection method using gauze pads. Z Ernahrungswiss 36:237-243

Coltman CA Jr, Rowe NJ, Atwell RJ (1966) The amino acid content of sweat in normal adults. Am J Clin Nutr 18:373-378. https://doi. org/10.1093/ajcn/18.5.373

Costa F, Calloway DH, Margen S (1969) Regional and total body sweat composition of men fed controlled diets. Am J Clin Nutr 22:52-58

Costill DL (1977) Sweating: its composition and effects on body fluids. Ann N Y Acad Sci 301:160-174

Costill DL, Cote R, Miller E, Miller T, Wynder S (1975) Water and electrolyte replacement during repeated days of work in the heat. Aviat Sp Environ Med 46:795-800

Costill DL, Cote R, Fink W (1976) Muscle water and electrolytes following varied levels of dehydration in man. J Appl Physiol 40:6-11

Cui CY, Schlessinger D (2015) Eccrine sweat gland development and sweat secretion. Exp Dermatol 24:644-650. https://doi. org/10.1111/exd.12773

Cui CY, Sima J, Yin M, Michel M, Kunisada M, Schlessinger D (2016) Identification of potassium and chloride channels in eccrine sweat glands. J Dermatol Sci 81:129-131. https://doi. org/10.1016/j.jdermsci.2015.11.001

Czarnowski D, Gorski J, Jozwiuk J, Boron-Kaczmarska A (1992) Plasma ammonia is the principal source of ammonia in sweat. Eur J Appl Physiol Occup Physiol 65:135-137

Dai X, Okazaki H, Hanakawa Y, Murakami M, Tohyama M, Shirakata Y, Sayama K (2013) Eccrine sweat contains IL-1alpha, IL-1beta and IL-31 and activates epidermal keratinocytes as a danger signal. PLoS ONE 8:e67666. https://doi.org/10.1371/ journal.pone.0067666

Delgado-Povedano MM, Calderon-Santiago M, Luque de Castro MD, Priego-Capote F (2018) Metabolomics analysis of human sweat collected after moderate exercise. Talanta 177:47-65. https://doi. org/10.1016/j.talanta.2017.09.028

Derbyshire PJ, Barr H, Davis F, Higson SP (2012) Lactate in human sweat: a critical review of research to the present day. J Physiol Sci 62:429-440. https://doi.org/10.1007/s12576-012-0213-z

DeRuisseau KC, Cheuvront SN, Haymes EM, Sharp RG (2002) Sweat iron and zinc losses during prolonged exercise. Int J Sport Nutr Exerc Metab 12:428-437

di Sant'Agnese PA, Powell GF (1962) The eccrine sweat defect in cystic fibrosis of the pancreas. Ann N Y Acad Sci 93:555-559

Didierjean L, Gruaz D, Frobert Y, Grassi J, Dayer JM, Saurat JH (1990) Biologically active interleukin 1 in human eccrine sweat: sitedependent variations in alpha/beta ratios and stress-induced increased excretion. Cytokine 2:438-446

Dill DB, Hall FG, Edwards HT (1938) Changes in composition of sweat during acclimatization to heat. Am J Physiol 123:412-419

Dobson RL (1965) The human eccrine sweat gland: structural and functional interrelationships. Arch Environ Health 11:423-429

Dobson RL, Sato K (1972) The secretion of salt and water by the eccrine sweat gland. Arch Dermatol 105:366-370

Doorn J, Storteboom TT, Mulder AM, de Jong WH, Rottier BL, Kema IP (2015) Ion chromatography for the precise analysis of chloride and sodium in sweat for the diagnosis of cystic fibrosis. Ann Clin Biochem 52:421-427. https://doi.org/10.1177/00045 63214549642

Dunstan RH et al (2016) Sweat facilitated amino acid losses in male athletes during exercise at $32-34{ }^{\circ} \mathrm{C}$. PLoS ONE 11:e0167844. https://doi.org/10.1371/journal.pone.0167844 
Dziedzic CE, Ross ML, Slater GJ, Burke LM (2014) Variability of measurements of sweat sodium using the regional absorbent patch method. Int J Sports Physiol Perform. https://doi. org/10.1123/ijspp.2013-0480

Eichner ER (2008) Genetic and other determinants of sweat sodium. Curr Sports Med Rep 7:S36-S40

Ekins R (1990) Measurement of free hormones in blood. Endocr Rev 11:5-46. https://doi.org/10.1210/edrv-11-1-5

Elizondo RS (1973) Local control of eccrine sweat gland function. Feder Proc 32:1583-1587

Elizondo RS, Banerjee M, Bullard RW (1972) Effect of local heating and arterial occlusion on sweat electrolyte content. J Appl Physiol 32:1-6. https://doi.org/10.1152/jappl.1972.32.1.1

Ely MR, Kenefick RW, Cheuvront SN, Chinevere TD, Lacher CP, Lukaski HC, Montain SJ (2011) Surface contamination artificially elevates initial sweat mineral concentrations. J Appl Physiol 110:1534-1540. https://doi.org/10.1152/japplphysiol.01437 .2010

Ely MR, Kenefick RW, Cheuvront SN, Chinevere T, Lacher CP, Lukaski HC, Montain SJ (2013) The effect of heat acclimation on sweat microminerals: artifact of surface contamination. Int $\mathrm{J}$ Sport Nutr Exerc Metab 23:470-479

Embden R, Tachau H (1910) Uber das Vorkommen von Serin im menschlichen. Schweisse Biochem Ztschr 28:230

Evans GH, James LJ, Shirreffs SM, Maughan RJ (2017) Optimizing the restoration and maintenance of fluid balance after exerciseinduced dehydration. J Appl Physiol (1985) 122:945-951. https ://doi.org/10.1152/japplphysiol.00745.2016

Falk B, Bar-Or O, MacDougall JD, McGillis L, Calvert R, Meyer F (1991) Sweat lactate in exercising children and adolescents of varying physical maturity. J Appl Physiol (1985) 71:1735-1740. https://doi.org/10.1152/jappl.1991.71.5.1735

Faulkner SH et al (2014) The detection and measurement of interleukin-6 in venous and capillary blood samples, and in sweat collected at rest and during exercise. Eur J Appl Physiol 114:12071216. https://doi.org/10.1007/s00421-014-2851-8

Fellmann N, Grizard G, Coudert J (1983) Human frontal sweat rate and lactate concentration during heat exposure and exercise. J Appl Physiol Respir Environ Exerc Physiol 54:355-360

Foy H, Kondi A (1957) Anaemias of the tropics; relation to iron intake, absorption and losses during growth, pregnancy and lactation. $\mathrm{J}$ Trop Med Hyg 60:105-118

Freyberg RH, Grant RL (1937) Loss of minerals through the skin of normal humans when sweating is avoided. J Clin Investig 16:729-731. https://doi.org/10.1172/JCI100897

Fukumoto T, Tanaka T, Fujioka H, Yoshihara S, Ochi T, Kuroiwa A (1988) Differences in composition of sweat induced by thermal exposure and by running exercise. Clin Cardiol 11:707-709. https://doi.org/10.1002/clc.4960111010

Gagnon D, Crandall CG (2018) Sweating as a heat loss thermoeffector. Handb Clin Neurol 156:211-232. https://doi.org/10.1016/B9780-444-63912-7.00013-8

Gagnon D, Jay O, Kenny GP (2013) The evaporative requirement for heat balance determines whole-body sweat rate during exercise under conditions permitting full evaporation. J Physiol 591:2925-2935. https://doi.org/10.1113/jphysiol.2012.248823

Gamella M, Campuzano S, Manso J, Gonzalez de Rivera G, LopezColino F, Reviejo AJ, Pingarron JM (2014) A novel non-invasive electrochemical biosensing device for in situ determination of the alcohol content in blood by monitoring ethanol in sweat. Anal Chim Acta 806:1-7. https://doi.org/10.1016/j.aca.2013.09.020

Gao W, Brooks GA, Klonoff DC (2018) Klonoff DC (2018) Wearable physiological systems and technologies for metabolic monitoring. J Appl Physiol (1985) 124:548-556. https://doi.org/10.1152/ japplphysiol.00407.2017
Gao W et al (2016) Fully integrated wearable sensor arrays for multiplexed in situ perspiration analysis. Nature 529:509-514. https ://doi.org/10.1038/nature16521

Gerrett N, Amano T, Inoue Y, Havenith G, Kondo N (2018) The effects of exercise and passive heating on the sweat glands ion reabsorption rates. Physiol Rep. https://doi.org/10.14814/phy2.13619

Gerrett N, Amano T, Havenith G, Inoue Y, Kondo N (2019) The influence of local skin temperature on the sweat glands maximum ion reabsorption rate. Eur J Appl Physiol 119:685-695. https://doi. org/10.1007/s00421-018-04059-5

Gibinski K, Kumaszka F, Zmudzinski J, Giec L, Waclawczyk J, Dosiak J (1973) Sodium 24Na and potassium 42K availability for sweat production after intravenous injection and their handling by sweat glands. Acta biologica et medica Germanica 30:697-708

Gibinski K, Zmudzinski JZJ, Kumaszka F, Giec L, Waclawczyk J (1974) Calcium transit to thermal sweat. Acta biologica et medica Germanica 32:199-204

Gibson LE, Cooke RE (1959) A test for concentration of electrolytes in sweat in cystic fibrosis of the pancreas utilizing pilocarpine by iontophoresis. Pediatrics 23:545-549

Gitlitz PH, Sunderman FW Jr, Hohnadel DC (1974) Ion-exchange chromatography of amino acids in sweat collected from healthy subjects during sauna bathing. Clin Chem 20:1305-1312

Godek SF, Bartolozzi AR, Godek JJ (2005) Sweat rate and fluid turnover in American football players compared with runners in a hot and humid environment. Br J Sports Med 39:205-211. https:// doi.org/10.1136/bjsm.2004.011767(discussion 205-211)

Godek SF, Peduzzi C, Burkholder R, Condon S, Dorshimer G, Bartolozzi AR (2010) Sweat rates, sweat sodium concentrations, and sodium losses in 3 groups of professional football players. J Athlet Train 45:364-371. https://doi.org/10.4085/1062-6050-45.4.364

Goodman BE, Percy WH (2005) CFTR in cystic fibrosis and cholera: from membrane transport to clinical practice. Adv Physiol Educ 29:75-82. https://doi.org/10.1152/advan.00035.2004

Goodwin ML, Harris JE, Hernández A, Gladden LB (2007) Blood lactate measurements and analysis during exercise: a guide for clinicians. J Diab Sci Technol 1:558-569

Gordon RS Jr, Cage GW (1966) Mechanism of water and electrolyte secretion by the eccrine sweat gland. Lancet 1:1246-1250

Gordon RS Jr, Thompson RH, Muenzer J, Thrasher D (1971) Sweat lactate in man is derived from blood glucose. J Appl Physiol 31:713-716. https://doi.org/10.1152/jappl.1971.31.5.713

Gordon RS Jr, Thompson RH, Thrasher D, Benson JW Jr (1976) Genesis of the sweat:plasma urea concentration gradient. J Investig Dermatol 66:218-221. https://doi.org/10.1111/1523-1747.ep124 82142

Goulet ED, Dion T, Myette-Cote E (2012) Validity and reliability of the Horiba C-122 compact sodium analyzer in sweat samples of athletes. Eur J Appl Physiol. https://doi.org/10.1007/s0042 1-012-2331-y

Goulet ED, Asselin A, Gosselin J, Baker LB (2017) Measurement of sodium concentration in sweat samples: comparison of five analytical techniques. Appl Physiol Nutr Metabol. https://doi. org/10.1139/apnm-2017-0059

Granger D, Marsolais M, Burry J, Laprade R (2003) $\mathrm{Na}^{+} / \mathrm{H}^{+}$exchangers in the human eccrine sweat duct. Am J Physiol Cell physiol 285:C1047-1058. https://doi.org/10.1152/ajpcell.00581.2002

Green JM, Bishop PA, Muir IH, McLester JR Jr, Heath HE (2000) Effects of high and low blood lactate concentrations on sweat lactate response. Int J Sports Med 21:556-560. https://doi. org/10.1055/s-2000-8483

Green JM, Pritchett RC, Crews TR, McLester JR, Tucker DC (2004) Sweat lactate response between males with high and low aerobic fitness. Eur J Appl Physiol 91:1-6 
Greenleaf JE, Castle BL, Ruff WK (1972) Maximal oxygen uptake, sweating and tolerance to exercise in the heat. Int J Biometeorol 16:375-387

Grellner W (2002) Time-dependent immunohistochemical detection of proinflammatory cytokines (IL-1beta, IL-6, TNF-alpha) in human skin wounds. Forensic Sci Int 130:90-96. https://doi. org/10.1016/s0379-0738(02)00342-0

Hammond KB, Turcios NL, Gibson LE (1994) Clinical evaluation of the macroduct sweat collection system and conductivity analyzer in the diagnosis of cystic fibrosis. J Pediatr 124:255-260

Hamouti N, Del Coso J, Ortega JF, Mora-Rodriguez R (2011) Sweat sodium concentration during exercise in the heat in aerobically trained and untrained humans. Eur J Appl Physiol 111:28732881. https://doi.org/10.1007/s00421-011-1911-6

Hamouti N, Fernandez-Elias VE, Ortega JF, Mora-Rodriguez R (2012) Ingestion of sodium plus water improves cardiovascular function and performance during dehydrating cycling in the heat. Scand $\mathbf{J}$ Med Sci Sports. https://doi.org/10.1111/sms.12028

Hanel KH, Cornelissen C, Luscher B, Baron JM (2013) Cytokines and the skin barrier. Int J Mol Sci 14:6720-6745. https://doi. org/10.3390/ijms14046720

Hargreaves M, Morgan TO, Snow R, Guerin M (1989) Exercise tolerance in the heat on low and normal salt intakes. Clin Sci (Lond) 76:553-557

Harshman SW et al (2019) Metabolomic stability of exercise-induced sweat. J Chromatogr B Anal Technol Biomed Life Sci 11261127:121763. https://doi.org/10.1016/j.jchromb.2019.121763

Hauke A et al (2018) Complete validation of a continuous and bloodcorrelated sweat biosensing device with integrated sweat stimulation. Lab Chip 18:3750-3759. https://doi.org/10.1039/c81c0 $1082 \mathrm{j}$

Hayden G, Milne HC, Patterson MJ, Nimmo MA (2004) The reproducibility of closed-pouch sweat collection and thermoregulatory responses to exercise-heat stress. Eur J Appl Physiol 91:748-751. https://doi.org/10.1007/s00421-004-1057-x

Heikenfeld J et al (2018) Wearable sensors: modalities, challenges, and prospects. Lab Chip 18:217-248. https://doi.org/10.1039/ c7lc00914c

Heikenfeld J, Jajack A, Feldman B, Granger SW, Gaitonde S, Begtrup G, Katchman BA (2019) Accessing analytes in biofluids for peripheral biochemical monitoring. Nat Biotechnol. https://doi. org/10.1038/s41587-019-0040-3

Henkin SD, Sehl PL, Meyer F (2010) Sweat rate and electrolyte concentration in swimmers, runners, and nonathletes. Int J Sports Physiol Perform 5:359-366

Hew-Butler T, Noakes TD, Soldin SJ, Verbalis JG (2010) Acute changes in arginine vasopressin, sweat, urine and serum sodium concentrations in exercising humans: does a coordinated homeostatic relationship exist? Br J Sports Med 44:710-715. https:// doi.org/10.1136/bjsm.2008.051771

Hew-Butler T, Hummel J, Rider BC, Verbalis JG (2014) Characterization of the effects of the vasopressin $\mathrm{V} 2$ receptor on sweating, fluid balance, and performance during exercise. Am J Physiol Regul Integr Compar Physiol 307:R366-375. https://doi. org/10.1152/ajpregu.00120.2014

Hier SW, Cornbleet T, Bergeim O (1946) The amino acids of human sweat. J Biol Chem 166:327-333

Hirasawa $G$ et al (1997) Colocalization of 11 beta-hydroxysteroid dehydrogenase type II and mineralocorticoid receptor in human epithelia. J Clin Endocrinol Metabol 82:3859-3863. https://doi. org/10.1210/jcem.82.11.4337

Hjortskov N, Jepsen LT, Nielsen B, Juul A, Skakkebaek NE (1995) Pilocarpine iontophoresis test: an index of physiological sweat secretion? Clin Physiol 15:409-414
Hladek MD, Szanton SL, Cho YE, Lai C, Sacko C, Roberts L, Gill J (2018) Using sweat to measure cytokines in older adults compared to younger adults: a pilot study. J Immunol Methods 454:1-5. https://doi.org/10.1016/j.jim.2017.11.003

Holloszy JO, Coyle EF (1984) Adaptations of skeletal muscle to endurance exercise and their metabolic consequences. J Appl Physiol Respir Environ Exerc Physiol 56:831-838. https://doi. org/10.1152/jappl.1984.56.4.831

Hooton K, Li L (2017) Nonocclusive sweat collection combined with chemical isotope labeling LC-MS for human sweat metabolomics and mapping the sweat metabolomes at different skin locations. Anal Chem 89:7847-7851. https://doi.org/10.1021/acs.analc hem.7b01988

Hoshi A, Watanabe H, Chiba M, Inaba Y, Kobayashi M, Kimura N, Ito $\mathrm{T}$ (2002) Seasonal variation of trace element loss to sweat during exercise in males. Environ Health Prev Med 7:60-63. https://doi. org/10.1007/BF02897331

Hsia SL, Witten VH, Hao YL (1964) In vitro metabolic studies of hydrocortisone-4-C14 in human skin. J Investig Dermatol 43:407-411. https://doi.org/10.1038/jid.1964.172

Hu Y, Converse C, Lyons MC, Hsu WH (2018) Neural control of sweat secretion: a review. Br J Dermatol 178:1246-1256. https://doi. org/10.1111/bjd.15808

Hussain R, Patwardhan VN (1959) Iron content of thermal sweat in iron-deficiency anaemia. Lancet 1:1073-1074

Ikai K, Sato K, Sugiyama K, Otsuka Y, Nitta H (1969) Comparison of human sweat electrolyte concentration in mental, thermal and exercise perspiration. Nagoya Med J 15:47-66

Inoue Y, Nakao M, Okudaira S, Ueda H, Araki T (1995) Seasonal variation in sweating responses of older and younger men. Eur J Appl Physiol Occup Physiol 70:6-12

Inoue Y, Havenith G, Kenney WL, Loomis JL, Buskirk ER (1999) Exercise- and methylcholine-induced sweating responses in older and younger men: effect of heat acclimation and aerobic fitness. Int J Biometeorol 42:210-216

Inoue R, Sohara E, Rai T, Satoh T, Yokozeki H, Sasaki S, Uchida $S$ (2013) Immunolocalization and translocation of aquaporin-5 water channel in sweat glands. J Dermatol Sci 70:26-33. https:// doi.org/10.1016/j.jdermsci.2013.01.013

Itoh S, Nakayama T (1952) Amino acids in human sweat. Jpn J Physiol 2:248-253. https://doi.org/10.2170/jjphysiol.2.248

Jacob RA, Sandstead HH, Munoz JM, Klevay LM, Milne DB (1981) Whole body surface loss of trace metals in normal males. Am J Clin Nutr 34:1379-1383

Jacobsen E (1952) The metabolism of ethyl alcohol. Pharmacol Rev 4:107-135

Jahnen-Dechent W, Ketteler M (2012) Magnesium basics. Clin Kidney J 5:i3-i14. https://doi.org/10.1093/ndtplus/sfr163

Jajack A, Brothers M, Kasting G, Heikenfeld J (2018) Enhancing glucose flux into sweat by increasing paracellular permeability of the sweat gland. PLoS ONE 13:e0200009. https://doi. org/10.1371/journal.pone.0200009

Jenkins ME, Rivarola MA, Brusilow SW, Migeon CJ (1969) Excretion of 4-14C-cortisol and 1,2-3H-D-aldosterone in human thermal sweat. J Clin Endocrinol Metabol 29:1102-1106. https://doi. org/10.1210/jcem-29-8-1102

Jia M, Chew WM, Feinstein Y, Skeath P, Sternberg EM (2016) Quantification of cortisol in human eccrine sweat by liquid chromatography-tandem mass spectrometry. Analyst 141:2053-2060. https://doi.org/10.1039/c5an02387d

Johnson RE, Pitts GC, Consolazio FC (1944) Factors influencing chloride concentration in human sweat. Am J Physiol 141:575-589

Johnson BB, Johnson RE, Sargent F 2nd (1969) Sodium and chloride in eccrine sweat of men and women during training with 
acetyl-B-methylcholine. J Investig Dermatol 53:116-121. https ://doi.org/10.1038/jid.1969.117

Jones AP, Webb LM, Anderson AO, Leonard EJ, Rot A (1995) Normal human sweat contains interleukin-8. J Leukoc Biol 57:434-437. https://doi.org/10.1002/jlb.57.3.434

Jones PM, McCullom V, Moore G, Eckhardt J (2008) How soon is "promptly"? storage and handling of samples for the analysis of sweat chloride lab. Medicine 39:547-549

Kaiser D, Songo-Williams R, Drack E (1974) Hydrogen ion and electrolyte excretion of the single human sweat gland. Pflugers Arch Eur J Physiol 349:63-72

Karlsen A, Nybo L, Norgaard SJ, Jensen MV, Bonne T, Racinais S (2015) Time course of natural heat acclimatization in welltrained cyclists during a 2-week training camp in the heat. Scand J Med Sci Sports 25(Suppl 1):240-249. https://doi.org/10.1111/ sms. 12449

Katchman BA, Zhu M, Blain Christen J, Anderson KS (2018) Eccrine sweat as a biofluid for profiling immune biomarkers. Proteom Clin Appl 12:e1800010. https://doi.org/10.1002/ prca.201800010

Keller RW, Bailey JL, Wang Y, Klein JD, Sands JM (2016) Urea transporters and sweat response to uremia. Physiol Rep. https ://doi.org/10.14814/phy2.12825

Kenouch S, Lombes M, Delahaye F, Eugene E, Bonvalet JP, Farman $\mathrm{N}$ (1994) Human skin as target for aldosterone: coexpression of mineralocorticoid receptors and 11 beta-hydroxysteroid dehydrogenase. J Clin Endocrinol Metabol 79:1334-1341. https:// doi.org/10.1210/jcem.79.5.7962326

Kintz P, Cirimele V, Ludes B (2000) Pharmacological criteria that can affect the detection of doping agents in hair. Forensic Sci Int 107:325-334. https://doi.org/10.1016/s0379 -0738(99)00176-0

Kirby CR, Convertino VA (1986) Plasma aldosterone and sweat sodium concentrations after exercise and heat acclimation. J Appl Physiol 61:967-970

Kirschbaum C, Hellhammer DH (1989) Salivary cortisol in psychobiological research: an overview. Neuropsychobiology 22:150-169. https://doi.org/10.1159/000118611

Kirschbaum C, Hellhammer DH (2000) Salivary cortisol. In: Fink G (ed) Encyclopedia of stress, 2nd edn. Academic, New York, pp 405-409

Klesges RC et al (1996) Changes in bone mineral content in male athletes. Mechanisms of action and intervention effects. JAMA 276:226-230

Koenders EE, Franken CPG, Cotter JD, Thornton SN, Rehrer NJ (2017) Restricting dietary sodium reduces plasma sodium response to exercise in the heat. Scand J Med Sci Sports 27:1213-1220. https ://doi.org/10.1111/sms.12748

Komives GK, Robinson S, Roberts JT (1966) Urea transfer across the sweat glands. J Appl Physiol 21:1681-1684. https://doi. org/10.1152/jappl.1966.21.6.1681

Kondo N, Shibasaki M, Aoki K, Koga S, Inoue Y, Crandall CG (2001) Function of human eccrine sweat glands during dynamic exercise and passive heat stress. J Appl Physiol (1985) 90:1877-1881

Kondo N, Takano S, Aoki K, Shibasaki M, Tominaga H, Inoue Y (1998) Regional differences in the effect of exercise intensity on thermoregulatory sweating and cutaneous vasodilation. Acta Physiol Scand 164:71-78. https://doi.org/10.1046/j.1365201X.1998.00407.x

Konikoff F, Shoenfeld Y, Magazanik A, Epstein J, Shapira Y (1986) Effects of salt loading during exercise in a hot dry climate. Biomed Pharmacother 40:296-300

Kozlowski S, Saltin B (1964) Effect of sweat loss on body fluids. J Appl Physiol 19:1119-1124

Kuno Y (1956) Human perspiration. Charles C. Thomas Publisher, Springfield
Kutchai HC (1998) Cellular membranes and transmembrane transport of solute and water. In: Berne RM, Levy MN (eds) Physiology. Mosby Press, St. Louis, pp 3-20

La Count TD, Jajack A, Heikenfeld J, Kasting GB (2018) Modeling glucose transport from systemic circulation to sweat. J Pharm Sci. https://doi.org/10.1016/j.xphs.2018.09.026

Ladell WSS, Shephard RJ (1961) Aldosterone inhibition and acclimatization to heat. Proc Physiol Soc 3-4:19P-20P

Lamont LS (1987) Sweat lactate secretion during exercise in relation to women's aerobic capacity. J Appl Physiol (1985) 62:194-198. https://doi.org/10.1152/jappl.1987.62.1.194

Langbein L, Rogers MA, Praetzel S, Cribier B, Peltre B, Gassler N, Schweizer J (2005) Characterization of a novel human type II epithelial keratin $\mathrm{K} 1 \mathrm{~b}$, specifically expressed in eccrine sweat glands. J Investig Dermatol 125:428-444. https://doi. org/10.1111/j.0022-202X.2005.23860.x

Lemon PW, Yarasheski KE, Dolny DG (1986) Validity/reliability of sweat analysis by whole-body washdown vs. regional collections. J Appl Physiol 61:1967-1971

Lewis JL Jr, Thorn GW (1955) 17-Hydroxycorticoid determinations in sweat. J Clin Endocrinol Metabol 15:829-831. https://doi. org/10.1210/jcem-15-7-829

Liappis N, Hungerland H (1972) Quantitative study of free amino acids in human eccrine sweat during normal conditions and exercise. Am J Clin Nutr 25:661-663. https://doi.org/10.1093/ ajen/25.7.661

Liappis N, Kelderbacher SD, Kesseler K, Bantzer P (1979) Quantitative study of free amino acids in human eccrine sweat excreted from the forearms of healthy trained and untrained men during exercise. Eur J Appl Physiol Occup Physiol 42:227-234. https:// doi.org/10.1007/bf00423292

Lichton IJ (1957) Osmotic pressure of human sweat. J Appl Physiol 11:422-424. https://doi.org/10.1152/jappl.1957.11.3.422

Lobitz WC Jr, Mason HL (1948) Chemistry of palmar sweat; discussion of studies on chloride, urea, glucose, uric acid, ammonia nitrogen and creatinine. Arch Derm Syphilol 57:907-915

Luetkemeier MJ, Hanisko JM, Aho KM (2017) Skin tattoos alter sweat rate and $\mathrm{Na}+$ concentration. Med Sci Sports Exerc 49:14321436. https://doi.org/10.1249/MSS.0000000000001244

Lugg JW, Ellis FP (1954) Some water-soluble vitamins in the sweat of tropically acclimatized European men. Br J Nutr 8:71-77

Mack GW, Nadel ER (1996) Body fluid balance during heat stress in humans. In: Fregly MJ, Blatteis CM (eds) Handbook of physiology, section 4, environmental physiology, vol 1. Oxford University Press for the American Physiological Society, New York, pp 187-214

Mark H, Harding CR (2013) Amino acid composition, including key derivatives of eccrine sweat: potential biomarkers of certain atopic skin conditions. Int J Cosmet Sci 35:163-168. https://doi. org/10.1111/ics.12019

Marques-Deak A et al (2006) Measurement of cytokines in sweat patches and plasma in healthy women: validation in a controlled study. J Immunol Methods 315:99-109. https://doi.org/10.1016/j. jim.2006.07.011

Maughan RJ, Shirreffs SM (1998) Fluid and electrolyte loss and replacement in exercise. In: Harries M, Williams C, Stanish WD, Micheli LL (eds) Oxford textbook of sports medicine, 2nd edn. Oxford University Press, New York, pp 97-113

McArdle HJ (1992) The transport of iron and copper across the cell membrane: different mechanisms for different metals? Proc Nutr Soc 51:199-209. https://doi.org/10.1079/pns19920030

McCance RA (1938) The effect of salt deficiency in man on the volume of the extracellular fluids, and on the composition of sweat, saliva, gastric juice and cerebrospinal fluid. J Physiol 92:208-218 
McCubbin AJ, Costa RJS (2018) The impact of dietary sodium intake on sweat sodium concentration in response to endurance exercise: a systematic review. Int J Sports Sci 8:25-37

McCubbin AJ, Lopez MB, Cox GR, Caldwell Odgers JN, Costa RJS (2019) Impact of 3-day high and low dietary sodium intake on sodium status in response to exertional-heat stress: a doubleblind randomized control trial. Eur J Appl Physiol 119:21052118. https://doi.org/10.1007/s00421-019-04199-2

McDermott BP et al (2017) National athletic trainers' association position statement: fluid replacement for the physically active. J Athlet Train 52:877-895. https://doi.org/10.4085/1062-6050-52.9.02

Mickelsen O, Keys A (1943) The composition of sweat, with special reference to the vitamins. J Biol Chem 149:479-490

Mishra A, Greaves R, Massie J (2005) The relevance of sweat testing for the diagnosis of cystic fibrosis in the genomic era. Clin Biochem Rev 26:135-153

Mitchell HH, Hamilton TS (1949) The dermal excretion under controlled environmental conditions of nitrogen and minerals in human subjects, with particular reference to calcium and iron. J Biol Chem 178:345-361

Mitsubayashi K, Suzuki M, Tamiya E, Karube I (1994) Analysis of metabolites in sweat as a measure of physical condition. Anal Chim Acta 289:27-34

Montagna W, Parakkal PF (1974a) Apocrine Glands. In: Montagna W, Parakkal PF (eds) The structure and function of skin, 3rd edn. Academic, New York, pp 332-365

Montagna W, Parakkal PF (1974b) Sebaceous glands. In: Montagna W, Parakkal PF (eds) The structure and function of skin, 3rd edn. Academic, New York, pp 280-331

Montain SJ, Cheuvront SN, Sawka MN (2006) Exercise associated hyponatraemia: quantitative analysis to understand the aetiology. Br J Sports Med 40:98-105. https://doi.org/10.1136/ bjsm.2005.018481

Montain SJ, Cheuvront SN, Lukaski HC (2007) Sweat mineral-element responses during $7 \mathrm{~h}$ of exercise-heat stress. Int J Sport Nutr Exerc Metab 17:574-582

Morgan RM, Patterson MJ, Nimmo MA (2004) Acute effects of dehydration on sweat composition in men during prolonged exercise in the heat. Acta Physiol Scand 182:37-43. https://doi. org/10.1111/j.1365-201X.2004.01305.x

Mosher HH (1933) Simultaneous study of constituents of urine and perspiration. J Biol Chem 99(3):781-790

Moyer J, Wilson D, Finkelshtein I, Wong B, Potts R (2012) Correlation between sweat glucose and blood glucose in subjects with diabetes. Diabetes Technol Ther 14:398-402. https://doi.org/10.1089/ dia.2011.0262

Murota H, Matsui S, Ono E, Kijima A, Kikuta J, Ishii M, Katayama I (2015) Sweat, the driving force behind normal skin: an emerging perspective on functional biology and regulatory mechanisms. J Dermatol Sci 77:3-10. https://doi.org/10.1016/j.jderm sci.2014.08.011

Murota H, Yamaga K, Ono E, Katayama I (2018) Sweat in the pathogenesis of atopic dermatitis. Allergol Int 67:455-459. https://doi. org/10.1016/j.alit.2018.06.003

Murphy PM (1995) Blood, sweat, and chemotactic cytokines. J Leukoc Biol 57:438-439. https://doi.org/10.1002/jlb.57.3.438

$\mathrm{Na} \mathrm{CH}$ et al (2019) Integrated transcriptomic and proteomic analysis of human eccrine sweat glands identifies missing and novel proteins. Mol Cell Proteom 18:1382-1395. https://doi.org/10.1074/ mcp.RA118.001101

Nadel ER (1979) Control of sweating rate while exercising in the heat. Med Sci Sports 11:31-35

Nadel ER, Bullard RW, Stolwijk JA (1971) Importance of skin temperature in the regulation of sweating. J Appl Physiol 31:80-87. https://doi.org/10.1152/jappl.1971.31.1.80
Nejsum LN et al (2002) Functional requirement of aquaporin-5 in plasma membranes of sweat glands. Proc Natl Acad Sci USA 99:511-516. https://doi.org/10.1073/pnas.012588099

Nichols J, Miller AT Jr (1948) Excretion of adrenal corticoids in the sweat. Proc Soc Exp Biol Med 69:448. https://doi. org/10.3181/00379727-69-16751

Nielsen B, Nielsen M (1965) Influence of passive and active heating on the temperature regulation of man. Acta Physiol Scand 64:323-331. https://doi.org/10.1111/j.1748-1716.1965.tb04186.x

Nielsen B, Strange S, Christensen NJ, Warberg J, Saltin B (1997) Acute and adaptive responses in humans to exercise in a warm, humid environment. Pflugers Archiv Eur J Physiol 434:49-56. https:// doi.org/10.1007/s004240050361

Nose K, Mizuno T, Yamane N, Kondo T, Ohtani H, Araki S, Tsuda T (2005) Identification of ammonia in gas emanated from human skin and its correlation with that in blood. Anal Sci 21:14711474. https://doi.org/10.2116/analsci.21.1471

Nyein HYY et al (2019) Regional and correlative sweat analysis using high-throughput microfluidic sensing patches toward decoding sweat. Sci Adv 5:eaaw9906. https://doi.org/10.1126/sciad v.aaw9906

Nyman E, Palmlov A (1936) The elimination of ethyl alcohol in sweat. Skand Arch Physiol 74:155-159

Ogawa T, Asayama M, Miyagawa T (1982) Effects of sweat gland training by repeated local heating. Jpn J Physiol 32:971-981

Ono E et al (2018) Sweat glucose and GLUT2 expression in atopic dermatitis: implication for clinical manifestation and treatment. PLoS ONE 13:e0195960. https://doi.org/10.1371/journ al.pone. 0195960

Palmer MS, Spriet LL (2008) Sweat rate, salt loss, and fluid intake during an intense on-ice practice in elite Canadian male junior hockey players. Appl Physiol Nutr Metabol 33:263-271. https:// doi.org/10.1139/H08-011

Pandolf KB, Cadarette BS, Sawka MN, Young AJ, Francesconi RP, Gonzalez RR (1988) Thermoregulatory responses of middleaged and young men during dry-heat acclimation. J Appl Physiol (1985) 65:65-71

Paton A (2005) Alcohol in the body. BMJ 330:85-87. https://doi. org/10.1136/bmj.330.7482.85

Patterson MJ, Galloway SD, Nimmo MA (2000) Variations in regional sweat composition in normal human males. Exp Physiol 85:869-875

Patterson MJ, Galloway SD, Nimmo MA (2002) Effect of induced metabolic alkalosis on sweat composition in men. Acta Physiol Scand 174:41-46

Paulev PE, Jordal R, Pedersen NS (1983) Dermal excretion of iron in intensely training athletes. Clin Chim Acta 127:19-27

Pawan GL, Grice K (1968) Distribution of alcohol in urine and sweat after drinking. Lancet 2:1016. https://doi.org/10.1016/s0140 $-6736(68) 91302-0$

Perogamvros I, Keevil BG, Ray DW, Trainer PJ (2010) Salivary cortisone is a potential biomarker for serum free cortisol. J Clin Endocrinol Metabol 95:4951-4958. https://doi.org/10.1210/ jc. $2010-1215$

Phillips M, McAloon MH (1980) A sweat-patch test for alcohol consumption: evaluation in continuous and episodic drinkers. Alcohol Clin Exp Res 4:391-395

Pilardeau PA, Chalumeau MT, Harichaux P, Vasseur P, Vaysse J, Garnier M (1988) Effect of physical training on exercise induced sweating in men. J Sports Med Phys Fit 28:176-180

Porter AM (2001) Why do we have apocrine and sebaceous glands? J R Soc Med 94:236-237

Prasad AS, Schulert AR, Sandstead HH, Miale A Jr, Farid Z (1963) Zinc, iron, and nitrogen content of sweat in normal and deficient subjects. J Lab Clin Med 62:84-89 
Price NT, Jackson VN, Halestrap AP (1998) Cloning and sequencing of four new mammalian monocarboxylate transporter (MCT) homologues confirms the existence of a transporter family with an ancient past. Biochem J 329(Pt 2):321-328. https://doi. org/10.1042/bj3290321

Pullan NJ, Thurston V, Barber S (2013) Evaluation of an inductively coupled plasma mass spectrometry method for the analysis of sweat chloride and sodium for use in the diagnosis of cystic fibrosis. Ann Clin Biochem 50:267-270. https://doi. org/10.1177/0004563212474565

Quinton PM (1981) Effects of some ion transport inhibitors on secretion and reabsorption in intact and perfused single human sweat glands. Pflugers Archiv Eur J Physiol 391:309-313

Quinton PM (1999) Physiological basis of cystic fibrosis: a historical perspective. Physiol Rev 79:S3-S22

Quinton PM (2007) Cystic fibrosis: lessons from the sweat gland. Physiology (Bethesda) 22:212-225. https://doi.org/10.1152/ physiol.00041.2006

Quinton PM, Reddy MM (1989) Cl- conductance and acid secretion in the human sweat duct. Ann N Y Acad Sci 574:438-446. https ://doi.org/10.1111/j.1749-6632.1989.tb25182.x

Randall WC (1946) Quantitation and regional distribution of sweat glands in man. J Clin Invest 25:761-767. https://doi. org/10.1172/JCI101760

Raul JS, Cirimele V, Ludes B, Kintz P (2004) Detection of physiological concentrations of cortisol and cortisone in human hair. Clin Biochem 37:1105-1111. https://doi.org/10.1016/j.clinb iochem.2004.02.010

Reddy MM, Quinton PM (1994a) Intracellular Cl activity: evidence of dual mechanisms of $\mathrm{cl}$ absorption in sweat duct. Am J Physiol 267:C1136-1144. https://doi.org/10.1152/ajpce 11.1994.267.4.C1136

Reddy MM, Quinton PM (1994b) Rapid regulation of electrolyte absorption in sweat duct. J Membr Biol 140:57-67

Reddy MM, Quinton PM (2003) Functional interaction of CFTR and ENaC in sweat glands. Pflugers Archiv Eur J Physiol 445:499503. https://doi.org/10.1007/s00424-002-0959-x

Reitamo S, Anttila HS, Didierjean L, Saurat JH (1990) Immunohistochemical identification of interleukin I alpha and beta in human eccrine sweat-gland apparatus. Br J Dermatol 122:315-323

Robertshaw D (1983) Apocrine sweat glands. In: Goldsmith LA (ed) Biochemistry and physiology of the skin, vol 1. Oxford University Press, New York, pp 642-653

Robinson S, Robinson AH (1954) Chemical composition of sweat. Physiol Rev 34:202-220

Robinson S, Gerking SD, Turrell ES, Kincaid RK (1950) Effect of skin temperature on salt concentration of sweat. J Appl Physiol 2:654-662

Robinson S, Nicholas JR, Smith JH, Daly WJ, Pearcy M (1955) Time relation of renal and sweat gland adjustments to salt deficiency in men. J Appl Physiol 8:159-165

Robinson S, Maletich RT, Robinson WS, Rohrer BB, Kunz AL (1956) Output of $\mathrm{NaCl}$ by sweat glands and kidneys in relation to dehydration and to salt depletion. J Appl Physiol 8:615-620

Rogers E, Irwin C, McCartney D, Cox GR, Desbrow B (2019) Tattoos do not affect exercise-induced localised sweat rate or sodium concentration. J Sci Med Sport Sports Med Aust. https ://doi.org/10.1016/j.jsams.2019.06.004

Roohani N, Hurrell R, Kelishadi R, Schulin R (2013) Zinc and its importance for human health: an integrative review. J Res Med Sci 18:144-157

Rose DP et al (2015) Adhesive RFID sensor patch for monitoring of sweat electrolytes. IEEE Trans Biomed Eng 62:1457-1465. https://doi.org/10.1109/TBME.2014.2369991

Rothman S, Sullivan MB (1949) Amino acids on the normal skin surface. J Investig Dermatol 13:319-321
Rothman S, Smiljanic AM, Murphy JC (1949) The nitrogenous material on normal human skin surface. J Investig Dermatol 13:317. https://doi.org/10.1038/jid.1949.103

Rowe SM, Miller S, Sorscher EJ (2005) Cystic fibrosis. N Engl J Med 352:1992-2001. https://doi.org/10.1056/NEJMra043184

Ruff RL (1999) Effects of temperature on slow and fast inactivation of rat skeletal muscle $\mathrm{Na}(+)$ channels. Am J Physiol 277:C937947. https://doi.org/10.1152/ajpcell.1999.277.5.C937

Russell E, Koren G, Rieder M, Van Uum SH (2014) The detection of cortisol in human sweat: implications for measurement of cortisol in hair. Ther Drug Monit 36:30-34. https://doi. org/10.1097/FTD.0b013e31829daa0a

Saat M, Sirisinghe RG, Singh R, Tochihara Y (2005) Effects of short-term exercise in the heat on thermoregulation, blood parameters, sweat secretion and sweat composition of tropicdwelling subjects. J Physiol Anthropol Appl Hum Sci 24:541549. https://doi.org/10.2114/jpa.24.541

Saint-Criq V, Gray MA (2017) Role of CFTR in epithelial physiology. CMLS 74:93-115. https://doi.org/10.1007/s0001 8-016-2391-y

Salim A, Lim S (2019) Recent advances in noninvasive flexible and wearable wireless biosensors. Biosens Bioelectron 141:111422. https://doi.org/10.1016/j.bios.2019.111422

Sato K (1973) Stimulation of pentose cycle in the eccrine sweat gland by adrenergic drugs. Am J Physiol 224:1149-1154

Sato K (1977) The physiology, pharmacology, and biochemistry of the eccrine sweat gland. Rev Physiol Biochem Pharmacol 79:51-131

Sato K (1980) Electrochemical driving forces for K+ secretion by rat paw eccrine sweat gland. Am J Physiol 239:C90-97. https://doi. org/10.1152/ajpcell.1980.239.3.C90

Sato K (1983) The physiology and pharmacology of the eccrine sweat gland. In: Goldsmith L (ed) Biochemistry and physiology of the skin. Oxford University Press, New York, pp 596-641

Sato K (1993) The mechanism of eccrine sweat secretion. In: Gisolfi CV, Nadel ER (eds) Exercise, heat, and thermoregulation Perspectives in exercise science and sports medicine, vol 6. Brown \& Benchmark, Dubuque, pp 85-117

Sato K, Dobson RL (1970) The effect of intracutaneous d-aldosterone and hydrocortisone on human eccrine sweat gland function. J Investig Dermatol 54:450-462

Sato K, Dobson RL (1973) Glucose metabolism of the isolated eccrine sweat gland II The relation between glucose metabolism and sodium transport. J Clin Investig 52:2166-2174. https://doi. org/10.1172/JCI107401

Sato K, Sato F (1987a) Nonisotonicity of simian eccrine primary sweat induced in vitro. Am J Physiol 252:R1099-1105. https://doi. org/10.1152/ajpregu.1987.252.6.R1099

Sato K, Sato F (1987b) Sweat secretion by human axillary apoeccrine sweat gland in vitro. Am J Physiol 252:R181-187

Sato K, Sato F (1990) $\mathrm{Na}^{+}, \mathrm{K}^{+}, \mathrm{H}^{+}, \mathrm{Cl}^{-}$, and $\mathrm{Ca}^{2+}$ concentrations in cystic fibrosis eccrine sweat in vivo and in vitro. J Lab Clin Med 115:504-511

Sato K, Sato F (1994) Interleukin-1 alpha in human sweat is functionally active and derived from the eccrine sweat gland. Am J Physiol 266:R950-959. https://doi.org/10.1152/ajpre gu.1994.266.3.R950

Sato K, Feibleman C, Dobson RL (1970) The electrolyte composition of pharmacologically and thermally stimulated sweat: a comparative study. J Investig Dermatol 55:433-438

Sato K, Leidal R, Sato F (1987) Morphology and development of an apoeccrine sweat gland in human axillae. Am J Physiol 252:R166-180

Sato K, Kang WH, Saga K, Sato KT (1989) Biology of sweat glands and their disorders. I. Normal sweat gland function. J Am Acad Dermatol 20:537-563 
Sato K, Ohtsuyama M, Samman G (1991) Eccrine sweat gland disorders. J Am Acad Dermatol 24:1010-1014

Sawka MN, Burke LM, Eichner ER, Maughan RJ, Montain SJ, Stachenfeld NS (2007) American College of Sports Medicine position stand. Exerc Fluid Replace Med Sci Sports Exerc 39:377-390. https://doi.org/10.1249/mss.0b013e31802ca597

Sawka MN, Leon LR, Montain SJ, Sonna LA (2011) Integrated physiological mechanisms of exercise performance, adaptation, and maladaptation to heat stress. Compr Physiol 1:1883-1928. https ://doi.org/10.1002/cphy.c100082

Schmidt FM, Vaittinen O, Metsala M, Lehto M, Forsblom C, Groop $\mathrm{PH}$, Halonen L (2013) Ammonia in breath and emitted from skin. J Breath Res 7:017109. https://doi.org/10.1088/17527155/7/1/017109

Schneeberger EE, Lynch RD (1992) Structure, function, and regulation of cellular tight junctions. Am J Physiol 262:L647-661. https:// doi.org/10.1152/ajplung.1992.262.6.L647

Schulz H, Heck H (2003) Glycogen depletion as indication of ammonia determination in exercise testing. Eur J Sport Sci 3:1-9

Schwartz IL, Thaysen JH, Dole VP (1953) Urea excretion in human sweat as a tracer for movement of water within the secreting gland. J Exp Med 97:429-437. https://doi.org/10.1084/ jem.97.3.429

Shamsuddin AK, Kuwahara T, Oue A, Nomura C, Koga S, Inoue Y, Kondo N (2005) Effect of skin temperature on the ion reabsorption capacity of sweat glands during exercise in humans. Eur J Appl Physiol 94:442-447. https://doi.org/10.1007/s0042 1-005-1354-Z

Shelley WB, Mescon H (1952) Histochemical demonstration of secretory activity in human eccrine sweat glands. J Investig Dermatol 18:289-301. https://doi.org/10.1038/jid.1952.31

Shibasaki M, Crandall CG (2010) Mechanisms and controllers of eccrine sweating in humans. Front Biosci (Schol Ed) 2:685-696

Shirreffs SM, Maughan RJ (1997) Whole body sweat collection in humans: an improved method with preliminary data on electrolyte content. J Appl Physiol 82:336-341

Shwachman H, Antonowicz I (1962) The sweat test in cystic fibrosis. Ann N Y Acad Sci 93:600-624

Sigal CB, Dobson RL (1968) The effect of salt intake on sweat gland function. J Investig Dermatol 50:451-455

Silvers S, Forster W, Talbert GA (1928) Simultaneous study of the constituents of the sweat, urine and blood, also gastric acidity and other manifestations resulting from sweating VI Sugar. Am J Physiol 84:577-582

Slominski A (2005) Neuroendocrine system of the skin. Dermatology 211:199-208. https://doi.org/10.1159/000087012

Smith RE, Maguire JA, Stein-Oakley AN, Sasano H, Takahashi K, Fukushima K, Krozowski ZS (1996) Localization of 11 betahydroxysteroid dehydrogenase type II in human epithelial tissues. J Clin Endocrinol Metabol 81:3244-3248. https://doi. org/10.1210/jcem.81.9.8784076

Sonner Z et al (2015) The microfluidics of the eccrine sweat gland, including biomarker partitioning, transport, and biosensing implications. Biomicrofluidics 9:031301. https://doi. org/10.1063/1.4921039

Souza SL, Graca G, Oliva A (2018) Characterization of sweat induced with pilocarpine, physical exercise, and collected passively by metabolomic analysis. Skin Res Technol 24:187-195. https://doi.org/10.1111/srt.12412

Talbert GA (1919) Effect of work and heat on the hydrogen concentration of the sweat. Am J Physiol 50:433-442

Talbert GA (1922) Further studies on the hydrogen ion concentration of human sweat. Am J Physiol 61:493-500

Talbert GA, Haugen CO (1927) Simultaneous study of the constituents of the sweat, urine, and blood, also gastric acidity and other manifestations resulting from sweating I Chlorides. Am J Physiol 81:74-80

Talbert GA, Silvers S, Johnson W (1927) Simultaneous study of the constituents of the sweat urine and blood, also gastric acidity and other manifestations resulting from sweating II Total nitrogen of sweat and urine; total non-protein nitrogen of blood. Am J Physiol 81:81-85

Tang YM et al (2016) Relationships between micronutrient losses in sweat and blood pressure among heat-exposed steelworkers. Ind Health 54:215-223. https://doi.org/10.2486/indhe alth.2014-0225

Taylor NA (2014) Human heat adaptation. Compr Physiol 4:325-365. https://doi.org/10.1002/cphy.c130022

Taylor NA, Machado-Moreira CA (2013) Regional variations in transepidermal water loss, eccrine sweat gland density, sweat secretion rates and electrolyte composition in resting and exercising humans. Extreme Physiol Med 2:4. https://doi. org/10.1186/2046-7648-2-4

Terao M, Katayama I (2016) Local cortisol/corticosterone activation in skin physiology and pathology. J Dermatol Sci 84:11-16. https ://doi.org/10.1016/j.jdermsci.2016.06.014

Thapar GS, Shenolikar IS, Tulpule PG (1976) Sweat loss of nitrogen and other nutrients during heavy physical activity. Indian J Med Res 64:590-596

Tian YW, Stacey MC (2003) Cytokines and growth factors in keratinocytes and sweat glands in chronic venous leg ulcers An immunohistochemical study. Wound Repair Regen 11:316-325

Tipton MJ, Pandolf KB, Sawka MN, Werner J, Taylor NAS (2008) Physiological adaptation to hot and cold environments. In: Taylor NAS, Groeller H (eds) Physiological bases of human performance during work and exercise. Elsevier, Edinburgh, pp 379-400

Turner C, Parekh B, Walton C, Spanel P, Smith D, Evans M (2008) An exploratory comparative study of volatile compounds in exhaled breath and emitted by skin using selected ion flow tube mass spectrometry. Rapid Commun Mass Spectrom 22:526-532. https ://doi.org/10.1002/rcm.3402

Umeda T, Hiramatsu R, Iwaoka T, Shimada T, Miura F, Sato T (1981) Use of saliva for monitoring unbound free cortisol levels in serum. Clin Chim Acta 110:245-253. https://doi. org/10.1016/0009-8981(81)90353-3

Ussing HH, Zerahn K (1951) Active transport of sodium as the source of electric current in the short-circuited isolated frog skin. Acta Physiol Scand 23:110-127. https://doi. org/10.1111/j.1748-1716.1951.tb00800.x

Van Heyningen R, Weiner JS (1952) A comparison of arm-bag sweat and body sweat. J Physiol 116:395-403

Vellar OD (1968a) Studies on sweat losses of nutrients I Iron content of whole body sweat and its association with other sweat constituents, serum iron levels, hematological indices, body surface area, and sweat rate. Scand J Clin Lab Investig 21:157-167

Vellar OD (1968b) Studies on sweat losses of nutrients. II. The influence of an oral iron load on the iron content of whole body cellfree sweat. Scand J Clin Lab Investig 21:344-346

Vellar OD, Askevold R (1968) Studies on sweat losses of nutrients. 3. Calcium, magnesium, and chloride content of whole body cell-free sweat in healthy unacclimatized men under controlled environmental conditions. Scand J Clin Lab Investig 22:65-71

Verde T, Shephard RJ, Corey P, Moore R (1982) Sweat composition in exercise and in heat. J Appl Physiol 53:1540-1545

Verissimo A et al (2007) Nuclear microscopy: a tool for imaging elemental distribution and percutaneous absorption in vivo. Microsc Res Tech 70:302-309. https://doi.org/10.1002/jemt.20402

Vimieiro-Gomes AC, Magalhaes FC, Amorim FT, Machado-Moreira CA, Rosa MS, Lima NR, Rodrigues LO (2005) Comparison of 
sweat rate during graded exercise and the local rate induced by pilocarpine. Braz J Med Biol Res 38:1133-1139

Waller MF, Haymes EM (1996) The effects of heat and exercise on sweat iron loss. Med Sci Sports Exerc 28:197-203

Walsh RM, Noakes TD, Hawley JA, Dennis SC (1994) Impaired high-intensity cycling performance time at low levels of dehydration. Int J Sports Med 15:392-398. https://doi. org/10.1055/s-2007-1021076

Walter A, Gutknecht J (1986) Permeability of small nonelectrolytes through lipid bilayer membranes. J Membr Biol 90:207-217. https://doi.org/10.1007/bf01870127

Wang Q, Lu Y, Yuan M, Darling IM, Repasky EA, Morris ME (2006) Characterization of monocarboxylate transport in human kidney HK-2 cells. Mol Pharm 3:675-685. https://doi.org/10.1021/ mp060037b

Watabe A, Sugawara T, Kikuchi K, Yamasaki K, Sakai S, Aiba S (2013) Sweat constitutes several natural moisturizing factors, lactate, urea, sodium, and potassium. J Dermatol Sci 72:177-182. https://doi.org/10.1016/j.jdermsci.2013.06.005

Webster HL (1983) Laboratory diagnosis of cystic fibrosis. Crit Rev Clin Lab Sci 18:313-338

Weiner JS, Hellmann K (1960) The sweat glands. Biol Rev 35:141-186

Weiner JS, van Heyningen R (1949) Lactic acid and sweat gland function. Nature 164(4165):351-352

Weiner JS, Van Heyningen RE (1952) Observations on lactate content of sweat. J Appl Physiol 4:734-744. https://doi.org/10.1152/jappl .1952 .4 .9 .734

Weintraub LR, Demis DJ, Conrad ME, Crosby WH (1965) Iron excretion by the skin Selective localization of iron-59 in epithelial cells. Am J Pathol 46:121-127

Wenger CB (1972) Heat of evaporation of sweat: thermodynamic considerations. J Appl Physiol 32:456-459

Wennig R (2000) Potential problems with the interpretation of hair analysis results. Forensic Sci Int 107:5-12. https://doi. org/10.1016/s0379-0738(99)00146-2

Wescor (2005) Sweat Chek ${ }^{\mathrm{TM}}$ sweat conductivity analyzer model 3120 instruction/service manual. Wescor Inc, USA

Wheeler EF, el-Neil H, Willson JO, Weiner JS (1973) The effect of work level and dietary intake on water balance and the excretion of sodium, potassium and iron in a hot climate. Br J Nutr 30:127-137

Whitehouse AGR (1935) The dissolved constituents of human sweat. Proc R Soc Lond Ser B Biol Sci 117:139-154

Wilson TE, Metzler-Wilson K (2015) Sweating chloride bullets: understanding the role of calcium in eccrine sweat glands and possible implications for hyperhidrosis. Exp Dermatol 24:177-178. https ://doi.org/10.1111/exd.12595
Wingo JE, Low DA, Keller DM, Brothers RM, Shibasaki M, Crandall CG (2010) Skin blood flow and local temperature independently modify sweat rate during passive heat stress in humans. J Appl Physiol 109:1301-1306. https://doi.org/10.1152/japplphysi ol.00646.2010

Wolfe S, Cage G, Epstein M, Tice L, Miller H, Gordon RS Jr (1970) Metabolic studies of isolated human eccrine sweat glands. J Clin Investig 49:1880-1884. https://doi.org/10.1172/JCI106407

Xie L, Jin L, Feng J, Lv J (2017) The expression of AQP5 and UTs in the sweat glands of uremic patients. Biomed Res Int 2017:8629783. https://doi.org/10.1155/2017/8629783

Yang NJ, Hinner MJ (2015) Getting across the cell membrane: an overview for small molecules, peptides, and proteins. Methods Mol Biol 1266:29-53. https://doi.org/10.1007/978-1-4939-2272-7_3

Yokozeki H, Hibino T, Takemura T, Sato K (1991) Cysteine proteinase inhibitor in eccrine sweat is derived from sweat gland. Am J Physiol 260:R314-320. https://doi.org/10.1152/ajpre gu.1991.260.2.R314

Yoshida T, Shin-ya H, Nakai S, Yorimoto A, Morimoto T, Suyama T, Sakurai M (2006) Genomic and non-genomic effects of aldosterone on the individual variation of the sweat $\mathrm{Na}^{+}$concentration during exercise in trained athletes. Eur J Appl Physiol 98:466471. https://doi.org/10.1007/s00421-006-0295-5

Yuyama H (1935) On the histological examination of distribution of glycogen in the skin of leprosy with special reference to the relationship between the function of sweat glands and the changes of glycogen content. J Derm Urol 37:811-832

Zech M, Bosel S, Tuthorn M, Benesch M, Dubbert M, Cuntz M, Glaser B (2015) Sauna, sweat and science-quantifying the proportion of condensation water versus sweat using a stable water isotope $((2) \mathrm{H} /(1) \mathrm{H}$ and $(18) \mathrm{O} /(16) \mathrm{O})$ tracer experiment. Isotop Environ Health Stud 51:439-447. https://doi.org/10.1080/10256 016.2015 .1057136

Zhang JM, An J (2007) Cytokines, inflammation, and pain. Int Anesthesiol Clin 45:27-37. https://doi.org/10.1097/AIA.0b013e3180 $34194 \mathrm{e}$

Zhou Y, Han H, Naw HPP, Lammy AV, Goh CH (2016) Real-time colorimetric hydration sensor for sport activities. Mater Des 90:1181-1185

Publisher's Note Springer Nature remains neutral with regard to jurisdictional claims in published maps and institutional affiliations. 